Illinois State University

ISU ReD: Research and eData

Theses and Dissertations

$9-1-2021$

\title{
Beyond the Mathematics Major: Identifying the Pedagogical Content Knowledge Exhibited by Preservice Secondary Mathematics Teachers
}

Steven R. Turner

Illinois State University, srturner0@gmail.com

Follow this and additional works at: https://ir.library.illinoisstate.edu/etd

\section{Recommended Citation}

Turner, Steven R., "Beyond the Mathematics Major: Identifying the Pedagogical Content Knowledge Exhibited by Preservice Secondary Mathematics Teachers" (2021). Theses and Dissertations. 1507. https://ir.library.illinoisstate.edu/etd/1507

This Dissertation is brought to you for free and open access by ISU ReD: Research and eData. It has been accepted for inclusion in Theses and Dissertations by an authorized administrator of ISU ReD: Research and eData. For more information, please contact ISUReD@ilstu.edu. 


\section{BEYOND THE MATHEMATICS MAJOR: IDENTIFYING THE PEDAGOGICAL CONTENT KNOWLEDGE EXHIBITED BY PRESERVICE SECONDARY MATHEMATICS TEACHERS}

\section{STEVEN R. TURNER}

\section{Pages}

The purpose of this study was to identify and characterize the pedagogical content knowledge (PCK) held by secondary mathematics preservice teachers. Task-based interviews were conducted to determine whether evidence of PCK exists in preservice teachers and, if so, what form that evidence took. Participants included preservice teachers near the end of their coursework and mathematics majors, whose experience ranged from having completed the calculus sequence to their first year in graduate school. Some experienced teachers were also included, allowing a comparison of their knowledge with the other groups. In this study I seek to gain a better understanding of the characteristics of pedagogical content knowledge exhibited by a group of pre-service secondary mathematics teachers.

KEYWORDS: pedagogical content knowledge, mathematics education, secondary education 
BEYOND THE MATHEMATICS MAJOR: IDENTIFYING THE PEDAGOGICAL CONTENT

KNOWLEDGE EXHIBITED BY PRESERVICE SECONDARY MATHEMATICS

TEACHERS

STEVEN R. TURNER

A Dissertation Submitted in Partial

Fulfillment of the Requirements

for the Degree of

DOCTOR OF PHILOSOPHY

Department of Mathematics

ILLINOIS STATE UNIVERSITY

2021 
(C) 2021 Steven R. Turner 


\section{BEYOND THE MATHEMATICS MAJOR: IDENTIFYING THE PEDAGOGICAL CONTENT KNOWLEDGE EXHIBITED BY PRESERVICE SECONDARY MATHEMATICS TEACHERS}

STEVEN R. TURNER

COMMITTEE MEMBERS:

Cynthia Langrall, Chair

David Barker

Sunil Chebolu

Edward Mooney

Matthew Winsor 


\section{CONTENTS}

Page

CONTENTS

TABLES iv

FIGURES

CHAPTER I: THE PROBLEM AND BACKGROUND 1

$\begin{array}{ll}\text { Pedagogical Content Knowledge } & 2\end{array}$

Teacher Preparation 3

Statement of Problem $\quad 5$

$\begin{array}{ll}\text { Research Question } & 6\end{array}$

$\begin{array}{lr}\text { Theoretical Perspective } & 6\end{array}$

Shulman's Concept of Pedagogical Content Knowledge $\quad 7$

$\begin{array}{ll}\text { Interpretivist Perspective } & 10\end{array}$

$\begin{array}{ll}\text { Chapter One Summary } & 11\end{array}$

CHAPTER II: REVIEW OF LITERATURE 13

$\begin{array}{ll}\text { PCK Conceptualizations } & 13\end{array}$

$\begin{array}{ll}\text { Conceptualizations of PCK } & 13\end{array}$

Alternative Conceptualizations of PCK 15

PCK Usage in Research $\quad 15$

$\begin{array}{ll}\text { Content Knowledge is Necessary but Not Sufficient } & 17\end{array}$

Development of PCK and Needs for Teacher Preparation 18

$\begin{array}{ll}\text { Development of PCK } & 18\end{array}$

Needs for Teacher Preparation 20 
Standards for Teacher Preparation

$\begin{array}{ll}\text { Chapter Two Summary } & 22\end{array}$

$\begin{array}{ll}\text { CHAPTER III: METHODS } & 24\end{array}$

$\begin{array}{ll}\text { Participants } & 24\end{array}$

Pre-Service Teacher Recruitment 25

$\begin{array}{ll}\text { Mathematics Major Recruitment } & 27\end{array}$

Professional Teacher Recruitment 28

$\begin{array}{ll}\text { Study Design } & 29\end{array}$

$\begin{array}{ll}\text { Data-Eliciting Task } & 29\end{array}$

$\begin{array}{ll}\text { Rationale } & 33\end{array}$

$\begin{array}{ll}\text { Analysis } & 34\end{array}$

Preparing the Data: Constant Comparative Method 34

Analyzing Outcome Propositions Within and Across Participant Groups 41

Chapter Three Summary $\quad 44$

CHAPTER IV: RESULTS

Outcome Propositions 45

$\begin{array}{ll}\text { Interpretations } & 46\end{array}$

$\begin{array}{ll}\text { Rationales } & 49\end{array}$

$\begin{array}{ll}\text { References To } & 51\end{array}$

Recommendations $\quad 53$

Relates to One's Own Experience $\quad 56$

$\begin{array}{ll}\text { Defining Characteristics of Each Group } & 59\end{array}$

$\begin{array}{ll}\text { Proposition Percentages by Group } & 60\end{array}$ 
Characteristics of PSTs 62

Characteristics of MATs 66

$\begin{array}{ll}\text { Characteristics of PROs } & 70\end{array}$

Differentiating Characteristics of Each Group 73

$\begin{array}{ll}\text { PSTs vs. MATs } & 73\end{array}$

$\begin{array}{ll}\text { PSTs vs. PROs } & 74\end{array}$

Different Responses by Group to a Given Video Segment 75

$\begin{array}{ll}\text { Conclusion } & 90\end{array}$

$\begin{array}{ll}\text { Chapter Four Summary } & 91\end{array}$

CHAPTER V: CONCLUSIONS 92

$\begin{array}{lr}\text { Summary of Study and Findings } & 92\end{array}$

Discussion of Findings $\quad 93$

Propositions as Related to Shulman's Definition of PCK 94

Outcome Propositions as Related to Other PCK Conceptualizations 96

Outcome Propositions as Related to Standards for Teacher Preparation $\quad 98$

$\begin{array}{ll}\text { Limitations } & 102\end{array}$

$\begin{array}{ll}\text { Significance of the Study } & 103\end{array}$

$\begin{array}{lr}\text { REFERENCES } & 105\end{array}$

$\begin{array}{ll}\text { APPENDIX A: CONSENT FORM } & 124\end{array}$

$\begin{array}{ll}\text { APPENDIX B: VIDEO TRANSCRIPT } & 126\end{array}$

APPENDIX C: INITIAL CATEGORIES AND RULES FOR INCLUSION 132

APPENDIX D: PARTICIPANTS' LESSON ANALYSIS SUMMARIES 137 


\section{TABLES}

Table

1. Summary of Outcome Propositions with Definitions

2. Percentage of Participants Associated with Each Proposition

Within Each Participant Group

3. Frequency of Responses Matching Each Proposition: PSTs

4. Frequency of Responses Matching Each Proposition: MATs

5. Frequency of Responses Matching Each Proposition: PROs 


\section{FIGURES}

Figure

Page

1. Summary of Participant Groups

2. Tutoring Task 30

3. Video Screenshot 31

4. Video Animation Sections 32

5. Initial Grouping of Excerpts 36

6. Excerpts by Category 38

7. Revised Post-Adjustment Spreadsheet 40

8. Participant Responses by Percentage 42

9. Individual Participant Spreadsheet 43

$\begin{array}{lll}\text { 10. PSTs vs. MATs } & 73\end{array}$

$\begin{array}{ll}\text { 11. MATs vs. PSTs } & 74\end{array}$

$\begin{array}{lll}\text { 12. PSTs vs. PROs } & 75\end{array}$

$\begin{array}{lll}\text { 13. PROs vs. PSTs } & 75\end{array}$ 


\section{CHAPTER I: THE PROBLEM AND BACKGROUND}

Since the publication of An Agenda for Action (National Council of Teachers of Mathematics [NCTM], 1980) and A Nation at Risk (Gardner, 1983), there has been a concerted effort in the United States to improve mathematics teaching at the primary through secondary levels. These efforts led to a standards movement, which focused on mathematics content, assessment, what it means to teach effectively, and what knowledge teachers need to possess to do so.

The Curriculum and Evaluation Standards for School Mathematics (NCTM, 1989) launched the school standards movement and set in motion a drive to move school mathematics into the "information age" with a shift from memorization and computation to conceptual understanding, mathematical modeling, and problem solving. The Professional Standards for Teaching Mathematics (NCTM, 1991) and the Assessment Standards for Teaching Mathematics (NCTM, 1995) called for a change in the role of assessment to being an integral part of instruction for facilitating instructional decisions. Principles and Standards for School Mathematics (NCTM, 2000) stated that students were to learn with understanding and build new knowledge upon their pre-existing knowledge. To learn with understanding, students were to engage in mathematical tasks involving a wide variety of topics presented from different perspectives and represented in different ways. The role of the effective teacher in this process was to "help students make, refine, and explore conjectures on the basis of evidence and use a variety of reasoning and proof techniques to confirm or disprove those conjectures" (NCTM, 2000, p. 5). The NCTM (2000) standards also provided a set of process standards which highlighted ways of acquiring and applying content knowledge, problem solving, reasoning and 
proof, communication, making connections, and using different representations. Building on this work a decade later, the Common Core State Standards for Mathematics (CCSSM; National Governors Association Center for Best Practices \& Council of Chief State School Officers [NGA \& CCSSO], 2010) presented another set of content standards as well as standards for mathematical practices. The content standards acknowledged the importance of procedural knowledge and also stressed the necessity of developing conceptual understanding of mathematics topics and justification of mathematical rules. The standards for mathematical practices involved making sense of problems, reasoning abstractly and quantitatively, constructing and critiquing arguments, mathematical modeling, strategic use of tools, solving for precision, and finding structure and reasoning. Many aspects of the CCSSM were based on what research has revealed about learning progressions and the development of students' mathematical knowledge.

The vision of school mathematics promoted by all of these standards calls for teaching to develop student's thinking and reasoning, that is, teaching for understanding (Ponte \& Chapman, 2006). Teaching mathematics for understanding has been much discussed over the past century with regard to both its importance and its meaning (Thompson, 2013). Educational thinkers such as Dewey (1910/1933), Piaget (1960), and Brownell (1947) pondered the idea of what it meant to teach for understanding and what it entailed. More recently, guidelines for teaching for understanding effectively were described in Principles to Actions (NCTM, 2014).

\section{Pedagogical Content Knowledge}

In Principles to Actions, the NCTM (2014) issued guidelines for effective mathematics teaching practices that include establishing mathematics goals to focus learning, implementing tasks that promote reasoning and problem solving, using and connecting mathematical 
representations, facilitating meaningful mathematical discourse, posing purposeful questions, building procedural fluency from conceptual understanding, providing support for productive struggle in learning mathematics, and eliciting and using evidence of student thinking. As these practices indicate, effective teaching involves more than knowledge of the mathematics content to be taught. According to Shulman (1986), the knowledge that a teacher possesses but a practitioner of the subject may not, is known as pedagogical content knowledge (PCK).

Shulman's description of PCK as the knowledge held by a teacher is certainly open to interpretation and, in fact, several different interpretations exist. Some of these will be discussed further in Chapter 2. Because pedagogical content knowledge is so open to interpretation, the term remains ill-defined. Questions also remain about how PCK is developed by teachers and aspiring teachers.

\section{Teacher Preparation}

Although it may be assumed that those with a strong knowledge of content are best prepared to teach it, this is not necessarily the case (NRC, 2001). A teacher's knowledge of the content being taught is different from the knowledge required to teach that content, and the Association of Mathematics Teacher Educators ([AMTE], 2017) standards reflect the recognition that knowledge exclusive to teaching is necessary to teach effectively.

Teacher knowledge of both content and pedagogy are crucial to teaching for understanding, and the development of this knowledge should be a central emphasis in teacher education programs. "Well-prepared beginning teachers of mathematics apply knowledge of a full range of students, standards, pedagogical content knowledge, knowledge of curriculum, and effective and equitable teaching practices to support students' understanding and to elicit and use evidence of students' thinking” (NCTM, 2020, p.23). 
There has been disagreement, however, on teacher knowledge and even whether knowledge beyond content knowledge (CK) is necessary for teaching for understanding.

Despite widespread recognition that teacher knowledge impacts mathematics teacher instruction and student learning, our understanding of teacher knowledge continues to emerge. We know that growth in student achievement varies with teachers who have similar backgrounds and classroom contexts due to differences in their content of knowledge, preparation, use of routines, and content coverage. However, debate continues about whether knowledge beyond content knowledge is critical for the teaching for understanding of mathematics (Lannin et al., 2013).

Lanin et al. (2014) stated that "despite its importance to teaching and learning, we need further insight into how mathematics teacher knowledge develops" (p. 404). Before teacher education programs can work to encourage the development of PCK in PSTs, that knowledge needs to be better understood and ongoing research is needed to reveal details of that knowledge (Chapman, 2015), and whether it can develop without actual classroom experience (Grossman, 1990; Lannin et al., 2013). Identifying the nature of the CK and PCK required for teaching for understanding, however, remains elusive (Ball et al., 2008). Many researchers found that gaps exist in PCK among both pre-service teachers (PSTs) and practicing teachers and that PSTs demonstrated PCK that was more geared toward teaching procedures rather than for developing students' conceptual understanding (Depaepe et al., 2013).

Standards have been developed for guiding and assessing the preparation of new teachers, and some of those standards specifically refer to pedagogical knowledge or PCK. The Standards and Related Indicators for Well-Prepared Beginning Teachers of Mathematics (AMTE, 2016) includes Pedagogical Knowledge and Practices for Teaching Mathematics as one 
of its four main standards. The standard Pedagogical Knowledge and Practices for Teaching Mathematics, of the AMTE (2016) Standards for Preparing Teachers of Mathematics states that well-prepared beginning teachers of mathematics have foundations of pedagogical knowledge, and are able to support students' sense making, understanding, and reasoning.

In 2020, the NCTM issued Standards for the Preparation of

Secondary Mathematics Teachers, in which PCK was described as a:

Core part of content knowledge for teaching that includes core activities of teaching, such as figuring out what students know; choosing and managing representations of ideas; appraising, selecting, and modifying textbooks; deciding among alternative courses of action and analyzing the subject matter knowledge and insight entailed in these activities. (NCTM 2020, p. 33).

It is clear, then, that PCK is considered to be an important element of teacher preparedness. What is not so clear is what PCK looks like, and how it is developed in beginning teachers.

\section{Statement of Problem}

Both the AMTE and NCTM standards are presented as actions, or verbs, rather than as types of knowledge that preservice teachers might develop during their teacher education programs. The actions are dependent on the knowledge which the preservice teachers possess and the presence of these actions can serve as evidence of knowledge, but they do not define or characterize the knowledge informing those actions. The identification of the specific characteristics of the knowledge which needs to be impressed upon aspiring teachers to make them as effective as possible from day one will help teacher educators to prepare them. 
Understanding these characteristics will allow teacher educators and researchers to consider what knowledge a beginning teacher should reasonably be expected to possess and the best ways to facilitate the development of that knowledge. If the goal is to optimize learning for students, then the acquisition of the specific teacher knowledge which leads to this goal should be the main focus of teacher preparation. The first step in connecting specific teacher knowledge to student outcomes is to identify and characterize that knowledge.

In order to gain insight into the development of PCK, it was necessary to seek out evidence of PCK, and use that evidence to characterize PCK. I was particularly interested in PCK for secondary teaching, but most of the existing research on PCK has been concerned with elementary teaching (DePaepe et al., 2013). This study, therefore, was aimed at characterizing the PCK of secondary PSTs. The underlying assumption guiding this research was that mathematics majors (MATs) would not have had the opportunity to develop PCK during their coursework, and that the differences that appeared between the two participant groups would provide evidence of its existence and character.

\section{Research Question}

What are the characteristics of pedagogical content knowledge exhibited by and unique to a group of pre-service secondary mathematics teachers at the end of their teaching program?

\section{Theoretical Perspective}

I considered two theoretical perspectives in the process of conducting this study. The first perspective is that described as Shulman's concept of PCK. Although there have been other conceptualizations and refinements of Shulman's ideas since they were first presented in 1986 and expanded upon in 1987, I will be relying closely on his original concept in my study. The second perspective is the interpretivist perspective. 


\section{Shulman's Concept of Pedagogical Content Knowledge}

Educational psychologist Lee Shulman did extensive research on teacher knowledge in the 1980s, which led to his introduction of the concept of pedagogical content knowledge in 1986. In 1987, he expanded on the idea of PCK with a discussion of a database for teaching as well as a set of standards to better articulate the expectations for professional teachers.

Shulman and his collaborators felt that research on learning was focused mainly on students and not enough on teachers. Their research sought to answer questions about teacher knowledge such as what are its sources? What does a teacher know and when do they come to know it? How is new knowledge acquired and old knowledge retreived? The answer to these questions form the basis of the formulation of PCK.

Shulman (1987) described a model of pedagogical reasoning and action which involves a cycle of learning in which an aspiring teacher develops teaching knowledge. This cycle involves comprehension of the subject matter, transformation of the material to a form suitable for teaching, instruction or presentation of the material, evaluation of both the students' and the teacher's performance, critical analysis of students' and teacher's performance through reflection, leading to new comprehensions of the subject matter. This process is seen as iterative, with the cycle repeating itself indefinitely.

In particular, the transformation stage is the part of the cycle in which "one move from personal comprehension to preparing for the comprehension of others". (Shulman, 1987, p.16). Within the transformation stage are: preparation, which involves the interpretation of texts and the structuring and development of a repertoire of curricula; representation, which requires the development of examples, demonstrations, and explanations; selection of instructional modes and organization; and adaptation to students, which involves an understanding of students' 
conceptions, misconceptions, and difficulties.

Shulman (1986) described PCK as going "beyond knowledge of subject matter per se to the dimension of subject matter for teaching" (p. 9). PCK includes, for example, knowledge of effective representations, explanations, and examples that help to make a subject make sense to others. PCK also includes understanding of what makes learning a given topic easy or difficult, and understanding the previous knowledge and likely misconceptions of students.

Shulman (1987) described a knowledge base for teaching and stated that among the categories:

Pedagogical Content Knowledge is of special interest because it identifies the distinctive bodies of knowledge for teaching. It represents the blending of content and pedagogy into an understanding of how particular topics, problems, or issues are organized, represented, and adapted to the diverse interests and abilities of learners, and presented for instruction. (p. 8)

He further argued for a need to understand how PSTs go from being learners to being teachers. That is, to understand how they become able to present materials in new ways so that it can be understood by students. He stated that the

key to distinguishing a knowledge base of teaching lies at the intersection of content and pedagogy, in the capacity of a teacher to transform the content knowledge he or she possesses into forms that are pedagogically powerful and yet adaptive to the variations in ability and background presented by the students. (p. 12)

Shulman (1987) saw PCK as a synthesis of pedagogy and content which constituted a new form of knowledge. Gess-Newsome (1999) described this as a transformative model, in that 
PCK was considered to be a thing unto itself. Rather than a teacher integrating pedagogy and content while teaching, PCK was considered to be a unique type of knowledge held by teachers.

Based on this transformative model, Shulman considered PCK to be a stand-alone concept, rather than an integration of knowledge during the act of teaching as in the integrative model (Gess-Newsome, 1999). Shulman (1987) listed specific forms of transformations as preparation, representation, instructional selections, and adaptation. These are described collectively as "aspects of the process wherein one moves from personal comprehension to preparing for the comprehension of others" which "are the essence of the act of pedagogical reasoning, of teaching as thinking, and of planning — whether explicitly or implicitly — the performance of teaching" (p. 16).

Shulman (1987) described this cycle from comprehension to preparing for the comprehension of others in a "model of pedagogical reasoning and action" which includes comprehension of the subject matter; transformation of the subject into a form which facilitates comprehension by others; instruction, or presentation, of the material; evaluation of both the students and one's own performance; reflection, which involves critically analyzing the students' as well as the teacher's own performance; and new comprehensions of the subject matter and teaching.

All of these stages are integral to the development of PCK. In particular, the transformation stage involves the work of changing the teacher's own comprehension of the content into a form that can be digested by the students. Shulman (1987) breaks the transformation stage into four parts: preparation, which involves interpretation of texts, structuring, and development of curricular repertoire; representation, which requires the development of examples, demonstrations and explanations; selection of instructional modes and 
organization; and adaptation to student characteristics, which involves student conceptions, misconceptions, and difficulties.

Within the model as a whole, a progression of pedagogical learning can be seen - a sort of map of development of PCK based on the teacher's comprehension of subject matter. The tools for relaying the subject comprehension to the students are developed in the transformation stage, practiced in the instruction stage, and tested in the evaluation stage. They are then refined on reflection and lead to new comprehensions.

Because Shulman (1986) described PCK as that knowledge unique to teachers and not generally held by content practitioners, I chose to use that basis to develop my own conceptualization without the filter of other conceptualizations that have come since. In order to identify the knowledge that I propose represents PCK, I sought to identify the pedagogical knowledge held by both PSTs and mathematics majors and compare the two groups.

Shulman called for researchers "to work with practitioners to develop codified representations of the practical pedagogical wisdom of able teachers" which "is derived from collecting, examining, and beginning to codify the emerging wisdom of practice among both inexperienced and experienced teachers" (Shulman, 1987, p.11). Based on this, I chose to include a third group, a group of experienced teachers, to develop my conceptualization and for comparison to the other two groups.

\section{Interpretivist Perspective}

An interpretivist perspective was chosen because of the nature of the study. Interpretivists seek a deep understanding within a context rather than a wide generalization, and generate that understanding inductively into a pattern of meanings (Al Riyami, 2015). Brundett and Rhodes (2013) described interpretivism as "a more 'people-centred' approach which acknowledges the 
research's integration within the research environment - that is, where each will impact on the perceptions and understandings of the other." (p. 14). Interpretivists are part of the research environment and attempt to find meaning through the perspective of the participants. "The evidence collected by interpretivists will be qualitative in nature, offering a rich and deep description of the research environment as a unique context." (p. 14).

Interpretivism allows for finding understanding, focusing on what is specific and unique and finding meaning (Pizam \& Mansfeld, 2009). An interpretivist lens was appropriate in my study because I was not so much interested in making theory or wide generalizations about what PCK is held by PSTs, but in better understanding the character of that knowledge. To that end, I designed my study to focus on a small group of PSTs from the same program and used their own statements describing a teaching session, looked for similar statements across the group of PSTs, and did the same with a group of mathematics majors and a smaller group of experienced teachers for contrast. Using the participants' own words allowed me to piece together evidence of their knowledge, and using the non-PST groups allowed me to sort out that knowledge that was unique to pre-service teachers.

\section{Chapter One Summary}

In chapter one, I discussed the background that led to a movement for more effective mathematics teaching. I discussed the standards produced by the NCTM and the AMTE related to teaching and teacher preparation. I then stated the problem as a need for better understanding of pedagogical content knowledge. My research question was presented: What are the characteristics of pedagogical content knowledge exhibited by and unique to a group of preservice secondary mathematics teachers at the end of their teaching program? I then discussed 
Shulman's concept of PCK and the interpretivist perspective, which together form the theoretical basis for my study. 


\section{CHAPTER II: REVIEW OF LITERATURE}

In this chapter, my aim is to use the literature on PCK as a basis for my research discussion. I will first discuss conceptualizations of PCK which have been developed beyond those set by Shulman (1986, 1987). I will then discuss the usage of PCK in the research literature, including an introduction of the distinction between transformative and integrative models. Next I will discuss the idea that content knowledge is necessary, but not sufficient, for effective teaching of mathematics. I will talk about research concerned with the development of PCK in both PSTs and teachers, as well as the needs which have been identified for PCK development for PSTs in teacher education programs.

\section{PCK Conceptualizations}

In this section I discuss the ways in which PCK has been conceptualized and the characteristics that have been identified. I will then discuss the different ways PCK has been defined in the various research studies.

\section{Conceptualizations of PCK}

Shulman asked whether it was necessary to have a separation between content and pedagogy, and spoke of a "transformation" in proposing his Model of Pedagogical Reasoning and Action (1987). Shulman (1986) had proposed three types of knowledge necessary for teaching: content knowledge, general pedagogical knowledge, and pedagogical content knowledge. In 1990, Grossman refined this model to also include context knowledge. In the sciences, Carlsen (1999) proposed that a greater emphasis should be placed on context related to various areas of knowledge. Magnusson, Krajik, and Borko (1999) built on Grossman's model

adding assessment knowledge as part of PCK, and Park and Oliver (2008) added teacher efficacy to the Magnusson et al. model. 
A model of teacher knowledge which came to be widely accepted was the MKT model proposed by Hill, Ball, \& Schilling (2008). The MKT model subdivides the knowledge required for teaching mathematics into two main categories. The first, subject matter knowledge (SMK) is further divided into common content knowledge (CCK), specialized content knowledge (SCK) and horizon subject knowledge (HCK). The second main category is PCK which is broken down into the three subcategories: knowledge of content and students (KCS), which focuses on how students learn particular mathematical content; knowledge of content and teaching (KCT), which concerns knowledge of teaching techniques, how to best build upon student thinking, and how best to remedy student errors; and knowledge of content and curriculum (KCC), which includes knowledge of curriculum materials (Hill et al., 2008, p. 377).

Transformative vs. integrative models. A distinction has been made between integrative and transformative models of PCK (Gess-Newsome, 1999). In the integrative model, PCK is not considered to be a separate phenomenon - teaching is integration of subject matter, pedagogy, and content occurring in the act of teaching. The different types of knowledge develop separately and are integrated during practice. In the transformative model, PCK was seen as a synthesis of pedagogy and content, combining to form a unique type of knowledge. GessNewsome (1999) likened the difference between the integrative and transformative models to the difference between a chemical mixture and a chemical compound, respectively. In a mixture the ingredients remain distinct and separable, in a compound a new product is formed and the initial separate parts no longer exist.

These two models are considered to be opposite ends of a continuum. The transformative model is closer to Shulman's (1986) conceptualization and treats PCK as a stand-alone concept. The difference between the integrative and transformative models can also be thought of as the 
difference between PCK being considered a noun or a verb. In the integrative model, PCK is described as an action which occurs during the act of teaching. In the transformative model, PCK is described as a thing-as a particular type of knowledge.

\section{Alternative Conceptualizations of PCK}

In some studies, researchers sought to explore concepts similar to PCK without actually using the term. A study by Leinhart and Smith (1985), which predates Shulman's coinage of the phrase, examined the relationship between subject matter knowledge and the classroom technique of practicing teachers using expert elementary teachers' display of fraction knowledge. They did not use the term PCK, but described lesson structure knowledge as including "the skills needed to plan and run a lesson smoothly, to pass easily from one segment to another, and to explain material clearly" (p. 2) and as a being a function of subject matter knowledge.

Some researchers sought to develop their own conceptualization of PCK. One such study involved a project in which the PCK and CK of secondary mathematics teachers were examined. The researchers sought to conceptualize PCK and CK separately to determine effects of each component on teachers' instruction and students' learning (p. 133) (Baumert et al., 2010). Another study sought to conceptualize PCK and CK specifically for secondary mathematics teachers (Krauss et al., 2008).

\section{PCK Usage in Research}

Much of the research addressing teacher knowledge was based on Shulman's (1986) concept of PCK and its sub-concepts (Hill et al., 2008). A survey of 60 studies by DePaepe et al. (2013) found that a majority, 51 studies, referenced Shulman $(1986,1987)$ and 26 of those used Shulman's definition of PCK. Nine studies used the MKT model and the corresponding definition of PCK. Six studies used the term PCK without definition (DePaepe et 
al. 2013, p. 15). Several authors also refer to Ma's (1999) profound understanding of

fundamental mathematics. Researcher's differ on whether they tend toward the transformative or integrative approach.

DePaepe et al. (2013) found four common characteristics related to research using Shulman's conceptualization: PCK connects at least two forms of knowledge, PCK deals with teachers' knowledge necessary to achieve the aims of teaching, PCK is particular to subject content, and CK is assumed to be an important and necessary prerequisite for teachers' PCK.

Depaepe et al. (2013) found a wide variation in what researchers considered to be components of PCK. They identified eight distinct components referenced in the literature: knowledge of students' misconceptions and difficulties, knowledge of instructional strategies, knowledge of mathematical tasks and cognitive demands, knowledge of educational ends, knowledge of curriculum and media, context knowledge, content knowledge, and pedagogical knowledge. Ten of the papers did not define any component of PCK.

It was found that in 16 of the studies PCK is thought to consist of Shulman's (1986) original components: teachers' knowledge of students' conceptions, misconceptions, and difficulties; and teachers' knowledge of instructional strategies and representations to make subject matter accessible. In the other identified categories of PCK, the influence of Shulman's original components were evident. Many researchers treated the concepts of CK and PCK as being distinct concepts, and some treated CK as a part of PCK (Hill, et al., 2008). Others made a theoretical distinction between CK and PCK but maintained that the two concepts were inseparable in practice (Depaepe et al., 2013). 


\section{Content Knowledge is Necessary but Not Sufficient}

It might be assumed that a strong understanding of mathematical contennt knowledge is sufficient for effective teaching, but that is not necessarily the case. There has been research regarding the relationship between $\mathrm{CK}$ and $\mathrm{PCK}$, as well as the effect of both on quality of instruction and student outcomes. Findings regarding the relationship between PCK and instructional practice have shown that good PCK, as well as CK, was needed for effective instruction, and that quality of instruction was more strongly correlated to PCK than CK (Depaepe et al., 2013). The relationship between PCK and student learning outcomes has also been shown to be positively related, and the correlation between PCK, instructional approaches and student outcomes was found to be significantly higher than with CK (Depaepe et al., 2013; Baumert et al., 2010).

Connections between CK and PCK have also been sought. In the survey by DePaepe et al. (2013) there were two major findings regarding the relationship between CK and PCK. First, there strong relationships existed between the two knowledge types in the act of teaching. It was also found that the two knowledge types are positively correlated, and that CK is necessary but not sufficient for PCK (Depaepe et al., 2013). Turnuklu \& Yesildere (2007) also found that it was necessary but not sufficient to hold a deep understanding in mathematics in order to teach it.

Krauss et al. (2008) found a stronger correlation between CK and PCK in teachers with a more thorough education in mathematics. Kleickmann et al. (2013) also found a positive connection, while observing differences in PCK between teachers. Teachers trained as specialized secondary mathematics teachers, who had more mathematics coursework, were found to outperform those trained as general elementary teachers. Other researchers found similar results (Krauss et al., 2008; Senk et al., 2012; Van Dooren, Verschaffel \& Onghena, 2002). Other studies have sought 
evidence of a relationship between PCK and CK, but the findings were inconsistent. Lloyd (2014), for one, did not find evidence to support such a connection.

\section{Development of PCK and Needs for Teacher Preparation}

If PCK is necessary for effective teaching, then developing PCK should be a main focus for teacher preparation programs. It is necessary, therefore, to understand how PCK is developed and then to consider how teacher preparation programs can use that undertanding to stimulate the development of PCK in beginning teachers.

\section{Development of PCK}

Research has shown that PSTs should possess PCK in order to be effective in teaching mathematics (Kinach, 1996). Multiple factors have been identified that can contribute to the development of PCK. Teaching experience has been shown to have a positive effect on PCK (Depaepe et al., 2013), and the importance of PSTs gaining PCK development through experiences in their coursework (Appleton 2003; Appleton and Kindt 2002) has also been cited. Other factors which have been found to contribute to the development of PCK are content knowledge and educational intervention.

According to Magnusson, Krajcik, \& Borko (1999), PCK development may be influenced by subject matter knowledge. Krauss et al. (2008) found that teachers with stronger mathematics training outscored other teachers on measures of both CK and PCK, as well as connectedness between the two. The authors then concluded that there may have been support for the idea that CK supported the development of PCK.

Some research evidence suggests that PSTs development of PCK can be influenced by educational intervention (NRC, 2001). In a study by Tirosh et al. (2011) it was found that PSTs PCK and CK could be boosted, as well as their instruction quality and the students' learning 
outcomes, by intervention. Imre and Akkoc (2012) concluded that it was possible to change PSTs understanding of student thinking and difficulties through a teaching intervention.

Evidence that elementary mathematics content courses specifically designed for elementary teaching may enhance CK and PCK was uncovered by Cardetti and Truxaw (2014), and a review of papers by Matthews, Rech \& Grandgenett (2010) showed that there was a large range of interventions which may be appropriate for PSTs. The literature included discussions of the effect of content units on PSTs, and the effect of mathematical pedagogy units on PSTs (Sowder, 2007), and of reinforcing theory and practice in programs for mathematics education (Emerick, Hirsch, \& Berry, 2003). Some studies involved the development of PCK in PSTs during their education and identified factors that contributed to that development such as collaborative learning, mentoring, and working in a professional community (Depaepe et al., 2013).

As an example of an intervention, in a study by Hubeňáková, Semanišinová, \& Šveda (2017) an approach was presented to improve the PCK of secondary PSTs by focusing on lesson plans presented by PSTs at the beginning and end of the course. The result was a measurable improvement in PCK as the PSTs demonstrated an ability to better integrate solutions, activities and explanations and to better explain their reasons for choosing tasks and activities.

Lannin et al. (2013) spoke of "superficial" development of PCK, stating that teachers who focused on curriculum without taking student learning into account were found to develop PCK more superficially than those working toward high quality instructional tasks. This points to the idea that some paths of development of PCK may be better than others. Callingham, Chick, \& Thornton (2013) thought that finding evidence of growth of PCK, as well as its connection to CK, was still a work in progress. 


\section{Needs for Teacher Preparation}

It has been stated that teacher education programs need to place greater emphasis on developing PSTs with strong PCK (Buss 2010; Hill, Rowan, and Ball, 2005). Teacher education program researchers have investigated the ways in which PSTs' PCK is developed (Beswick \& Goos, 2012), as well as their mathematical CK (Meany \& Lange, 2012), however there has been no consensus on how to prepare PSTs to teach mathematics (Ball, Hill \& Bass, 2003; Chapman, 2005).

Most research on PCK for mathematics has focused on elementary teaching. Researchers have found that elementary teachers tended to leave education programs with limited mathematics and science PCK (Hill, Rowan, and Ball 2005; Hill, Schilling, and Loewenberg Ball, 2004). It has been said that preparation of elementary PSTs was a concern for teacher preparation programs (Matthews, Rech \& Grandgenett, 2010).

The concern for secondary teacher programs was somewhat different than for elementary programs. Secondary teaching programs tended to include courses leading to a mathematics major or its equivalent, plus some courses specifically directed toward mathematics teaching (Barker et al., 2004; Conference board of the Mathematical Sciences, 2001, 2012), and secondary mathematics teacher preparation programs tended to separate the learning of content and the learning of teaching without adequate integration of the two parts (Steele \& Hillen, 2012). According to Sowder (2007), novice secondary teachers tended to have had fewer pedagogy and education classes than elementary teachers and therefore were more likely to fall back upon traditional practices.

Research efforts have focused on preparation approaches such as coursework or interventions for PSTs emphasizing PCK (Beswick \& Goos 2012; Shulman 1986; Shulman 
1987), and CK (Meany \& Lange 2012; Ponte \& Chapman, 2008). Researchers have also discussed ways to best support elementary and secondary teachers and PSTs' PCK, such as having them analyze their own mathematics lessons (Aguirre, del Rosario Zavala \& Katanyoutanant 2012) or examining what teachers learn about teaching (Kennedy, Ball \& McDiarmid 1993); and CK, such as looking at conceptual content in a STEM modelling activity (Stohlmann, Moore \& Cramer, 2013).

Teachers must possess PCK and multiple ways to represent material in order to help students learn with understanding (Shulman, 1987). Grossman (1990) stated that experience from previous education is an important base of knowledge. PSTs should acquire skills over time to study their teaching, as it is unrealistic to expect them to enter the profession as expert teachers (Hiebert, Morris, Berk and Jansen, 2007). Pre-service teachers, however, need a context which allows them to see the topics they will eventually teach in a different way (Furinghetti, 2007).

\section{Standards for Teacher Preparation}

The development of the necessary knowledge and skills for effective teaching should begin in one's teacher education program. In fact, the Association of Mathematics Teacher Educators (AMTE) has developed a set of standards aimed at guiding teacher education programs to better prepare beginning teachers. Those standards that directly address teacher knowledge pertain to mathematics concepts, practices, and curriculum. Standards regarding mathematics content involve knowing relevant mathematical concepts, demonstrating mathematical practices and processes, exhibiting productive mathematical dispositions, and analyzing the mathematical content of curriculum. Standards addressing pedagogical knowledge 
and practices for teaching mathematics include planning for effective instruction, implementing effective instruction, and analyzing teaching practice. Standards pertaining to students as learners of mathematics focus on anticipating and attending to students' thinking, understanding and recognizing students' engagement, and anticipating and attending to students' dispositions (Association of Mathematics Teacher Educators [AMTE], 2017).

The NCTM (2020) published Standards for the Preparation of Secondary Mathematics Teachers. These include a standard for mathematics concepts, practices and curriculum which involves knowing relevant mathematical content, demonstration of mathematical practices and processes, exhibiting productive mathematical dispositions, analyzing the mathematical content of curriculum, and analyzing mathematical thinking. The standard for pedagogical knowledge and practices for teaching mathematics includes planning for effective instruction, implementing effective instruction, and analyzing teaching practice. There is also a standard concerning students as learners of mathematics which includes anticipating and attending to students' thinking about mathematical content and understanding and recognizing students' engagement in mathematical practices.

\section{Chapter Two Summary}

In this chapter I discussed conceptualizations of PCK which have been developed beyond that set by Shulman $(1986,1987)$. I then discussed the usage of PCK in the research literature, including an introduction of the distinction between transformative and integrative models. Next I discussed the idea that content knowledge is necessary, but not sufficient, for effective teaching of mathematics. I also talked about research concerned with the development of PCK in both PSTs and teachers, as well as the needs which have been identified for PCK development for 
PSTs in teacher education programs. 


\section{CHAPTER III: METHODS}

A qualitative case study design was chosen because it was best suited to the descriptive and interpretive intent of this study. Basic qualitative research can be used to develop understanding and identify recurrent patterns as themes or categories. The product of a qualitative study is richly descriptive, and the design leads to evolving, emergent understanding and discovery (Merriam, 1998). Case studies are appropriate when variables cannot be isolated from context (Merriam, 1998) and are appropriate to examine "how" and "why" questions (Yin, 1994, p. 9).

This study was designed and conducted as a multiple-case study. A case consists of either a single unit such as an individual or group, and a multiple-case study involves making comparisons between individuals or groups (Merriam, 1998). The cases in this study consisted of three groups: a group of PSTs who had completed the secondary mathematics education program at a given university, a group of undergraduate mathematics students (MAT) who had completed all or a significant portion of their required coursework, and a group of participants who possessed professional teaching experience (PRO). Comparisons facilitated the identification of similarities and differences between the PST and MAT groups, and those differences constitute the evidence for PCK that was being sought. Comparisons between the PSTs and PROs were also done, in case any noticeable differences in aspects of teacher knowledge gained by experience could provide insight.

\section{Participants}

In this section, I identify the desired characteristics for members of each of the three participant groups and discuss how I went about identifying and recruiting participants. 


\section{Pre-Service Teacher Recruitment}

Because the purpose of the study was to identify the knowledge held by PSTs which was not held by others, I needed to interview PSTs who had completed their teacher education program but had not started teaching. This necessitated approaching students after the completion of student teaching but before they began teaching. My intent for selecting participants was to have the PSTs' mathematics education professors, their student teaching seminar instructors in particular, identify potential participants.

I had planned to seek out PSTs for interviews who would possess strong PCK and be able to articulate it well. The first semester that I sought to recruit participants was Spring 2018, and I contacted the professors who were teaching the student teaching seminar at that time. The professors contacted those PSTs whom they deemed to be good candidates and they were to contact me or the mathematics office if they were interested in participating. This did not result in any potential participants coming forward.

The need to have students who had finished student teaching but had not started regular teaching should have allowed several months for data collection, the entire summer following their graduation. Finding students interested in participating once they had graduated, however, turned out to be very difficult. The actual window of opportunity turned out to be the few days at the end of the semester when students were on campus but before graduation. Finding enough interested students then still proved difficult, so the nine PST participants were selected from two different graduating classes, 2018 and 2019.

I made an announcement during the 2018 student teaching seminar and was able to recruit two PSTs who showed interest at that time. Similarly, I recruited one more PST at the 2019 seminar the following year. Dr. Langrall, my dissertation director, made an announcement 
at the 2019 PST awards ceremony, and two more interested PSTs approached me and were interviewed that same day. All of these first five PSTs were interviewed in the mathematics office or a classroom on the mathematics floor. Four more PST participants were recruited and interviewed by Dr. Langrall during the conclusion of their student teaching seminar in 2019.

The teacher preparation program. The PSTs in this study were involved in a program developed by Winsor, Barker, and Kirwan (2020) as a secondary mathematics teacher program aimed at integrating teacher knowledge of content, learners, and pedagogy. This program involved teaching connected content and pedagogy courses as well as daily clinical experience in a high school.

Before entering their final year, PSTs in the program had taken a battery of content courses comparable to a mathematics major, as well as an introduction to mathematics teaching course focused on analyzing teaching standards. PSTs also took non mathematics-specific courses: on focused on social forces influencing secondary schools, another regarding curriculum and instruction, and another involving strategies and techniques to promote literacy in all content areas.

Two courses taught in tandem were a senior level pedagogy course in secondary mathematics and a capstone content course in secondary mathematics. These courses were taught together in order to develop knowledge integration between pedagogy and content. The content course involved college-level mathematics to help develop a deep understanding of secondary concepts such as functions and polynomials. Group work, problem solving, connections, justification, and mathematical communication were emphasized in order to help PSTs understand mathematics at a conceptual level to support meaningful instruction. 
The pedagogy course was intended to develop requisite knowledge, dispositions, and abilities in PSTs. The instructor of the course emphasized group work, critical thinking, and justification of pedagogical choices. Some of the topics covered included: posing problems to students, giving effective feedback, establishing objectives, questioning, assessment, task selection, levels of cognitive demand, and inplementing teaching standards. Along with the pedagogy class PSTs had one hour per day, five days a week, of clinical experience at a local secondary school. This experience allowed them to observe and test the pedagogical practice discussed in class and to implement tasks and examine student work.

\section{Mathematics Major Recruitment}

The original plan was to get MAT participants at the same point in their studies as the PSTs_-just before graduation — and I targeted mathematics classes that had seniors near the end of their program. This turned out to be even less fruitful than with the PSTs, so the MAT participants were selected without the constraint of being at the very end of their final semester. The MAT participants who ultimately were selected, therefore, had a wider range of experiences than the PST group, from having completed the calculus/differential equations sequence to first year graduate students. MAT participants had the additional constraint that they had not taken any education courses.

I sent announcements regarding the nature of the study to mathematics teachers who had seniors in their classes, and made announcements in those classes myself. In all, only three students approached me with interest in participating in the study in the Spring of 2018. Further efforts at the same university in the Spring of 2019 resulted in no participants. In the Summer of 2019, I contacted the mathematics department chair at a community college where I had taught classes. She sent out an announcement to instructors of higher-level undergraduate courses who 
made announcements to their respective classes. Five students contacted me and were interviewed as a result.

The MAT participant interviews at the university were held in the mathematics office. The others were held in the mathematics office of the community college or at various coffee shops.

\section{Professional Teacher Recruitment}

Participants in the professional group, those with teaching experience, had a minimum of two years classroom teaching experience. One of the PROs had experience as a high school mathematics teacher, held a PhD in Mathematics Education, and was currently teaching mathematics at the university. Another had experience as an elementary teacher and was in the graduate school completing her PhD in Mathematics Education at the same university. The third had graduated from the university with a bachelor's degree in Mathematics Education and was nearing the end of his second year as a teacher.

I recruited the PRO participants simply by asking people I thought might be interested in participating. The university interviews were done in the mathematics office conference room in Spring 2018. The other was done in Spring 2019 in a high school classroom.In total, twenty participants were interviewed. Nine of those participants were PSTs, eight were MATs, and three were PROs. The PST participants were identified as TCH1-TCH9, the MAT participants as MAT1-MAT8, and the PRO participants as PRO1-PRO3. The sample was a convenience sample, as participants were not chosen randomly, were from the same program and were essentially self-selected. A summary of each participant group is given in Figure 1. All participants received a $\$ 20$ electronic Amazon gift card for their participation, and they all signed informed consent (see appendix A) forms. 


\begin{tabular}{|l|l|c|l|}
\hline $\begin{array}{l}\text { Participant } \\
\text { Group }\end{array}$ & Acronyms & $\begin{array}{l}\text { Number of } \\
\text { Participants }\end{array}$ & Characteristics for Recruitment \\
\hline $\begin{array}{l}\text { Pre-Service } \\
\text { Teachers }\end{array}$ & TCH1 - TCH9 & 9 & $\begin{array}{l}\text { These participants were PSTs who had completed } \\
\text { their teacher education program but had not yet } \\
\text { started teaching. }\end{array}$ \\
\hline $\begin{array}{l}\text { Mathematics } \\
\text { Majors }\end{array}$ & $\begin{array}{l}\text { MAT1 - } \\
\text { MAT8 }\end{array}$ & 8 & $\begin{array}{l}\text { The MAT participants had a wider range of } \\
\text { experiences than the PST group, from having } \\
\text { completed the calculus/differential equations } \\
\text { sequence to first year graduate students. MAT } \\
\text { participants also had the additional constraint that } \\
\text { they had not taken any education courses. }\end{array}$ \\
\hline Professionals & PRO1 - PRO3 & 3 & $\begin{array}{l}\text { Participants in the professional group had a } \\
\text { minimum of two years classroom teaching } \\
\text { experience. All three were associated with the mid- } \\
\text { sized Midwestern university where the study had } \\
\text { been performed. I recruited the PRO participants } \\
\text { simply by asking people who I thought might } \\
\text { be interested in participating. }\end{array}$ \\
\hline
\end{tabular}

Figure 1. Summary of Participant Groups.

\section{Study Design}

Data were collected through task-based interviews conducted with individual

participants. Such interviews "for the study of mathematical behavior involve minimally a subject (the problem solver) and an interviewer (the clinician), interacting in relation to one or more tasks (questions, problems, or activities) introduced to the subject by the clinician in a preplanned way" (Goldin, 2000, p. 519). Each interview lasted approximately 30-45 minutes and was audio recorded. The audio recordings were transcribed and served as the data for this study.

\section{Data-Eliciting Task}

A data-eliciting task, which I named the Tutoring Task (Figure 2), was the basis for each interview. The task was presented within the context of a tutoring session, so that it would resemble an experience familiar to participants in all three groups. The task was composed of 
two parts: solving an algebraic problem involving a system of linear equations and critiquing an animated video of a mathematics lesson in which the same problem was presented to a small group of students.

\section{Tutoring Task}

A family friend has asked you to help their son, a high school student, with the following homework problem:

Two competing wireless companies offer pay-by-the-minute plans. The first company advertises as sample rates 400 minutes for $\$ 30$ a month, and 700 minutes for $\$ 45$ a month. The second company advertises that you only pay for the minutes you use - there is no fixed monthly charge - and gives an example rate of 600 minutes for $\$ 42$.

Which plan offers the better deal? Why?

Part 1, Problem Solving: Solve the problem and discuss your solution strategies.

Part 2, Lesson Critique: Watch a short video of the student's math teacher conducting a lesson on the same problem. The video will stop at certain intervals and you will be asked to discuss the lesson and compare it to what you may have done. Keep in mind that the lesson as it is presented has its own strengths and weaknesses, and should not necessarily be considered as the correct or only way to teach the lesson.

Figure 2. Tutoring Task.

For the problem-solving part of the task, the participant was left to interpret the problem on their own, though it was sometimes necessary for the interviewer to answer questions for clarification. While solving the problem, the participants talked through their thought process. The purpose of having the participants solve the problem themselves was so they were familiar with the problem and had thought about it and how they might help the student they were hypothetically tutoring before seeing the teacher's lesson.

For the lesson critique part of the task, the participants watched an animated adaptation 
from the transcript of an actual lecture taught by me, which included responses by those students who were in attendance. The video showed six students representing the class in a lecture hall format as well as the teacher (see Figure 3). Although my identity as the teacher was never discussed, the lesson was presented as an animation rather than the original format so that participants could critique the video without any concerns that they were criticizing an actual teacher. The entire video was about seven minutes long and was broken down into five shorter video clips. The participants were asked to discuss their thoughts regarding the teacher's actions and the students' responses after each segment. Descriptions of each clip and the associated response prompts are shown in Figure 4. The full video can be viewed here at https://youtu.be/6jNI08MsYcc and a transcript of the video can be found in Appendix B.

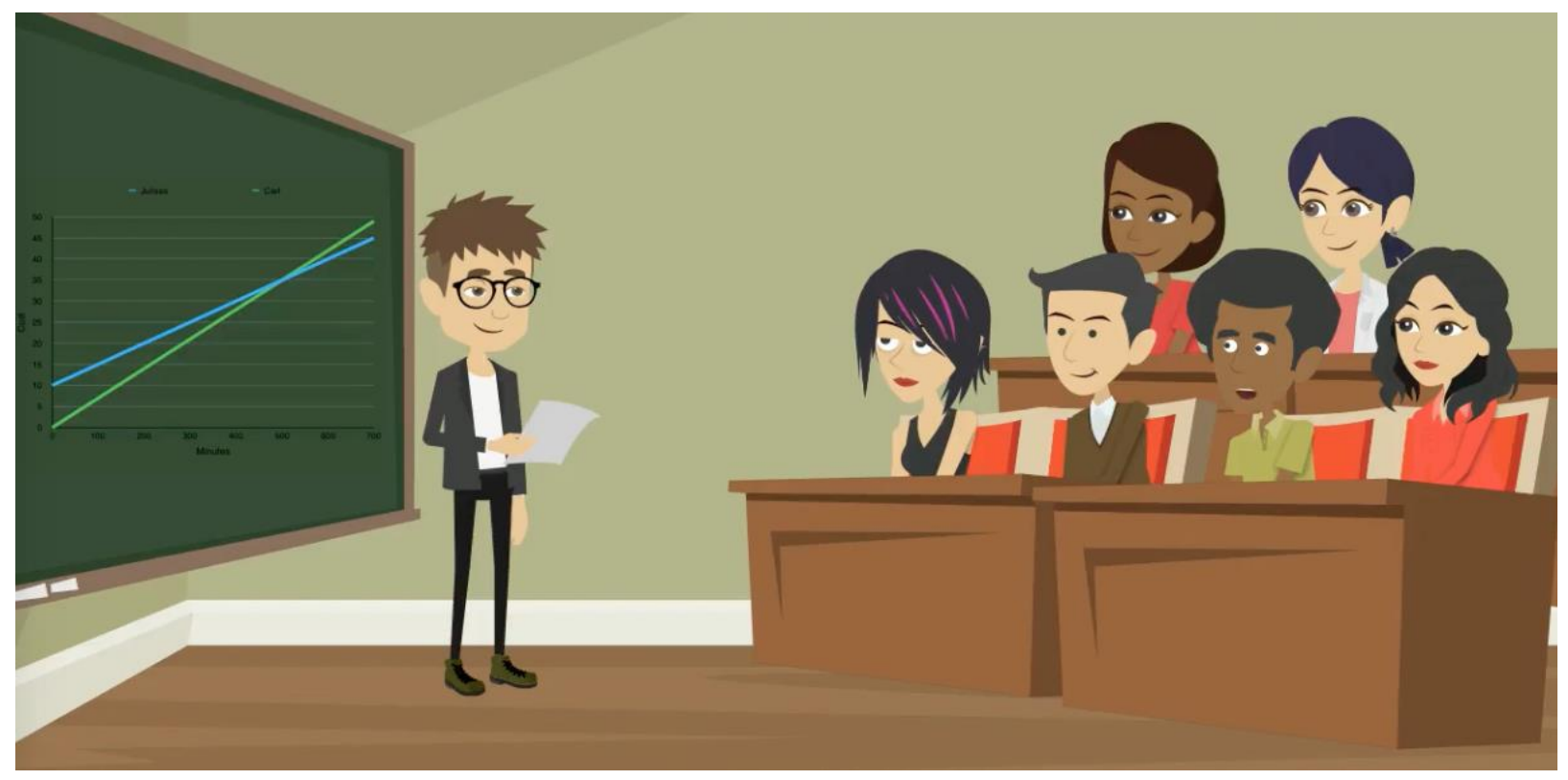

Figure 3. Video Screenshot. 


\begin{tabular}{|c|c|c|}
\hline Title (elapsed time) & Description & Prompts \\
\hline Introduction $(0: 00-1: 37)$ & $\begin{array}{l}\text { Students introduce the task by } \\
\text { reading from the board. The } \\
\text { known points of the graph are } \\
\text { identified. }\end{array}$ & $\begin{array}{l}\text { a) What did the teacher do? } \\
\text { b) Why do you think the } \\
\text { teacher did what he did? } \\
\text { c) Would you have done } \\
\text { anything differently and why? } \\
\text { d) Any other comments? }\end{array}$ \\
\hline Formulas (1:38-2:18) & $\begin{array}{l}\text { Students are asked to recall } \\
\text { relevant formulas and begin } \\
\text { work finding equations. }\end{array}$ & $\begin{array}{l}\text { a) What did the teacher do? } \\
\text { b) Why do you think the } \\
\text { teacher did what he did? } \\
\text { c) Would you have done } \\
\text { anything differently and why? } \\
\text { d) Any other comments? }\end{array}$ \\
\hline Explanation $(2: 19-3: 18)$ & $\begin{array}{l}\text { Students go to the board to } \\
\text { explain their equations. }\end{array}$ & $\begin{array}{l}\text { a) What did the teacher do? } \\
\text { b) Why do you think the } \\
\text { teacher did what he did? } \\
\text { c) Would you have done } \\
\text { anything differently and why? } \\
\text { d) Any other comments? }\end{array}$ \\
\hline Discussion (3:19-5:31) & $\begin{array}{l}\text { Class discussion of the } \\
\text { meaning of the graphs } \\
\text { including significance of } \\
\text { slope and y-intercept within } \\
\text { the context of the phone } \\
\text { plans. }\end{array}$ & $\begin{array}{l}\text { a) What did the teacher do? } \\
\text { b) Why do you think the } \\
\text { teacher did what he did? } \\
\text { c) Would you have done } \\
\text { anything differently and why? } \\
\text { d) Any other comments? }\end{array}$ \\
\hline Interpretation $(5: 32-6: 37)$ & $\begin{array}{l}\text { Class is asked which plan is } \\
\text { the better deal and discusses } \\
\text { why the answer depends on } \\
\text { phone usage. }\end{array}$ & $\begin{array}{l}\text { a) What did the teacher do? } \\
\text { b) Why do you think the } \\
\text { teacher did what he did? } \\
\text { c) Would you have done } \\
\text { anything differently and why? } \\
\text { d) Any other comments? } \\
\text { e) Considering the overall } \\
\text { lesson, in what ways would } \\
\text { you have taught it differently? }\end{array}$ \\
\hline
\end{tabular}

Figure 4. Video Animation Sections. 


\section{Rationale}

Shulman (1986) proposed the concept of PCK as being that knowledge held by teachers beyond that held by subject practitioners. This includes, for example, knowledge of effective representations, explanations, and examples, that could help a learner make sense of a given subject. PCK, as he proposed it, also includes understanding of what makes learning given topics easy or difficult, and understanding students' previous knowledge and their possible misconceptions. I designed the task to discern any differences in the knowledge that the different groups of participants drew upon when critiquing the video.

I chose an algebraic problem because I considered the topic of algebra to be equally familiar to each group. This particular problem typifies an algebraic performance task, contains multiple steps requiring elements of both conceptual understanding and instrumental knowledge to properly solve and interpret, and the system of linear equations context was accessible to the PSTs, MATs, and PROs. The problem was chosen because it involved elements of interpretation — both of the problem itself and its solution — and because there were multiple ways of going about answering the open question of which plan was the better deal. Solving the problem could involve multiple representations such as graphs, equations, and tables. The question also left open to the discretion of the participant the amount of mathematical rigor and the depth of interpretation necessary to answer. This task, then, gave the participants a lot to talk about and many different ways to answer each of the interview questions - therefore, providing a great opportunity to differentiate between participant groups.

The lesson critique part of the task was intended to elicit the participants' knowledge of and thoughts about teaching as they responded to a set of fixed prompts for each video clip. I used open questions such as What did the teacher do? Why did he do it? and What would you 
have done differently? as a means to tease out what a given participant saw as important, the significance to the lesson of what they saw, whether they agreed with it or not, and how they may have handled it differently themselves. This gave clues about their teaching knowledge and priorities. The differences between the types of statements made by the group of PSTs and those made by the group of mathematics majors lead to my characterization of PCK.

\section{Analysis}

A goal of qualitative analysis is to develop propositions or "statements of fact inductively derived from a rigorous and systematic analysis of the data" (Maykut \& Morehouse, 1994, p. 126). The process of qualitative analysis involves deriving "meaning from the words and actions of the participants of the study, framed by the researcher's focus of inquiry (Maykut

$\&$ Morehouse, 1994, p. 128). The constant comparative method described by Glaser and Strauss (1967) is one technique for analyzing data to identify such propositions. It is an inductive approach in which relevant variables are not pre-determined and meaning is discerned from the data through multiple iterations of analysis (Lincoln \& Guba, 1985; Maykut \& Morehouse, 1994).

\section{Preparing the Data: Constant Comparative Method}

The constant comparative method involves three steps with multiple iterations within each step. In the sections below, I describe the general procedures for each step and then explain how I applied those procedures in analyzing the data for my study.

Unitizing and coding the data. The first step in analysis involves unitizing the data (Lincoln \& Guba, 1985) or identifying "chunks of meaning” (Marshall, 1981, p. 395). This 
begins by isolating small units of meaning in the transcripts of the recorded data. Each of these units must be understandable without additional information and help to define larger categories of data. Next, a word or phrase is attached to each unit which summarizes its meaning. These units are then separated so that they can be sorted into potential categories (Maykut \& Morehouse, 1994). This is referred to as open coding by Strauss \& Corbin (1998) and is described as the process by which concepts are identified and their properties are discovered.

Broadly speaking, during open coding, data are broken down into discrete parts, closely examined, and compared for similarities and differences. Events, happenings, objects, and actions/interactions that are found to be conceptually similar in nature or related in meaning are grouped under more abstract concepts called "categories." Closely examining data for both differences and similarities allows for fine discrimination and differentiation among categories. (Strauss \& Corbin, 1998, p.102)

In this study, the structure of the interview facilitated the process of unitizing the data. Participants' responses to each of the questions posed for each video clip (What did the teacher do? Why do you think the teacher did what he did? Would you have done anything differently and why? Any other comments?) served as meaningful units of data. However, participants did not always respond to each of the questions and sometimes they addressed two questions within a response. Thus, a particular unit of data was often characterized with more than one summarizing statement.

Initially, I worked from paper copies of the interview transcripts and wrote in the margins words or phrases that characterized each unit of data. I then created five spreadsheets, one for each video clip, and recorded these hand-written summary statements for each participant. Each 
row of the spreadsheet was designated for one of the four interview questions (or units of data) and each column was assigned to a participant. My characterizations of the participants' responses were recorded on the spreadsheet accordingly. I labeled each cell of the spreadsheet with a letter identifying the participant, a number indicating the video clip, and a second number indicating the particular question for that video clip. Participants were, at this point, labeled only with letters so that their group affiliation would not be known. This enabled me to trace each summary statement back to its corresponding excerpt in the original transcript as needed. An example of a spreadsheet for Video 1 is shown in Figure 5.

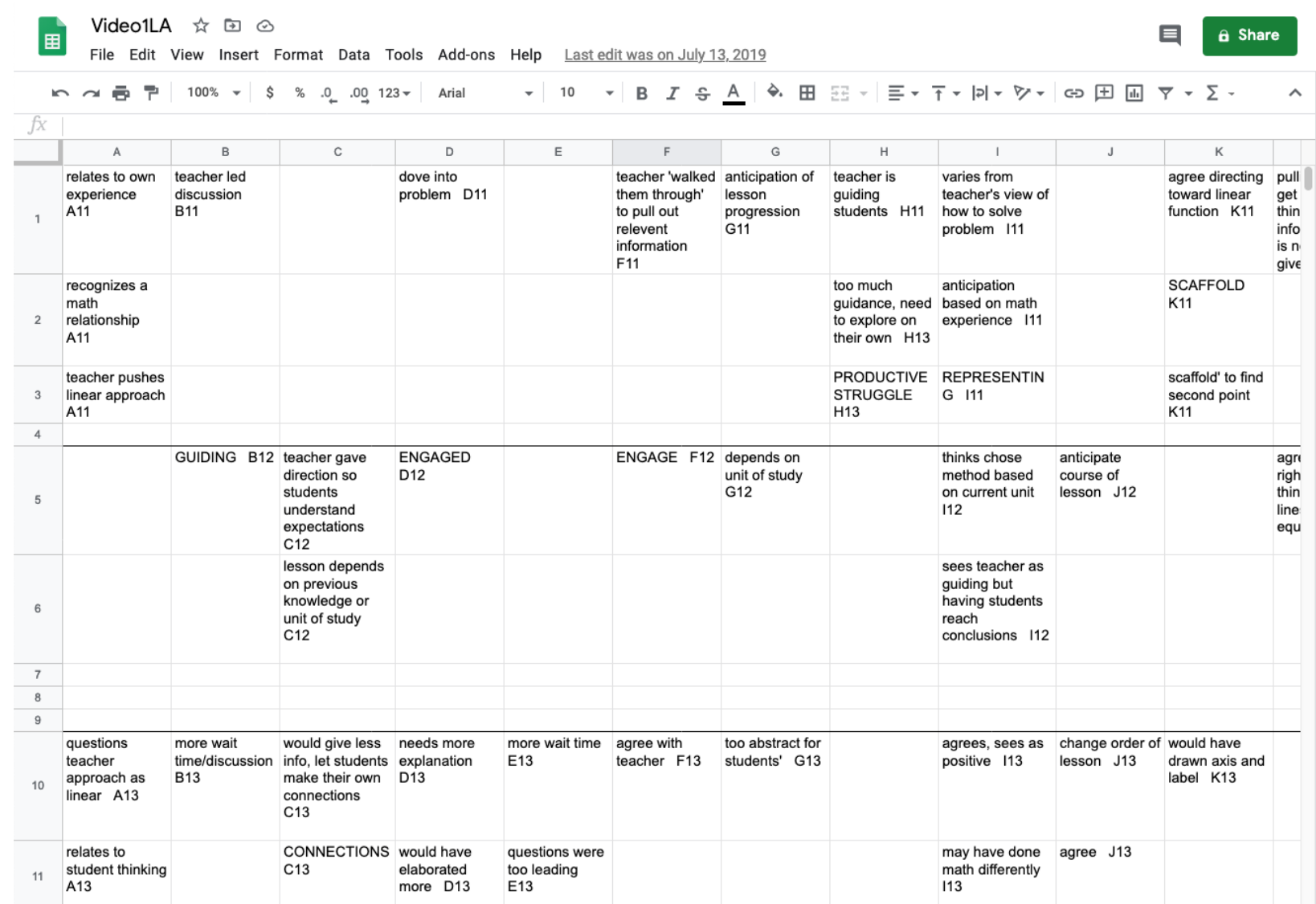

Figure 5. Initial Grouping of Excerpts. The spreadsheet example is for one video. Each column contains excerpts for one participant. Rows are grouped by questions.

Categorization. According to the constant comparative method, the phrases created to summarize each of the data units are used to begin identifying common ideas and patterns that 
provide tentative categories. Once some provisional categories have been identified, the summary phrases matching the first category are added, and compared to the existing phrases in that category. Those phrases that do not "look alike" or "feel alike" compared to the first category are compared to a second, third, and so on until all have been categorized. Categories are refined continuously as they are merged, changed, deleted, or new categories are formed (Lincoln \& Guba, 1985).

For this part of the analysis, I created a second set of five spreadsheets, one for each video. These spreadsheets were organized with a row for each participant and each column constituting a category. I began the process of categorizing by placing a summary statement in the first empty column in the row for a given participant. The next summary statement was then compared to the first. If it seemed similar to the first, the statement was placed into the same column, if not a new column was formed. Tentative column labels were attached as columns were created. These column labels were to become the categories. Figure 6 shows an example of one of these spreadsheets. 


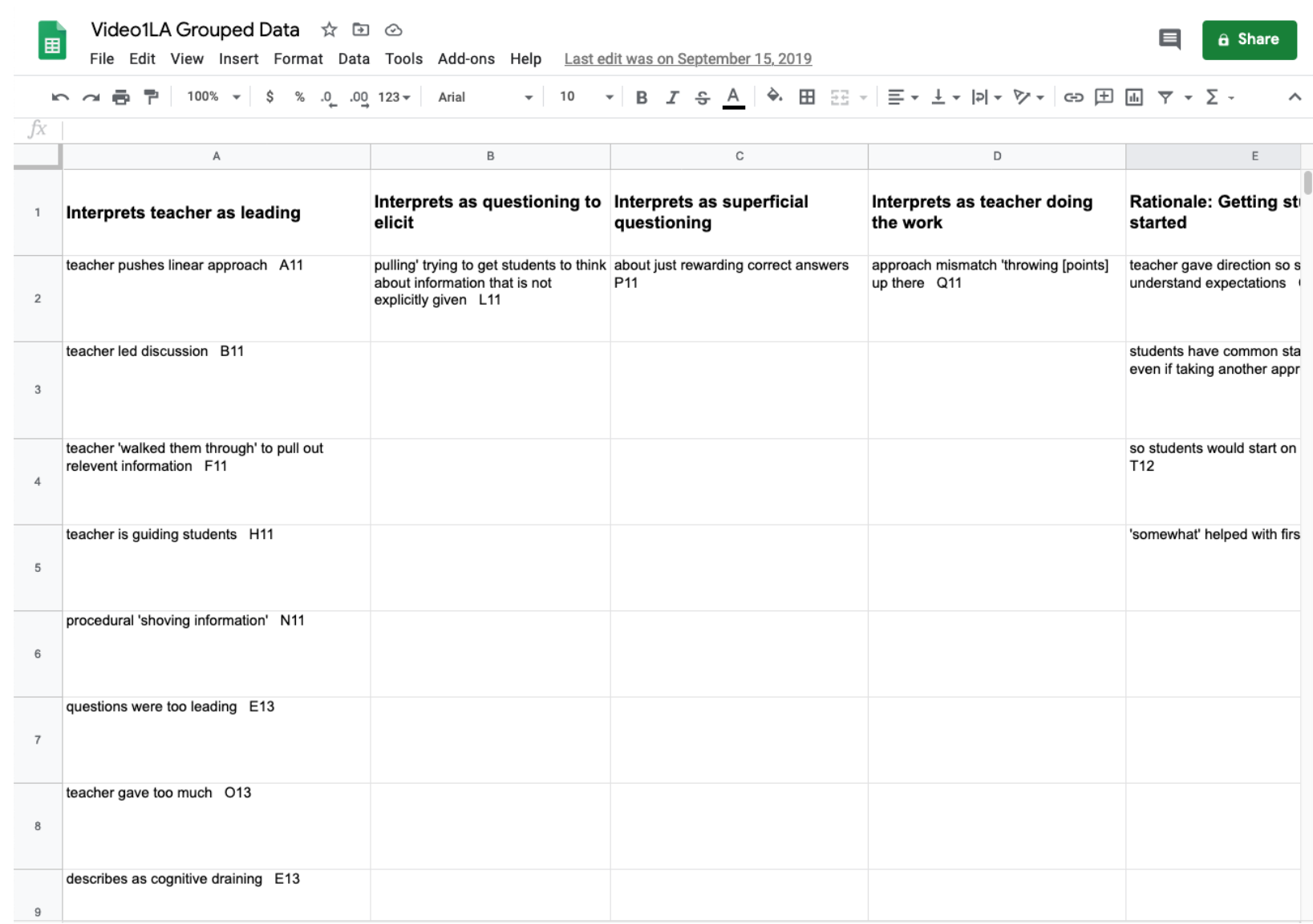

Figure 6. Excerpts by Category. Columns contain similar excerpts. Column headings are descriptive statements based on the contents of the column. Spreadsheet shown is for one video.

Once all of the summary statements for the first video were placed, I carried the accumulated categories to the spreadsheet for the next video. These categories along with new ones added during categorization of that video were transferred to the next, until categorization of all five videos was completed.

By the time the spreadsheet for the last video had been completed, several new categories had been added to the initial set generated by the first video. I then applied the final set of categories to all five videos, and made appropriate adjustments to the placement of the summary statements. This adjustment consisted of revisiting each previously placed statement and moving it if it was determined to fit better into one of the new categories. 
Check coding. All participant's transcripts were assigned an identifying letter and were labeled without reference to which group each belonged. Five of the letters were chosen at random and Dr. Langrall did open coding on the corresponding transcripts using the same basic method that I had used for every transcript. We then compared summary statements for each of those five transcripts. We compared the phrases that we had excerpted and the summary statement that we had written for each phrase, as well as the designated category for each statement.

We calculated an $84 \%$ agreement. That is, $84 \%$ of our original summary statements were essentially the same and categorized similarly. When there was a mismatch, we discussed the differences and negotiated an adjustment of a statement or a refinement of a category.

Consolidation and adjustment of categories. As a result of the check coding negotiations, some categories were combined when one or more categories seemed to be essentially the same, and some of the category names and definitions were changed to better reflect their contents. I revisited all of the entries for each of the five videos to see if their categorization should change in light of the new definitions. Forty of the initial entries were tagged for reconsideration, and 30 of those ended up being moved to new categories. For example, I combined the categories interprets teacher as leading, interprets as direct instruction, and interprets as teacher doing the work into one category called interprets the teacher as leading. A revised spreadsheet is shown in Figure 7. Note that the cells were color-coded by participant group in preparation for the division of the data by group. Red cells were PST excerpts, yellow were MATs, and blue were PROs. 


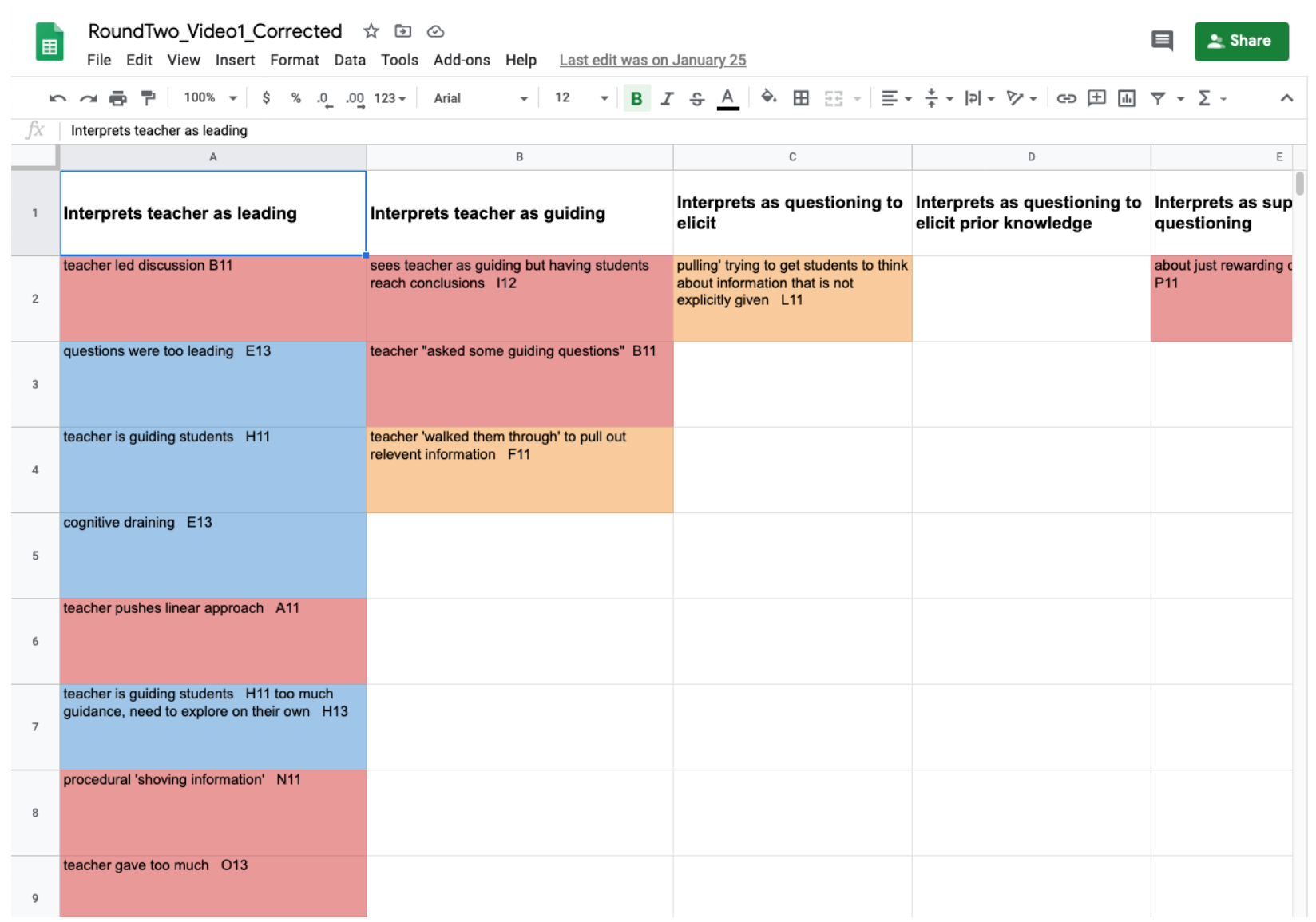

Figure 7. Revised Post-Adjustment Spreadsheet. Similar to Figure 7 with placement of excerpts adjusted after consolidation of some categories. Cells were color-coded by participant group, with red indicating PSTs, orange indicating MATs, and blue indicating PROs.

Development of propositions. Following the constant comparative method, once a category contains several units of data, a rule for inclusion can be developed. The rule for inclusion to a category is based on common characteristics or meaning of units in the group and provides a basis for including or excluding subsequent data. These rules are stated as propositional statements, reflecting a shift from categorization to stating the collective meaning of excerpts in a given category. The propositional statements are then examined for relationships and patterns across categories. Some propositions may stand alone and others may be combined to form outcome propositions (Maykut \& Morehouse, 1994).

In my analysis, I adjusted category names to fit the summary statements within each 
category, and I wrote a general description of the statements within each category in the form of a rule for inclusion or propositional statement. An example of a category is Interprets teacher as leading, and its corresponding rule of inclusion is "The participant sees the teacher as providing the students with more guidance than appropriate." Another example is Rationale: Getting students started, with the rule "The participant sees the teacher's introductory procedure as a starting point for solving the problem." A complete list of the categories and their rules for inclusion from this process, as well as a description of changes made in the process of developing the outcome propositions, can be found in Appendix C. I grouped the propositional statements into clusters labeled interpretations, rationales, references to, recommendations, relates to one's own experience. Having made the final adjustments, these propositional statements and related categories will be thought of as outcome propositions and their labels, respectively, and referred to as outcome propositions.

\section{Analyzing Outcome Propositions Within and Across Participant Groups}

To characterize the PCK as that which is unique to PSTs, I analyzed the outcome propositions within and across participant groups.I arranged the outcome propositions in a way that would highlight the differences between the three groups. To do this I set up three spreadsheets, one for each participant group, organized with participants as rows and outcome propositions as columns. On these spreadsheets I recorded the percentage of the participants who had offered a response related to each outcome proposition. This was done to gauge the relative importance of each outcome proposition in each participant group. I then color-coded the column headings to indicate whether all (green), most (yellow), red (some), or none (white) of the participants had responses related to that outcome proposition, with orange and green bars indicating a proposition cluster. Each participant group had a separate spreadsheet. Part of the 
PST spreadsheet is shown in Figure 8.

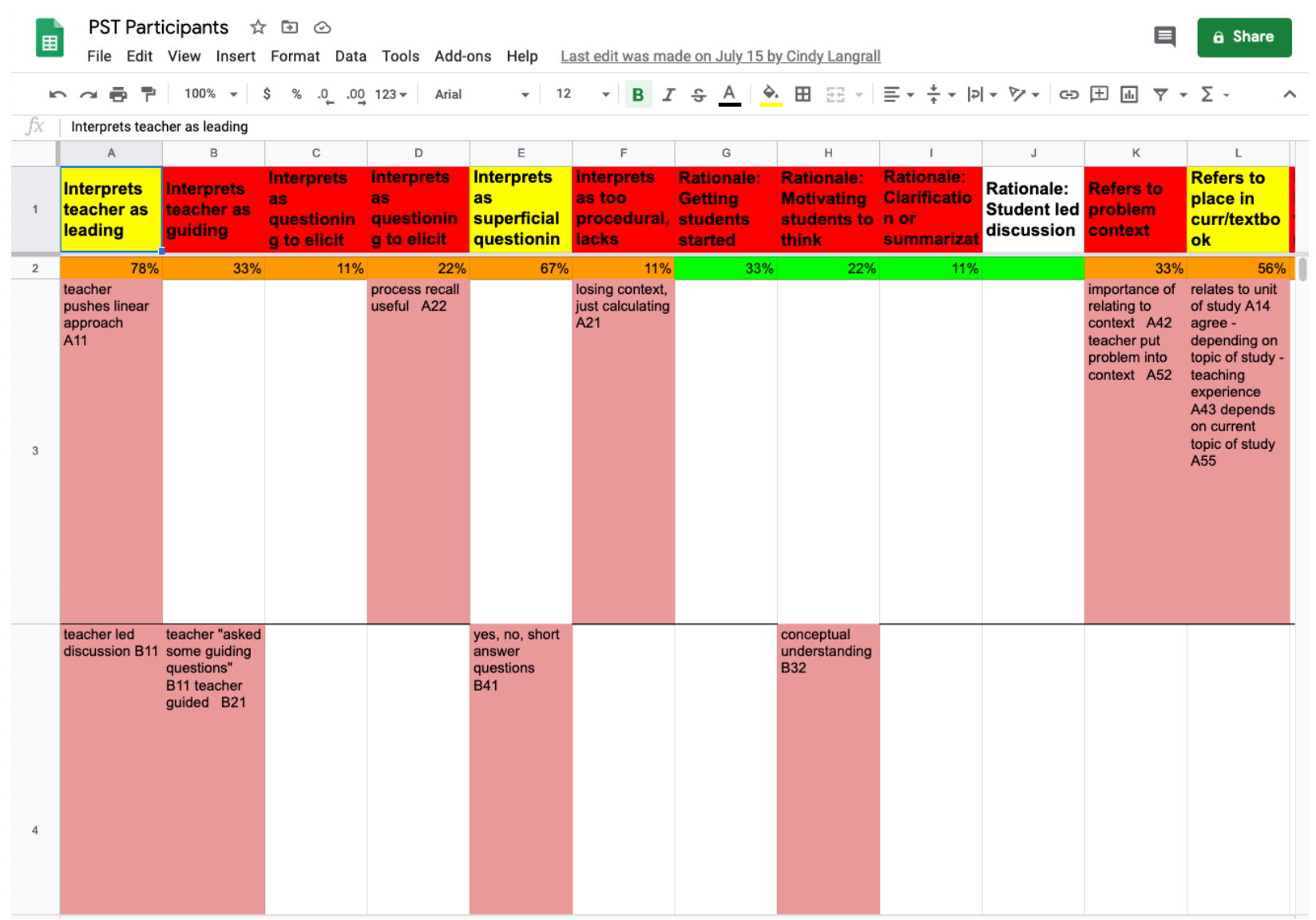

Figure 8. Participant Responses by Percentage. Column heading are color-coded by percentage range. Orange and green bars indicate a proposition cluster.

I then looked at differences between the various participant groups. I differentiated between the participant group pairs PST and MAT, and PST and PRO by comparing those outcome propositions for which most or all of one group had entries and the other group had none.

Agreed with teacher. I thought that there might be value in isolating all of the statements by the participants that signaled agreement with what the teacher was doing, whether it was to elicit additional insight or to support eventual conclusions. I created a separate spreadsheet on which I collected all of the relevant statements made by participants of all three groups so that 
they could easily be compared. Attached to each statement were notations of the teacher's actions or aspects of the lesson with which they were agreeing, why they were agreeing with it, and any stated suggestions. I gleaned the subject of their agreement from the context and recorded their reason for agreeing only when it was explicitly stated, often in the form of a "because" phrase.

Individual data. I created twenty individual spreadsheets, one for each participant, which contained all categories from all five transcripts for each respective participant. Each spreadsheet contains all summarizing statements for the individual participant, with categories organized in columns and relevant videos organized by row. An example is shown in Figure 9. These individual spreadsheets were used to compose a brief summary of each participant's interview. Those summaries can be found in Appendix D.

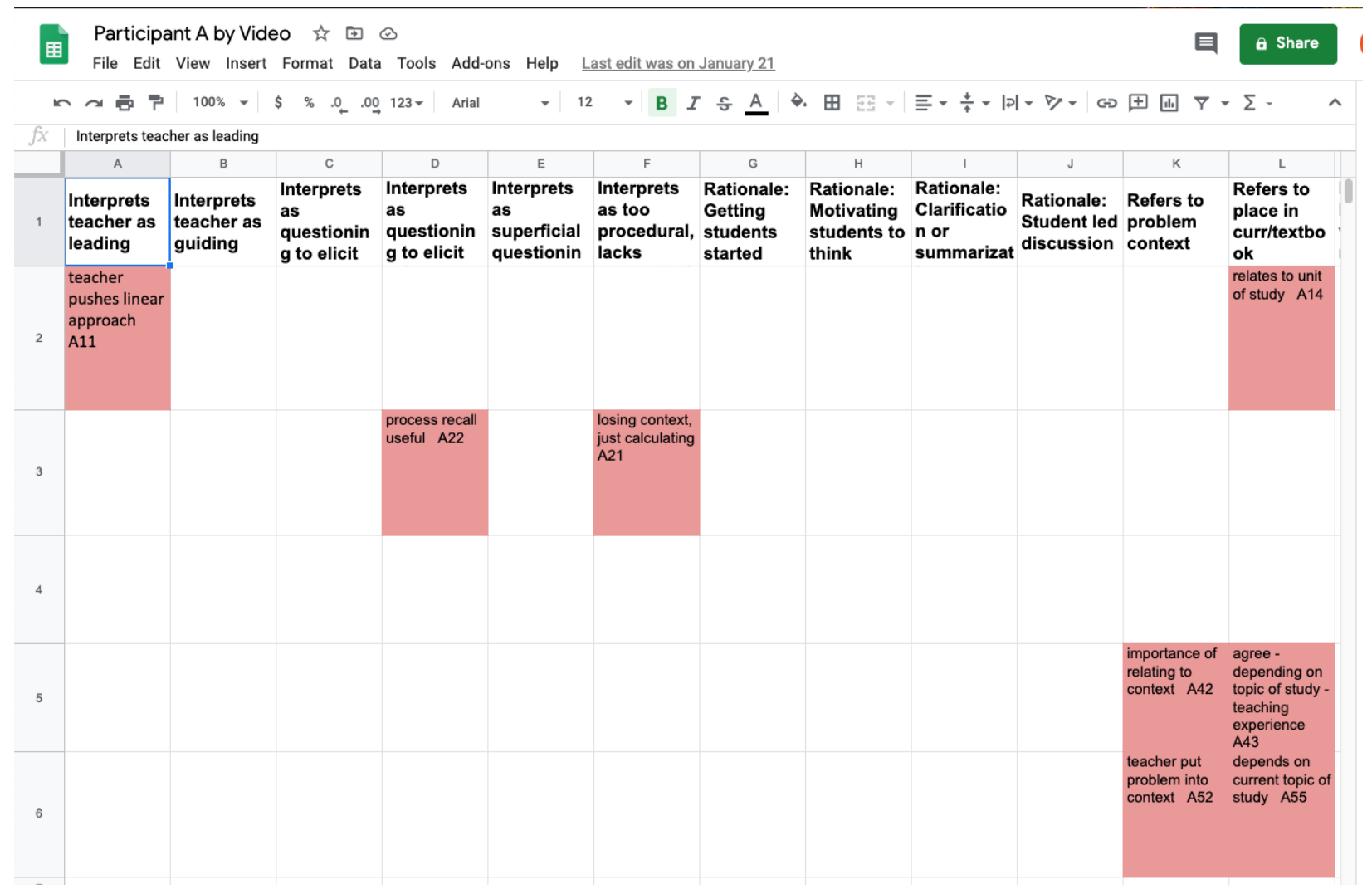

Figure 9. Individual Participant Spreadsheet. Excerpts are organized by proposition (columns) and video (rows). 


\section{Chapter Three Summary}

In this chapter, I described the participants and the criteria for choosing the participants. I then discussed the design of the study as well as the task-based interview and data-eliciting task. The choice of qualitative analysis for the study was discussed, and an introduction was given to the constant comparative method which was used for analysis of the data. The basis for the development of categories and their rules for inclusion was also discussed. In the next chapter, I will elaborate on the development of the outcome propositions, and describe the findings of my analysis. 


\section{CHAPTER IV: RESULTS}

The aim of this study was to characterize elements of PCK exhibited by PSTs by differentiating between PCK held by PSTs and MATs. I used statements made by participants of all three participant groups; PSTs, MATs, and PROs; as they critiqued a lesson presented as a set of animated videos in order to generate a set of propositions which described their perceptions, insights, and suggestions regarding the teaching approach they observed. In this chapter I present the final set of outcome propositions, describe the defining characteristics of each participant group, and differentiate between each group. I then use the differences between groups to characterize the PCK of the PSTs.

\section{Outcome Propositions}

My analysis of the data resulted in the identification of 26 outcome propositions, which are organized in five clusters: interpretations, rationales, references to, recommendations, and relationships to one's own experience. Although the interview prompts assisted me in unitizing the data for analysis, outcome propositions were not necessarily associated with particular interview prompts. For example, participants discussed ideas that were characterized by the propositions organized as interpretations (describing what the teacher did), rationales (justifying why the teacher might have done what he did), and recommendations (suggesting what the participant might have done differently) not only in response to those specific prompts but also at various times throughout the interview. In the sections below, I describe each proposition and present excerpts from interview transcripts to illustrate each through the words of the participants. 


\section{Interpretations}

Seven outcome propositions characterized the participants' interpretations of a statement or action by the teacher. Three of the propositions referred to teacher actions that participants deemed inappropriate or lacking in some way: interpreting the teacher as leading the students, asking superficial questions, and being too procedural. Three other propositions addressed teacher actions that participants viewed more favorably: providing guidance, stimulating student thinking and eliciting prior knowledge, and informal assessment of students' knowledge.

Interprets teacher as leading. This proposition characterizes the participants' view that the teacher was providing the students with more guidance than they thought was appropriate. For example, when critiquing Video 1, in which students read the problem and known points are identified, PRO2 ${ }_{11}$ stated that the teacher was "guiding them too much. They didn't have time to think about it and explore." Because the teacher was the first to suggest using linear equations, some participants referred to the teacher as providing direct instruction—-simply telling the students what they need to know rather than having an interactive discussion-or stated that the teacher was doing the work for the students. According to $\mathrm{PRO1}_{23}$, "He is pigeonholing the students and limiting them to 'here is what I expect you to do'. 'Here are the formulas I expect you to use', and so the understanding the students are going to have is also going to be limited because of that." TCH6 $6_{11}$ said, "It seemed like he was just shoving information at the kids." Responding to the lesson as a whole, $\mathrm{PRO} 1_{55}$ stated, "There's too much of the thinking being done for the students. The students are not doing enough of the thinking on their own.”

Interprets as superficial questioning. This proposition characterizes participants' views that the teacher's questioning was mostly eliciting affirmation—drawing a yes, no, or short answer that simply agrees with what the teacher is saying, rather than challenging the students to 
think about their response. In critiquing Video 3 in which students went to the board, $\mathrm{TCH} 8_{31}$ identified missed opportunities to discuss what the variables in the students' equations represented and for the students to grapple with how to scale the graphs of those equations. This participant stated, "He's not really pushing any of the students for explanation about why they did what they did. But, very much just rewarding a correct answer.” In Video 4, the class discussed the graph and its components. $\mathrm{TCH} 3_{41}$ described this segment as follows: "A lot of times he asks a question and gets an answer, and then if it's not the answer he's looking for, then he doesn't really press them for reasoning as to why they give that answer. He just kind of asks for another answer, then someone gives the answer he's looking for and then just moves on with it - he never really discusses the difference between the two answers and why one is correct and one is not correct.

Interprets teacher as being too procedural. Some participants interpreted the teacher's actions as promoting procedural learning at the expense of conceptual understanding. PRO2 23 thought that in Video 2, the students should have attempted to graph on their own before the teacher introduced formulas, saying "because I think when you just think of it as Y2 minus Y1 over X2 minus X1 they're not really thinking about what slope is. I mean maybe you are, but they're not really thinking about it's the minutes per the amount of money." In responding to the same video, $\mathrm{PRO}_{23}$ explicitly used the phrases procedural understanding and conceptual understanding: "The teacher is asking the students about the formulas, and they were telling the formulas, but it appears that he is going for very procedural understanding here. There is really no development of conceptual understanding whatsoever." Regarding Video 3, in which two students show their work at the board, MAT6 ${ }_{31}$ thought the teacher should have explained more rather than having the students just "plug and chug" using the slope formula. 
Interprets teacher as guiding. This proposition characterizes the view that the teacher was providing an appropriate amount of information and guidance, as opposed to offering too much as described in the teacher as leading proposition. In responding to Video 1 in which the teacher asked questions and put the points on the board, $\mathrm{TCH} 1_{12}$ said, "The teacher, I think, was kind of guiding them, [to] maybe see if they can reach a conclusion on their own, or maybe why what they're doing may not be the best way to reach it." This proposition also describes the teacher as getting students "on the same page"; that is, making sure all students understand before moving on in the lesson. Regarding Video 3, $\mathrm{TCH} 9_{31}$ noted, "Again, it seemed like he was really leading them to 'we are doing this a certain way' and they do it that certain way and they'll get the right answer that way and then_ it's good what he did with the graph there I think at the end there where he said 'What's on each axis?' and 'How far out that we need to go?' Here I should note that although the participant used the word 'leading', this excerpt fits my definition for guiding because in this case the teacher's actions are seen as a positive - that is, the participant indicates that the teacher is providing an appropriate amount of information.

Interprets teacher as questioning to stimulate student thinking. In this proposition, the participants see the teacher as asking questions of the students in such a way as to make them think about the problem and the solution approach. This proposition is seen as positive, unlike the superficial questioning proposition. Responding to the part in Video 1 when the teacher is questioning the students about points and equations, MAT4 11 stated that the teacher was, "kind of pulling, trying to get them to think about other information that's not necessarily explicit." Referring to the discussion of the significance of the graphs and equations in the context of the phone plans in Video 4 and to the final class discussion in which they attempt to answer the 
question "which is the better plan?" in Video 5, MAT6 ${ }_{51}$ said, "The teacher made them understand this whole problem in terms of rates and saving money."

Interprets as questioning to recall formulas. Like the preceding proposition, this one generally characterizes the teacher's actions in a positive light. It is based on participants' critiques of the teacher as questioning students to have them recall relevant formulas which they have learned in the past that are needed for the present lesson. For example, when asked what the teacher was doing in response to Video 2, in which the students were asked to help set up the formulas, MAT2 21 responded, "It's like he said 'alright so what's the equation?' 'What kind of formulas do you know?' and they figured out they were going to use the slope formula. And then he walked through exactly what the slope formula was."

Informal assessment. This proposition is based on statements by the participants which indicate that questioning by the teacher was seen as a means to gauge student understanding. In response to Video 3, for example, $\mathrm{TCH}_{32}$ said "I think he asked the questions like 'Oh, what's your intercept and what is your slope? or 'What is this?' to kind of make sure they know what each part is representing in their equation of a line, or what they're actually finding instead of just plugging numbers into a formula."

\section{Rationales}

The set of outcome propositions clustered as rationales pertain to the reasons that participants attributed to the teachers' actions. There were four propositions that described the rationales participants discussed; they addressed getting students started, motivating students to think, clarifying or summarizing, and actively engaging students.

To get students started. For this proposition, the participants saw the teacher's initial questions about the axes and points, as a starting point for the students to solve the problem. It 
applied only to Video 1 in which the teacher had the students read the problem and then decide on a set of points that could be used to solve it. $\mathrm{TCH}_{12}$ saw the setup as a suggestion and justified the teacher's actions as providing the students "some sort of starting point. Even if they don't want to take this approach with graphing, at least they know what - we're qualifying each of the variables here, assigning a variable for each unit."

To motivate students to think. Some participants who had responses related to this proposition saw the teacher's encouragement of class discussion and questioning as a means to have the students form ideas about solving the problem. After watching Video 1, MAT5 12 stated, "He definitely is using the audience, or the students, to answer the questions, so that was good participation to make them think." Others saw it as a means to make sense within the context of the problem, relate the context to the graph and equations, and interpret the meaning of the solution. Responding to the "why" prompt for Video 3, in which students went to the board and explained their graphs and equations, $\mathrm{TCH} 332$ said that the class was "going through this process and creating the graph the way they are so that they can then look and see if they actually make sense in the context of this problem."

To clarify or summarize. This proposition was related to those statements by participants who considered the teacher's reiteration of a discussion as a means to reinforce the procedure for solving the problem or the meaning of the problem. In Video 2, students recite the formulas necessary for solving the problem as a set of linear equations. $\mathrm{TCH} 7_{22}$ saw the reiteration of the formulas as a means for reinforcement, stating "Instead of just sending them off, he's giving them what formulas they're using and they're writing them on the board so students can check their understanding or make sure that they know that they're supposed to be using that." In Video 4, the class discussed the meaning of the graphs, intercepts, and slopes 
within the context of the phone plans. In response to that part of the lesson, MAT6 41 stated, "I think that the teacher really tried to make the students understand what this problem actually means and how to portray it with a graph."

To actively engage students. This proposition is related to those responses in which the participants described the actions of the teacher as allowing students to solve the equations, to explain a procedure or meaning to gain experience in articulating their thinking, or to help other students understand. Responding to the student presentations in Video 3, MAT5 32 said, "He probably wanted them to do it so that they could get experience doing the work themselves." Regarding the same video, MAT5 32 stated, "If they make a mistake he can correct them, also correct the class if everyone else is having the same mistake." MAT432 said, "It's good to have students go up and show their work...where it's only student work put up on the board, and it instills confidence to make the class seem a little more collaborative that way if students are commenting on other students' work."

\section{References To}

In their responses to interview prompts, participants sometimes referred to, or wondered about, different aspects of the lesson or the teacher's actions. Five propositions comprise this cluster. Two propositions involve statements in which the participants made reference to the place in the curriculum or textbook where the lesson would have appeared or the purpose of the particular lesson. Two others relate to the problem context or visual representation of the problem on the board. One proposition was derived from statements in which participants noted that the teacher did not respond to a student's question or comment.

Refers to place in curriculum/textbook. Some participants questioned whether the lesson was appropriate based on the students' grade level or prior knowledge. TCH5 $5_{12}$ stated, 
"Well I can't say that I know exactly what they have been taught up to this point and what they are going to be taught" in response to the teacher's suggestion that they use linear equations to solve the problem in Video 1.

Some participants referred to the place in the curriculum or textbook, seeing the teacher as addressing basic content that students will need in the future. In Video 4, the teacher and the class made connections between the phone plan and the graph, slope, and intercepts. MAT4 23 considered this to be an introduction to linear equations, saying that "this class is clearly setting up, like they're probably having lessons on point-slope, because most of the time it was just always using point-slope form."

Refers to purpose of lesson. Some participants identified the lesson as a review, questioned the goal of the lesson, or assumed the direction it was taking. When describing the teacher's actions in Video 1, TCH6 ${ }_{12}$ suggested that the lesson must be "review material of some sort" to explain why instruction was moving so fast and the teacher was "shoving information at the kids." Similarly, $\mathrm{TCH}_{11}$ was concerned that in Video 1, students might be confused and stated: "I'm assuming here in a second they're gonna talk about the function as a whole." This participant went on to say, "It also depends on where they're at in their unit of study that they're looking at this, but just knowing that students struggle with trying to relate real world experiences with the graph, these two points at the end and the two points they talk about at the beginning without labeling them and putting them on the graph, I feel like it's very abstract to them at that point in time."

Refers to problem context. This proposition was generated from statements made by the participants in reference to the connection between calculations and the context of the problem. 
Referring to the class discussion of the graph and equations within the context of the phone plans. $\mathrm{TCH}_{42}$ stated, "So after that, they talked about, I think they talked about the intersection then and what that meant.”

Refers to visual representation. This proposition relates to participant's references to the graph or formulas that were presented on board. $\mathrm{TCH} 7_{12}$ referred to the visual representation on the board of the ordered pairs in Video 1, saying that "I think with this, especially if they're just learning about rate of change and slope, would be a good way to see visually the change in price between the two companies and the minutes." Note that this participant also speculated about the placement of the lesson in the overall curriculum.

Teacher not answering/responding. Statements which indicated that the participants saw the teacher as being unresponsive to students' responses led to this proposition. For example, when responding to Video 4, $\mathrm{PRO}_{41}$ stated, "But the teacher never really addressed it. You never explained to the student who got the answer wrong, why they were getting it incorrect."

\section{Recommendations}

Another set of propositions characterizes the participants' disagreement with the teacher's approach and their suggestions as to what the teacher could or should have done differently. Participants' recommendations resulted in six propositions related to making connections, having more discussion, asking more questions, allowing for more wait time and opportunities for student exploration and problem solving, interpreting graphical representations, and providing more direct information. A seventh proposition describes participants' agreement with the teacher's approach, which sometimes included suggestions for changes. 
Recommends making connections. This proposition involved statements in which participants recommended making connections between the problem, real-life experience, and calculations. TCH5 13 suggested that students should be allowed to make connections on their own before the teacher gives them instructions, saying in response to Video 1: "Maybe pull back a little bit and not give them as much if we' $d$ been working with that kind of stuff and let them make the connections themselves." PRO3 31 noticed that the teacher was encouraging the connection of multiple representations in Video 3 as the students were presenting their work on the board: "When they would, like multiple ways of representing slope, like you said what is your slope?, they said one over twenty, you said or what else could you call it? And they said $.05 . "$

Recommends more discussion. Some participants recommended more and/or higher quality class discussion. MAT6 23 thought there should be more discussion of the meaning of the variables when the formulas were being presented: "I'd rather they just say what each variable means rather than saying like 'y2 minus y1'.” Some participants recommended more student-led discussion. When discussing Video $2, \mathrm{PRO}_{23}$ suggested more discussion of why the relationship should be treated as linear: "So I would want the kids discussing it, talking about that, bring out those ideas that this is linear. Why is it linear? What is it that makes this situation a linear relationship?"

Recommends more questioning. This proposition is related to participants' recommendations that the teacher as more and/or higher quality questioning of students. After viewing Video 3, TCH6$_{33}$ stated, 'I would have liked to have seen a 'why?' after that", referring to the teacher's questioning of the students about setting up the graph. 


\section{Recommends more student exploration, problem solving, or wait time.}

Recommendations by the participants for wait time contributed to this proposition, as well as recommendations for students to try to explore on their own or present their solutions. After watching Video $1, \mathrm{PRO}_{13}$ recommended more wait time for students to respond after being asked a question such as "Is that the only point we have?" This participant stated, "There are a couple of places where the teacher asked a question and did not wait for a response and then followed up with the second question, so it didn't allow students to think about the first question." TCH6 13 would also have liked to see more wait time in Video 1: "You just kind of do the thinking for the kids and they don't do any discovery on their own." For Video 2, in which students are prompted to recite the formulas and work on the equations, $\mathrm{PRO}_{23}$ recommended that students present their solutions: "I would ask students to put on the board any representations whether they are coordinate points or a table of values. Have different representations of the data they've got so far for each of the companies."

Recommendations related to graphical display. This proposition resulted from recommendations by the participants regarding graphics presented on the board including graphs, points, and equations. Responding to prompts for Video 1, MAT614 said, "I think that he didn't really explain how this problem is exactly, like correlates to a type of problem that you can look at in like a graphical perspective maybe." MAT6 did not see how this problem translated to a graphical representation and would have liked more explanation about why it should be seen in terms of $\mathrm{x}$ and $\mathrm{y}$.

Recommends being more direct or giving more information. Some participants felt that more direct instruction would be appropriate or suggested lowering the problem complexity. $\mathrm{TCH}_{23}$ would have "focused maybe a little bit more on how to solve that problem than spending 
a lot of time" on the formula recitation and graph setup in Video 2. For Video 4, $\mathrm{TCH} 1_{44}$ thought that using smaller numbers would clarify the graph and suggested that the teacher "could make up more unrealistic numbers so it would fit on the graph, it would still illustrate your point."

Agreed with teacher's approach; may suggest changes. This proposition derives from statements in which the participants fundamentally agreed with the teacher, but may or may not suggest changes. In response to Video $2, \mathrm{TCH}_{23}$ agreed with the teacher but did not suggest changes, saying "I think he was just guiding them through the formulas or, like, the process of what to do. And I don't think I would have done anything differently in that teaching segment." MAT1 $_{13}$ essentially agreed with the teacher's actions in Video 1 , but made a suggestion regarding the order of the lesson: "Would I have done anything differently? Um, no. I guess that makes sense other than just plotting immediately rather than showing points."

\section{Relates to One's Own Experience}

When critiquing the video segments, some participants drew upon their own experiences. They made comments that related to their experience as a teacher, their experience solving the problem before watching the video, and their own experience learning or practicing mathematics.

Experience as teacher. This proposition included statements by participants which related to, or appeared to be relying upon, their own experience teaching or tutoring. According to PRO1 ${ }_{13}$, responding to Video 1, "I've actually taught this problem type before many times, in an intermediate algebra class, and I don't ask questions. I let them start the problem on their own without pointing them in a particular direction or getting them to see variables are there or what's going on in the problem." Although the MATs did not formally have teaching experience, two of the participants made statements that fell under the criteria for this proposition. 
Experience solving problem. This proposition included statements by participants which related to, or appeared to be relying upon, their own experience solving the tutoring task. After seeing how the teacher set up the problem in Video $1, \mathrm{TCH}_{11}$ said, referring to his own solution of the problem, "So, this was done a little bit differently, making them into linear equations and starting with zero zero and then going to the point, basically its $\mathrm{x}$ and $\mathrm{y}$ each representing, one of them the number of minutes the other of them the number of dollars."

Experience with math. This proposition characterizes statements by participants which related to, or appeared to be relying upon, their own experience learning or practicing mathematics. In response to the teacher's setup in Video 2, MAT3 ${ }_{21}$ said, "I think the teacher would do that because obviously that's how you're gonna solve the equation, so you need to know what the slope is in order to figure out where the break-even point is for both." A summary of the outcome propositions and their definitions is provided in Table 1. Table 1

Summary of outcome propositions with definitions.

\begin{tabular}{|c|c|c|}
\hline Cluster & Outcome Proposition & Definition Summary \\
\hline \multirow[t]{5}{*}{ Interpretations } & $\begin{array}{l}\text { Interprets teacher as } \\
\text { leading }\end{array}$ & $\begin{array}{l}\text { Participants viewed the teacher as providing the } \\
\text { students with more guidance than was appropriate. }\end{array}$ \\
\hline & $\begin{array}{l}\text { Interprets as superficial } \\
\text { questioning }\end{array}$ & $\begin{array}{l}\text { Participants' viewed teacher's questioning as } \\
\text { eliciting affirmation, rather than challenging the } \\
\text { students to think about their responses. }\end{array}$ \\
\hline & $\begin{array}{l}\text { Interprets teacher as } \\
\text { being too procedural }\end{array}$ & $\begin{array}{l}\text { Participants interpreted the teacher's actions as } \\
\text { promoting procedural learning at the expense of } \\
\text { conceptual understanding. }\end{array}$ \\
\hline & $\begin{array}{l}\text { Interprets teacher as } \\
\text { guiding }\end{array}$ & $\begin{array}{l}\text { Participants viewed the teacher as providing an } \\
\text { appropriate amount of information and guidance, } \\
\text { as opposed to offering too much. }\end{array}$ \\
\hline & $\begin{array}{l}\text { Interprets teacher as } \\
\text { questioning to stimulate } \\
\text { student thinking }\end{array}$ & $\begin{array}{l}\text { Participants see the teacher as asking questions of } \\
\text { the students to make them think about the problem } \\
\text { and the solution approach. }\end{array}$ \\
\hline
\end{tabular}

(Table Continues) 
Interprets as

questioning to recall

formulas

Informal assessment
Participants view teacher as questioning students to have them recall relevant formulas that are needed for the present lesson.

Participants indicate that questioning by the teacher was seen as a means to gauge student understanding.

\begin{tabular}{|c|c|c|}
\hline \multirow[t]{4}{*}{ Rationales } & To get students started & $\begin{array}{l}\text { Participants viewed the teacher's initial questions } \\
\text { as a starting point for the students to solve the } \\
\text { problem. }\end{array}$ \\
\hline & $\begin{array}{l}\text { To motivate students to } \\
\text { think }\end{array}$ & $\begin{array}{l}\text { Encouragement of discussion and questioning was } \\
\text { seen as a means to have the students form ideas or } \\
\text { to make sense within context. }\end{array}$ \\
\hline & To clarify or summarize & $\begin{array}{l}\text { Participants considered the teacher's reiteration of } \\
\text { discussion as a means to reinforce the procedure or } \\
\text { meaning of the problem. }\end{array}$ \\
\hline & $\begin{array}{l}\text { To actively engage } \\
\text { students }\end{array}$ & $\begin{array}{l}\text { Participants viewed allowing students to explain to } \\
\text { gain experience in articulating their thinking, or to } \\
\text { help other students understand. }\end{array}$ \\
\hline \multirow[t]{5}{*}{ References To } & $\begin{array}{l}\text { Refers to place in } \\
\text { curriculum/textbook }\end{array}$ & $\begin{array}{l}\text { Participants questioned appropriateness based on } \\
\text { grade level or prior knowledge, or referred to the } \\
\text { place in the curriculum or textbook. }\end{array}$ \\
\hline & $\begin{array}{l}\text { Refers to purpose of } \\
\text { lesson }\end{array}$ & $\begin{array}{l}\text { Participants identified the lesson as a review, } \\
\text { questioned the goal of the lesson, or assumed the } \\
\text { direction it was taking. }\end{array}$ \\
\hline & $\begin{array}{l}\text { Refers to problem } \\
\text { context }\end{array}$ & $\begin{array}{l}\text { Participants made reference to the connection } \\
\text { between calculations and the context of the } \\
\text { problem. }\end{array}$ \\
\hline & $\begin{array}{l}\text { Refers to visual } \\
\text { representation }\end{array}$ & $\begin{array}{l}\text { Proposition relates to participant's references to } \\
\text { the graph or formulas that were presented on } \\
\text { board. }\end{array}$ \\
\hline & $\begin{array}{l}\text { Teacher not } \\
\text { answering/responding }\end{array}$ & $\begin{array}{l}\text { Participants viewed the teacher as being } \\
\text { unresponsive to students' responses. }\end{array}$ \\
\hline \multirow[t]{2}{*}{ Recommendations } & $\begin{array}{l}\text { Recommends making } \\
\text { connections }\end{array}$ & $\begin{array}{l}\text { Participants recommended making connections } \\
\text { between the problem, real-life experience, and } \\
\text { calculations. }\end{array}$ \\
\hline & $\begin{array}{l}\text { Recommends more } \\
\text { discussion }\end{array}$ & $\begin{array}{l}\text { Participants recommended more and/or higher } \\
\text { quality class discussion, or recommended more } \\
\text { student-led discussion. }\end{array}$ \\
\hline
\end{tabular}

(Table Continues) 
Recommends more questioning

Recommends more exploration, problem solving, or wait time

Recommendations related to graphical display

Recommends being more direct or giving more information

Agreed with teachers's approach; may suggest changes

Relates to One's Own Experience

\author{
Experience as teacher
}

Experience solving problem

Experience with math
This proposition is related to participants' recommendations that the teacher have more and/or higher quality questioning of students.

Participants suggest more wait time, or recommend that students try to explore on their own or present their solutions.

Participants' recommendations regarding graphics presented on the board such as graphs, points, and equations.

Participants felt that more direct instruction would be appropriate or suggested lowering the problem complexity.

Participants fundamentally agreed with the teacher, but may or may not suggest changes.

Participants' statements which related to, or appeared to be relying upon, their own experience teaching or tutoring.

Participants' statements which related to, or appeared to be relying upon, their own experience solving the tutoring task.

Participants' statements which related to, or appeared to be relying upon, their own experience learning or practicing mathematics.

\section{Defining Characteristics of Each Group}

I determined the defining characteristics of each group based on the outcome propositions. My goal was to identify differences between the participant groups and the identification of those defining characteristics gave context to those differences. In particular, I sought to identify evidence of knowledge that is unique to PSTs.

This section is organized into four subsections. The first, proposition percentages by group, is an overview of the findings with a discussion of the percentage of participants within each group who made statements related to each proposition. The other three subsections, 
characteristics of PSTs, characteristics of MATs, and characteristics of PROs, include a

narrative of what was typical—having characteristics shared by most of the group—of the participants in this study and a breakdown by proposition group of the frequency of occurrences of responses related to each proposition.

\section{Proposition Percentages by Group}

The number of participants associated with each outcome proposition varied by group. The relative percentages of participants within their respective groups who made statements related to each outcome proposition are shown in Table 2.

Although almost half of the propositions were attributed to fewer than 50\% of any participant group, for some propositions the participant groups were fairly evenly distributed whereas others were associated with only two groups. Two propositions were attributed to only one participant group; only the PSTs interpreted the teacher's questioning as being superficial and only MATs explained the teacher's actions as actively engaging the students.

Only one outcome proposition — agreed with teacher's approach —was associated with more than $50 \%$ of participants in each of the groups. Some of the findings under this proposition were that half the MATs liked the formula recall in Video 2, most of the PSTs thought the students going to the board in Video 3 was good, most MATs thought the class discussion about the components of the linear equations in Video 4 was good, and most PSTs saw the attempt to make connections in Video 5 as a positive. Ultimately, I felt that this proposition did not help distinguish among the groups, so statements were moved into other appropriate recommendation propositions. The proposition agreed with teacher's approach, therefore, is not included in the subsequent report of findings. 
Table 2

Percentage of participants associated with each proposition within each participant group.

\begin{tabular}{|c|c|c|c|c|}
\hline \multirow{2}{*}{$\begin{array}{l}\text { Outcome } \\
\text { Proposition } \\
\text { Cluster }\end{array}$} & \multirow[t]{2}{*}{ Outcome Proposition } & \multicolumn{3}{|c|}{ Percentage } \\
\hline & & PSTs & MATs & PROs \\
\hline \multirow[t]{7}{*}{ Interpretations } & Interprets teacher as leading & $78 \%(7)$ & $13 \%(1)$ & $100 \%(3)$ \\
\hline & Interprets as superficial questioning & $67 \%(6)$ & $0 \%$ & $0 \%$ \\
\hline & Interprets teacher as being too procedural & $11 \%(1)$ & $25 \%(2)$ & $67 \%(2)$ \\
\hline & Interprets teacher as guiding & $33 \%(3)$ & $13 \%(1)$ & $0 \%$ \\
\hline & $\begin{array}{l}\text { Interprets teacher as questioning to } \\
\text { stimulate student thinking }\end{array}$ & $11 \%(1)$ & $50 \%(4)$ & $0 \%$ \\
\hline & $\begin{array}{l}\text { Interprets as questioning to recall } \\
\text { formulas }\end{array}$ & $22 \%(2)$ & $38 \%(3)$ & $0 \%$ \\
\hline & Informal Assessment & $22 \%(2)$ & $25 \%(2)$ & $33 \%(1)$ \\
\hline \multirow[t]{4}{*}{ Rationales } & To get students started & $33 \%(3)$ & $13 \%(1)$ & $0 \%$ \\
\hline & To motivate students to think & $22 \%(2)$ & $38 \%(3)$ & $33 \%(1)$ \\
\hline & To clarify or summarize & $11 \%(1)$ & $50 \%(4)$ & $0 \%$ \\
\hline & To actively engage students & $0 \%$ & $38 \%(3)$ & $0 \%$ \\
\hline \multirow[t]{5}{*}{ References to } & Refers to place in curriculum/textbook & $56 \%(5)$ & $75 \%(6)$ & $33 \%(1)$ \\
\hline & Refers to purpose of lesson & $67 \%(6)$ & $38 \%(3)$ & $33 \%(1)$ \\
\hline & Refers to problem context & $33 \%(3)$ & $38 \%(3)$ & $33 \%(1)$ \\
\hline & Refers to visual representation & $11 \%(1)$ & $25 \%(2)$ & $33 \%(1)$ \\
\hline & Teacher not answering/responding & $22 \%(2)$ & $0 \%$ & $33 \%(1)$ \\
\hline
\end{tabular}

(Table Continues) 


\begin{tabular}{|c|c|c|c|c|}
\hline \multirow[t]{7}{*}{ Recommendations } & Make connections & $67 \%(6)$ & $0 \%$ & $67 \%(2)$ \\
\hline & More discussion & $67 \%(6)$ & $25 \%(2)$ & $67 \%(2)$ \\
\hline & More questioning & $22 \%(2)$ & $0 \%$ & $33 \%(1)$ \\
\hline & $\begin{array}{l}\text { More student exploration/problem solving } \\
\text { or wait time }\end{array}$ & $67 \%(6)$ & $25 \%(2)$ & $100 \%(3)$ \\
\hline & $\begin{array}{l}\text { Recommendations related to graphical } \\
\text { display }\end{array}$ & $22 \%(2)$ & $50 \%(4)$ & $33 \%(1)$ \\
\hline & Be more direct or give more information & $44 \%(4)$ & $38 \%(3)$ & $0 \%$ \\
\hline & $\begin{array}{l}\text { Agreed with teacher's approach; may } \\
\text { suggest changes }\end{array}$ & $89 \%(8)$ & $100 \%(8)$ & $67 \%(2)$ \\
\hline \multirow{3}{*}{$\begin{array}{l}\text { Relates to One's } \\
\text { Own Experience }\end{array}$} & Experience as teacher & $56 \%(5)$ & $13 \%(1)$ & $67 \%(2)$ \\
\hline & Experience solving problem & $33 \%(3)$ & $38 \%(3)$ & $33 \%(1)$ \\
\hline & Experience with math & $33 \%(3)$ & $25 \%(2)$ & $67 \%(2)$ \\
\hline
\end{tabular}

\section{Characteristics of PSTs}

Twenty-four outcome propositions were associated with the PSTs. Most of these propositions (16) described the responses of fewer than $50 \%$ of the PSTs. However, eight propositions were associated with a majority of the PSTs and I used those as the basis for characterizing the teaching knowledge exhibited by the PSTs in this study. In Table 3, each proposition is categorized as describing most, some, or none of the PST participants' responses. 
Table 3

Frequency of Responses Matching each Proposition: PSTs.

\begin{tabular}{|c|c|c|c|}
\hline \multirow{2}{*}{$\begin{array}{l}\text { Outcome Proposition } \\
\text { Group }\end{array}$} & \multicolumn{3}{|c|}{ Frequency } \\
\hline & Most & Some & None \\
\hline \multirow[t]{5}{*}{ Interpretations } & $\begin{array}{l}\text { Interprets teacher as } \\
\text { leading }(78 \%)\end{array}$ & $\begin{array}{l}\text { Interprets teacher as } \\
\text { guiding }(33 \%)\end{array}$ & \\
\hline & $\begin{array}{l}\text { Interprets as superficial } \\
\text { questioning }(67 \%)\end{array}$ & $\begin{array}{l}\text { Interprets as } \\
\text { questioning to } \\
\text { stimulate student } \\
\text { thinking }(11 \%)\end{array}$ & \\
\hline & & $\begin{array}{l}\text { Interprets as } \\
\text { questioning to recall } \\
\text { formulas }(22 \%)\end{array}$ & \\
\hline & & $\begin{array}{l}\text { Interprets teacher as } \\
\text { being too procedural } \\
(11 \%)\end{array}$ & \\
\hline & & $\begin{array}{l}\text { Informal assessment } \\
(22 \%)\end{array}$ & \\
\hline \multirow[t]{3}{*}{ Rationales } & & $\begin{array}{l}\text { To get students started } \\
(33 \%)\end{array}$ & $\begin{array}{l}\text { To actively engage } \\
\text { students }\end{array}$ \\
\hline & & $\begin{array}{l}\text { To motivate students to } \\
\text { think }(22 \%)\end{array}$ & \\
\hline & & $\begin{array}{l}\text { To clarify or summarize } \\
(11 \%)\end{array}$ & \\
\hline \multirow[t]{3}{*}{ References to } & $\begin{array}{l}\text { Refers to place in } \\
\text { curr/textbook }(56 \%)\end{array}$ & $\begin{array}{l}\text { Refers to problem } \\
\text { context }(33 \%)\end{array}$ & \\
\hline & $\begin{array}{l}\text { Refers to purpose of } \\
\text { lesson }(67 \%)\end{array}$ & $\begin{array}{l}\text { Refers to visual } \\
\text { representation }(11 \%)\end{array}$ & \\
\hline & & $\begin{array}{l}\text { Teacher not } \\
\text { answering/responding } \\
(22 \%)\end{array}$ & \\
\hline
\end{tabular}

(Table Continues) 


\begin{tabular}{lll}
\hline Recommendations & $\begin{array}{l}\text { Make connections } \\
(67 \%)\end{array}$ & $\begin{array}{l}\text { More questioning } \\
(22 \%)\end{array}$ \\
More discussion $(67 \%)$ & $\begin{array}{l}\text { Recommendations } \\
\text { related to graphical } \\
\text { display (22\%) }\end{array}$ \\
$\begin{array}{l}\text { More student } \\
\text { exploration/problem } \\
\text { solving or wait time } \\
(67 \%)\end{array}$ & $\begin{array}{l}\text { Be more direct or give } \\
\text { more information } \\
(44 \%)\end{array}$ \\
\hline $\begin{array}{l}\text { Relates to One's Own } \\
\text { Experience }\end{array}$ & $\begin{array}{l}\text { Experience as teacher } \\
(56 \%)\end{array}$ & $\begin{array}{l}\text { Experience solving } \\
\text { problem (33\%) }\end{array}$ \\
& & $\begin{array}{l}\text { Experience w/ math } \\
(33 \%)\end{array}$ \\
\hline
\end{tabular}

Most of the PSTs stated or interpreted some of the teacher's actions as being too leading; that is, the class was too teacher-led rather than being a collaboration of teacher and students (interprets teacher as leading). PSTs indicated that too much information was given rather than allowing the students to think for themselves and construct, or attempt to construct, their own knowledge. They described the lesson as being too rigidly structured, in that the procedure for solving the given problem was dictated. The students were not allowed to determine their own method of answering the question and were directed to use a system of linear equations.

The majority of the PSTs saw some of the teacher's questioning of students as superficial (interprets as superficial questioning). Three of the participants saw the questioning as eliciting only yes, no, or short answers $\left(\mathrm{TCH}_{41}, \mathrm{TCH}_{41}, \mathrm{TCH}_{44}\right)$. Some saw the questioning as eliciting student confirmation ( $\left.\mathrm{TCH}_{43}\right)$ or just to reward correct answers $\left(\mathrm{TCH} 8_{11}\right)$. $\mathrm{TCH}_{55}$ described the process as call and response, and $\mathrm{TCH} 5_{23}$ saw it as too formula oriented.

Most PSTs stated that the appropriateness of the lesson was dependent on the curriculum and that the way the lesson was taught may be appropriate if linear equations were the current topic (refers to place in curriculum/textbook). $\mathrm{TCH}_{12}$, for example, stated regarding the 
teacher's approach "I think this, especially if they are just learning about rate of change and slope, would be a good way to see visually the change in price between the two companies and the minutes." Most also discussed the purpose of the lesson, either in anticipating the direction of the lesson or stating that it seemed like a review (refers to purpose of lesson). $\mathrm{TCH} 3_{11}$ said "I'm assuming here in a second they're gonna talk about the function..." and both $\mathrm{TCH}_{12}$ and $\mathrm{TCH} 8_{12}$ saw the lesson as review.

The students, most thought, should have been allowed to explore and attempt to make their own connections (recommends more student exploration/wait time). Several participants specifically called for wait time $\left(\mathrm{TCH} 3_{55}, \mathrm{TCH}_{13}, \mathrm{TCH}_{13}\right)$, or having students work on their own $\left(\mathrm{TCH}_{53}, \mathrm{TCH}_{13}, \mathrm{TCH}_{23}, \mathrm{TCH} 8_{33}\right)$. $\mathrm{TCH}_{23}$, for example, would have let the students work on their own after being told to use linear equations. $\mathrm{TCH} 9_{13}$ would have let them work on the problem before suggesting linear equations. $\mathrm{TCH} 855$ said that learning comes from being allowed to make mistakes.

More than half of the PSTs suggested there should be more or higher quality discussion during the lesson (recommends more discussion). $\mathrm{TCH}_{43}$, for example, suggested that the teacher should have "gone a little deeper" with the discussion in order to identify and clear up any misconceptions. $\mathrm{TCH}_{23}$ wanted more discussion before moving on from the introduction of formulas in Video 2, and $\mathrm{TCH}_{53}$ wanted more at the very end of the lesson. Both $\mathrm{TCH}_{43}$ and TCH8 33 noted that they would have liked more discussion about the meaning of the intersection of the two lines.

Most PSTs would like to have seen more connections being made (recommends making connections). Four of them mentioned multiple representations $\left(\mathrm{TCH}_{34}, \mathrm{TCH} 2_{24}, \mathrm{TCH}_{42}\right.$, 
$\left.\mathrm{TCH}_{23}\right), \mathrm{TCH}_{34}$ also said the connections should have real-world relevance. $\mathrm{TCH} 5_{23}$ and TCH9 ${ }_{43}$ both stated that the students should be making their own connections.

In total, five PSTs referred to their own teaching (experience as teacher). They discussed various aspects of pedagogy in their critiques of the video clips. For example, $\mathrm{TCH} 255$ acknowledged a difference between direct instruction and critical thinking skills .TCH5 55 commented on the importance of student engagement and $\mathrm{TCH} 1_{55}$ would have stimulated the discussion differently.

\section{Characteristics of MATs}

Twenty-one outcome propositions were associated with MATs. Only one was associated with more than $50 \%$ of the participants, and three were at exactly $50 \%$. In Table 4, each proposition is categorized as having most, some, or none of the MAT participants offering relevant responses. 
Table 4

Frequency of Responses Matching each Proposition: MATs.

\begin{tabular}{|c|c|c|c|}
\hline \multirow{2}{*}{$\begin{array}{l}\text { Outcome Proposition } \\
\text { Group }\end{array}$} & \multicolumn{3}{|c|}{ Frequency } \\
\hline & Most & Some & None \\
\hline \multirow[t]{6}{*}{ Interpretations } & & $\begin{array}{l}\text { Interprets teacher as } \\
\text { leading }(13 \%)\end{array}$ & $\begin{array}{l}\text { Interprets as superficial } \\
\text { questioning }\end{array}$ \\
\hline & & $\begin{array}{l}\text { Interprets teacher as } \\
\text { guiding }(13 \%)\end{array}$ & \\
\hline & & $\begin{array}{l}\text { Interprets teacher as } \\
\text { questioning to stimulate } \\
\text { student thinking }(50 \%)\end{array}$ & \\
\hline & & $\begin{array}{l}\text { Interprets as } \\
\text { questioning to recall } \\
\text { formulas ( } 38 \%)\end{array}$ & \\
\hline & & $\begin{array}{l}\text { Interprets teacher as } \\
\text { being too procedural } \\
(25 \%)\end{array}$ & \\
\hline & & $\begin{array}{l}\text { Informal assessment } \\
(25 \%)\end{array}$ & \\
\hline \multirow[t]{4}{*}{ Rationales } & & $\begin{array}{l}\text { To get students started } \\
(13 \%)\end{array}$ & \\
\hline & & $\begin{array}{l}\text { To motivate students to } \\
\text { think }(38 \%)\end{array}$ & \\
\hline & & $\begin{array}{l}\text { To clarify or summarize } \\
(50 \%)\end{array}$ & \\
\hline & & $\begin{array}{l}\text { To actively engage } \\
\text { students }(38 \%)\end{array}$ & \\
\hline
\end{tabular}

(Table Continues) 


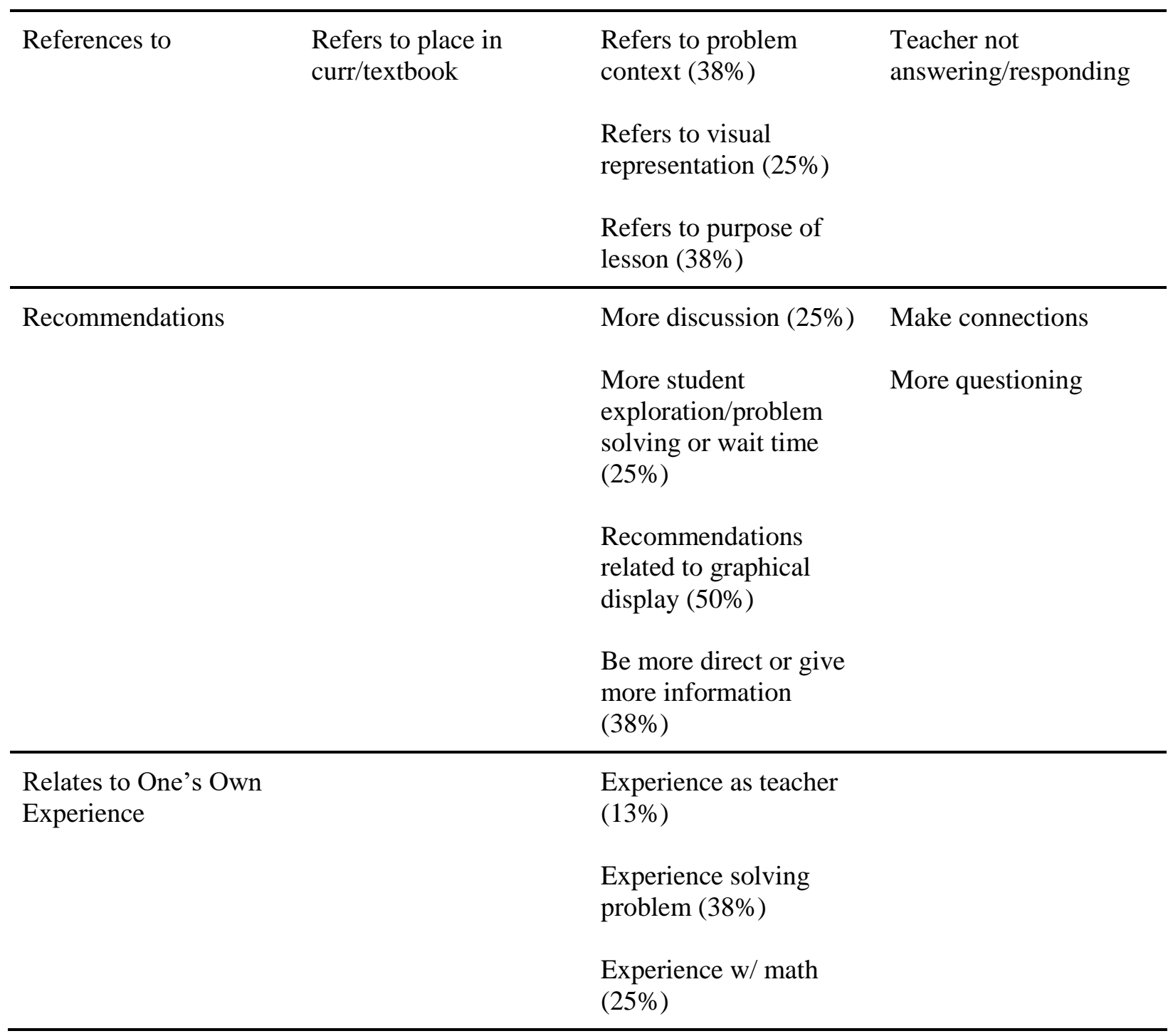

Most MATs had statements which referred to the appropriateness of the lesson depending on where it appeared in the curriculum (refers to place in curriculum/textbook). Some referred to prior knowledge "it kind of depends on what they know beforehand" (MAT2 55 ) or the level of the student (MAT354, MAT854). Some referred to the unit of study (MAT152, MAT354), and one participant stated "If the class were working on linear equations then, yeah, I would frame it that way" (MAT4 14$)$. Another saw the task as preparation for harder problems (MAT642). 
Exactly half had statements under the propositions: interprets teacher as stimulating student thinking, to clarify or summarize, and recommendations related to graphical display.

MATs who made statements that contributed to the student thinking proposition saw the teacher as questioning the students to make them think (interprets teacher as stimulating student thinking). MAT4 said the teacher was "pulling, trying to get students to think about information that is not explicitly given" $\left(\right.$ MAT4 $\left._{11}\right)$. Others stated that the teacher was trying to make the students come to a conclusion (MAT5 $5_{51}$ ), the teacher made students show understanding of the problem (MAT252), and "Made students understand the problem in terms of rates and saving money" (MAT6 65$)$.

The clarify or summarize proposition included statements in which participants noted that the teacher was reiterating points in a discussion (to clarify or summarize). One participant saw the teachers actions as a summary, stating that the teacher graphed the equations "so that everyone could see the correct answer" (MAT542). Others saw the teachers actions as clarification: the teacher "clarified understanding of concepts" (MAT341), the teacher "emphasized graph and slope" (MAT6 $6_{21}$ ), and the teacher "did this to make sure the students really understood each segment of the graph and what information that can give to them" (MAT842).

Suggestions related to graphical displays were aimed at the drawing itself-its presence or absence, scales, labels, etc. (recommendations related to graphical display). Two participants thought the teacher should have left the equations up on the board when graphing (MAT5 ${ }_{13}$, MAT7 55 ), and MAT5 would have liked to see the points labeled and the graphs color coded. One participant would have drawn the graph closer to the beginning of the lesson (MAT1 $\left.{ }_{53}\right)$. Another 
participant saw the teacher's explanation of how the problem correlates to the graph as inadequate (MAT6 14$)$.

\section{Characteristics of PROs}

Seventeen outcome propositions were associated with PROs. Of those, 7 were associated with more than $50 \%$ of the participants. In Table 5, each proposition is categorized as having most, some, or none of the PRO participants offering relevant responses. The statements made by the PRO group were more concentrated - covered by a fewer number of propositions - than either of the other two participant groups. This meant that several propositions were generated by the other groups that were not found relevant to the PRO group.

\section{Table 5}

Frequency of Responses Matching each Proposition: PROs.

\begin{tabular}{|c|c|c|c|}
\hline \multirow{2}{*}{$\begin{array}{l}\text { Outcome Proposition } \\
\text { Group }\end{array}$} & \multicolumn{3}{|c|}{ Frequency } \\
\hline & Most & Some & None \\
\hline \multirow[t]{4}{*}{ Interpretations } & $\begin{array}{l}\text { Interprets teacher as } \\
\text { leading }(100 \%)\end{array}$ & $\begin{array}{l}\text { Informal assessment } \\
(33 \%)\end{array}$ & $\begin{array}{l}\text { Interprets teacher as } \\
\text { guiding }\end{array}$ \\
\hline & $\begin{array}{l}\text { Interprets teacher as } \\
\text { being too procedural } \\
(67 \%)\end{array}$ & & $\begin{array}{l}\text { Interprets teacher as } \\
\text { questioning to stimulate } \\
\text { student thinking }\end{array}$ \\
\hline & & & $\begin{array}{l}\text { Interprets as } \\
\text { questioning to recall } \\
\text { formulas }\end{array}$ \\
\hline & & & $\begin{array}{l}\text { Interprets as superficial } \\
\text { questioning }\end{array}$ \\
\hline \multirow[t]{3}{*}{ Rationales } & & $\begin{array}{l}\text { To motivate students to } \\
\text { think }(33 \%)\end{array}$ & To get students started \\
\hline & & & To clarify or summarize \\
\hline & & & $\begin{array}{l}\text { To actively engage } \\
\text { students }\end{array}$ \\
\hline
\end{tabular}

(Table Continues) 


\begin{tabular}{|c|c|c|c|}
\hline \multirow[t]{5}{*}{ References to } & & Refers to problem & \\
\hline & & $\begin{array}{l}\text { Refers to place in } \\
\text { curr/textbook }(33 \%)\end{array}$ & \\
\hline & & $\begin{array}{l}\text { Refers to visual } \\
\text { representation }(33 \%)\end{array}$ & \\
\hline & & $\begin{array}{l}\text { Teacher not } \\
\text { answering/responding } \\
(33 \%)\end{array}$ & \\
\hline & & $\begin{array}{l}\text { Refers to purpose of } \\
\text { lesson }(33 \%)\end{array}$ & \\
\hline \multirow[t]{3}{*}{ Recommendations } & $\begin{array}{l}\text { Make connections } \\
(67 \%)\end{array}$ & $\begin{array}{l}\text { More questioning } \\
(33 \%)\end{array}$ & $\begin{array}{l}\text { Be more direct or give } \\
\text { more information }\end{array}$ \\
\hline & More discussion (67\%) & $\begin{array}{l}\text { Recommendations } \\
\text { related to graphical }\end{array}$ & \\
\hline & $\begin{array}{l}\text { More student } \\
\text { exploration/problem } \\
\text { solving or wait time } \\
(100 \%)\end{array}$ & display $(33 \%)$ & \\
\hline \multirow[t]{2}{*}{$\begin{array}{l}\text { Relates to One's Own } \\
\text { Experience }\end{array}$} & $\begin{array}{l}\text { Experience as teacher } \\
(67 \%)\end{array}$ & $\begin{array}{l}\text { Experience solving } \\
\text { problem }(33 \%)\end{array}$ & \\
\hline & $\begin{array}{l}\text { Experience w/ math } \\
(67 \%)\end{array}$ & & \\
\hline
\end{tabular}

All three of the PROs stated or interpreted some of the teacher's actions as being too leading and too teacher-led, rather than being a collaboration of teacher and students (interprets teacher as leading). PRO1, for example, stated that "there's too much of the thinking being done for the students" (PRO155). Others commented that the students' thinking was limited by giving too much instruction (PRO255) and that the teacher is nearly "spoon feeding" the students information $\left(\mathrm{PRO}_{11}\right)$.

All PRO participants thought the students should have been allowed to explore and attempt to make their own connections (recommends more student exploration/problem solving 
or wait time). Two PRO participants said the students should be allowed more opportunity to work on their own $\left(\mathrm{PRO}_{23}, \mathrm{PRO}_{23}\right)$. PRO1 was more specific, stating that the students should start on their own (PRO1 13$)$ and present their solutions (PRO1 23$)$, and the teacher could have built on the students graphs ( $\left.\mathrm{PRO}_{33}\right)$.

Two PRO participants saw the teacher as promoting procedural learning at the expense of conceptual understanding (interprets teacher as being too procedural). Both participants saw the lesson as not conducive to conceptual understanding ( $\left.\mathrm{PRO} 1_{23}, \mathrm{PRO} 2_{23}\right)$.

Most PROs would like to have seen more connections being made (recommends making connections). Both recommended using multiple representations ( $\left.\mathrm{PRO}_{23}, \mathrm{PRO}_{54}\right)$. One also noted that the students should make the connections rather than the teacher (PRO1 43$)$.

More than half of the PROs suggested there should be more or higher quality discussion during the lesson (recommends more discussion). One PRO would have had the discussion more student led (PRO253). Another PRO participant would have the students discuss if and why linear equations are appropriate, would have had them present their own solutions $\left(\mathrm{PRO}_{23}\right)$, and would have elaborated on the meaning of the graph $\left(\mathrm{PRO}_{54}\right)$.

Two PROs referred to their own teaching experience (experience as teacher). While both referred to previous teaching experience $\left(\mathrm{PRO}_{13}, \mathrm{PRO} 3\right)$, One participant elaborated that the graph would be "pretty difficult" for students to do by hand (PRO353).

Two of the three PROs referred to their experience with mathematics (experience with math). Both PRO1 and PRO3 noted that there were other ways to solve the problem (PRO1 21 , $\left.\mathrm{PRO}_{23}\right)$. One brought up the concept of rate of change in particular ( $\left.\mathrm{PRO} 1_{23}\right)$. 


\section{Differentiating Characteristics of Each Group}

I compared the outcome propositions associated with the PST participant group to those associated with both the MAT and PRO groups. To find the differentiating characteristics, I identified those categories for which one group had responses from a majority of the participants and the other group had less than $50 \%$.

\section{PSTs vs. MATs}

Most PSTs had entries in the propositions interprets as superficial questioning and recommends making connections, while the MAT group had none. None of the MATs saw the questioning as superficial. Some gave reasons for the questioning such as recall of prior knowledge, to show understanding, or to make students think and come to a conclusion.

The Figure 10 shows PSTs minus MATs. The first column lists all of the propositions associated with the PSTs with a frequency of greater than 50\%. The second column lists those propositions associated with the MATs with frequency of more than 50\% which also appear in the first column. The third is the "minus" column, which shows the differences between the two groups - that is, propositions unique to PSTs. Figure 11 shows the reverse, beginning with the MATs and subtracting out the corresponding PSTs.

\begin{tabular}{|c|c|c|}
\hline PSTs & MATs & PSTs minus MATs \\
\hline Interprets teacher as leading & * & Interprets teacher as leading \\
\hline Interprets as superficial questioning & * & Interprets as superficial questioning \\
\hline Refers to place in curriculum/textbook & Refers to place in curriculum/textbook & * \\
\hline Recommends making connections & * & Recommends making connections \\
\hline Recommends more discussion & * & Recommends more discussion \\
\hline $\begin{array}{l}\text { Recommends more student } \\
\text { exploration/problem solving or wait time }\end{array}$ & * & $\begin{array}{l}\text { Recommends more student } \\
\text { exploration/problem solving or wait time }\end{array}$ \\
\hline Refers to purpose of lesson & * & Refers to purpose of lesson \\
\hline Experience as teacher & * & Experience as teacher \\
\hline
\end{tabular}

Figure 10. PSTs vs. MATs. The first column lists all propositions associated with most (>50\%) PSTs. The second column lists all propositions associated with most MATs which are common to the first column. The third column shows the differences between the first two. Asterisks appear in empty cells for clarity. 


\begin{tabular}{|l|l|l|}
\hline MATs & PSTs & MATs minus PSTs \\
\hline Refers to place in curriculum/textbook & Refers to place in curriculum/textbook & * \\
\hline
\end{tabular}

Figure 11. MATs vs. PSTs. The first column lists all propositions associated with most (>50\%) MATs. The second column lists all propositions associated with most PSTs which are common to the first column. The third column shows the differences between the first two. Asterisks appear in empty cells for clarity.

From the figure it can be seen that there are seven propositions associated with most of the PSTs that are different from most MATs. Those propositions are: interprets teacher as leading, interprets as superficial questioning, recommends making connections, recommends more discussion, recommends more student exploration/problem solving or wait time, refers to purpose of lesson, and experience as teacher. There are no propositions associated with most MATs that are not associated with most PSTs.

\section{PSTs vs. PROs}

Most PSTs had entries in the category interprets as superficial questioning, while PROs had none. These two groups showed the greatest amount of agreement in terms of number of common propositions.

Most PSTs stated that the questioning by the teacher in the videos was superficial—many questions could be answered by a yes, no, or short answer without explanation; that questions were too formula oriented; or that questions were too much about confirmation and rewarding correct answers.

Interestingly, PROs had no entries related to any of the questioning propositions. The only statement regarding questioning fell under the interprets teacher as leading proposition.

In Figure 12, it can be seen that PSTs minus PROs resulted in three propositions unique to PSTs: interprets as superficial questioning, refers to place in curriculum/textbook, and refers to purpose of lesson. Looking at PROs minus PSTs, Figure 13, revealed that PROs had two unique propositions: interprets teacher as being too procedural, and experience with math. 


\begin{tabular}{|l|l|l|}
\hline PSTs & PROs & PSTs minus PROs \\
\hline Interprets teacher as leading & Interprets teacher as leading & * \\
Interprets as superficial questioning & $*$ & Interprets as superficial questioning \\
Refers to place in curriculum/textbook & $*$ & Refers to place in curriculum/textbook \\
Recommends making connections & Recommends making connections & * \\
Recommends more discussion & Recommends more discussion & * \\
Recommends more student & Recommends more student \\
exploration/problem solving or wait time & exploration/problem solving or wait time & * \\
Refers to purpose of lesson & $*$ & Refers to purpose of lesson \\
Experience as teacher & Experience as teacher & * \\
\hline
\end{tabular}

Figure 12. PSTs vs. PROs. The first column lists all propositions associated with most (>50\%)

PSTs. The second column lists all propositions associated with most PROs which are common to the first column. The third column shows the differences between the first two. Asterisks appear in empty cells for clarity.

\begin{tabular}{|l|l|l|}
\hline PROs & PSTs & Pros minus PSTs \\
\hline Interprets teacher as leading & Interprets teacher as leading & * \\
Interprets teacher as being too procedural & $*$ & Interprets teacher as being too procedural \\
Recommends making connections & Recommends making connections & * \\
Recommends more discussion & Recommends more discussion & $\star$ \\
Recommends more student & Recommends more student \\
exploration/problem solving or wait time & exploration/problem solving or wait time & * \\
Experience as teacher & Experience as teacher & Experience with math \\
Experience with math & $*$ & Ex \\
\hline
\end{tabular}

Figure 13. PROs vs. PSTs. The first column lists all propositions associated with most $(>50 \%)$ PROs. The second column lists all propositions associated with most PSTs which are common to the first column. The third column shows the differences between the first two. Asterisks appear in empty cells for clarity.

\section{Different Responses by Group to a Given Video Segment}

The video lesson is divided into five segments: introduction, formulas, explanation, discussion, and interpretation. Here I will take one of the five segments and give a deeper discussion of the video and provide some actual responses by participants. I will then discuss how these responses illustrate differences between the participant groups.

Description. The video segment that I will focus on is the fourth, discussion. I chose this particular segment because it seemed to elicit responses that best illustrated the differences I was seeking. This segment can be found at this link: https://youtu.be/2EAty6hOErs. Along with the description of the discussion segment, I will give briefer descriptions of the other video segments for context. 
The first video segment is the Introduction, in which students introduced the task by reading from the board, and known points from the problems were identified. A student read the relevant information for the first company which gave two sample rates: 400 minutes for 30 dollars per month or 700 minutes for 4 dollars a month. The teacher then asked if there is a linear equation and a student responded that the points will be $(400,30)$ and $(700,45)$. The teacher then asked which will be on the $\mathrm{x}$-axis. There was a discussion of which variables are dependent and independent. The next plan was introduced by another student which advertised that you pay only for the minutes you use, and gave a sample rate as 600 minutes for $\$ 42$. The teacher asked for the relevant points, and a student said $(600,42)$. The teacher then asked if that was the only point and prompted "what does it cost if you talk zero minutes?" A student said "nothing", and another student said $(0,0)$.

Next was the Formula segment of the video in which students were asked to recall relevant formulas and began the work of finding equations for the two lines. The teacher told the class that they were going to find linear equations and asked for the needed formulas. A student recited the slope formula and the teacher wrote it on the board. The teacher then asked for the other needed formula and the point-slope formula was given and written on the board. The teacher then gave instructions to the students to find the equations on their own.

The next segment was Explanation. Two students went to the board, one at a time, and each discussed one of the line equations. The first student discussed how she derived the line equation for the first phone plan and the teacher asked her questions about the components of the equation. Another student did the same for the equation for the other plan. The teacher then asked the students to individually graph both lines on the same paper. 
The Discussion segment of the video is the one that I will be focusing on and therefore I will go into it in more depth. This section involved a class discussion of the meaning of the graphs including the significance of slope and y-intercept within the context of the phone plans. The line for the first plan was shown on the board and the teacher asked what the line described. A student (Student 2) stated "The more minutes you use, the more money." The teacher then asked "For which plan?" And another student (Student 6) said "JulissaPhone" (the first plan). The teacher then continued to ask a series of questions of the class which were answered by various students.

Teacher: "What is the y-intercept?"

Multiple students: "Ten."

Teacher: "What does the y-intercept mean?"

Student 5: " "The amount of money that you spend."

Student 3: "The amount you spend on the phone."

Teacher: "Right, it's a flat ten dollars before you even talk and then what?"

Student 2: "It goes up per minutes you use."

Teacher: "How much?"

Student 3: "Five cents."

Teacher: "What do you know about the 5 cents in the equation? It's the what?"

Student 4: "Slope."

Student 2: "The fixed monthly rate."

Student 6: "No, it's the slope."

Teacher: "Good. What in the equation represents the fixed monthly rate?"

Student 3: "Five." 
Student 5: "No, the ten."

Teacher: "The ten. The?"

Student 1: "The y-intercept."

Teacher: "Yep. What does the slope represent?"

Student 6: "The amount you pay for each minute."

Teacher: "Correct. Good. So, JulissaPhone is going to cost you 10 bucks and five cents per minute. Right?"

A similar discussion then occurred for the second phone plan.

Teacher: "Now, tell me about TeleCarl" (the second plan).

Student 5: "He doesn't charge you for the first minutes."

Teacher: "OK, somebody tell me about Carl's good deal."

Student 2: "Basically, Carl's saying that it's based on what you use."

Teacher: "OK, so if I talk zero minutes in a month what is going to cost me?"

Student 6: "Nothing."

Teacher: "So the rate is based entirely on?"

Student 5: " "How much you talk."

Teacher: "Good. What does a minute cost?"

Student 2: "Seven cents."

Teacher: "Seven cents. Right?"

Student 5: "So, that's how they get you?"

Teacher: "Yes, that's how they get you." Now, when I graph the line, where are our two points?"

Student 6: “( $\quad(0,0) . ”$ 
Student 1: “(600, 42).”

The teacher plotted the points and drew the two lines, then asked the class where the line crossed.

Student 3: "At 500."

Teacher: "And this way?"

Student 6: “35, 37?”

Teacher: "Right. Which one is the best deal?"

The last segment of the video was Interpretation. Here the class attempted to answer the question posed by the teacher in the previous segment. The class talked out the problem and came to the conclusion that the turning point was at 500 minutes, and which plan offered the better deal depended on how much you talked.

Responses. Typically, participants did not respond to a particular point in the lesson but to a video segment as a whole. From the responses to segment four, a big idea in which differences between participant groups could be seen began to emerge. Many of the participants commented on the class discussion or the teacher's use of questioning. For each participant who made such a comment for segment four, I have provided a brief overview of their lesson reactions as a whole and then isolated quotes specific to video segment four. These are organized by participant group. In the next section I will discuss how the reactions to segment four contribute to the identification of differences between groups.

PSTs. TCH2 was not sure if the first plan was linear and so would have discussed "staying consistent" in discussing it. She then stated that the teacher in the video had asked the students to pull the appropriate data from the problem and start doing calculations, having students recall the process for the point-slope form. She would have graphed the equations at this 
point and have the visual representation up on the board and use multiple representations rather than the equations alone. By the end of the third segment, she began to see where the teacher was headed and agreed with his direction. TCH2 agreed that this is similar to the way that she herself had presented such material, relating contextual word problems to linear equations. She would have gone further after the teacher had concluded the lesson, however. She would have continued to explore the conclusion and model it in words and symbols. TCH2 thought that the appropriateness of the lesson depended upon where the lesson falls in the sequence of teaching linear equations. She would have liked to see the lesson be more student rather than teacher-led, and would have left the choice of tools for solving the problem more open, allowing the students to choose the best path for solving the problem. Describing what the teacher was doing in segment four, TCH2 stated "Ok, getting those lines on the same graph, the students before they did that, I guess, there was the great discussion I think is always needed about kind of the fixed values per month and what's changing, what's that slope and what does it mean in terms of the context of the problem."

TCH3 initially saw the first plan as a piecewise function and thought graphing it would be confusing to students and that the problem was too abstract. He asked what the target age of the lesson would be. At the end of the second video segment, he did not see where the lesson was going. He stated that the teacher had asked the students to graph two lines, although he thought there was only one. He called into question the teacher's response to a student when the student suggested slope-intercept form. He noted that the teacher corrected the student and said it should be in point-slope form, even though the former could actually have been used. Segment three was mostly algebraic manipulation and he stated that he would have done the same. He also noted that the pacing seemed very quick, and that the choice of methods for solving the problem 
may have come from the unit they were studying at the time. Overall, TCH3 felt that the students should have been allowed to attempt the problem on their own first and decide for themselves how to go about solving it rather than being pushed to solve it as a system of linear equations. TCH3 described what the teacher was in doing in segment four by saying "I think, a lot of times he asks a question and gets an answer, and then if it's not the answer he's looking for then he doesn't really press them for reasoning as to why they give that answer, he just kind of asks for another answer, then someone gives the answer he's looking for and then just moves on with it. He never really discusses the difference between the two answers and why one is correct and one is not correct." TCH3 then went on to offer suggestions for what he would have done differently in that segment: "I would have liked to have spent more time discussing the differences of answers and why they exist."

TCH4 noted that the teacher asked guiding questions, and pointed out a moment when a student did not get a response to her question as a good place for discussion. For the first three segments, she would not have done anything differently, and especially liked having the students go to the board. In the fourth segment, she felt that the discussions could have gone deeper than just having students supply answers to questions, as a way to deal with possible errors or conceptual misunderstandings. TCH4 liked the class discussion of which plan is the better deal, but dismissed the part about for whom the plan was better as "mathematically irrelevant." Overall, she would have taught much the same. She would ask more guiding questions that required more than one word answers. She would spend more time discussing student answers, rather than just saying right or wrong. Describing what the teacher was doing in segment four, she said "The teacher just asked direct questions that were just, either some of them were yes or no questions that they didn't have to expand on that much. And then other ones were where they 
just had to give, like, a certain number and then he determined whether it was right or wrong" (TCH4). In suggesting what she would have done differently she said "I would have gone a little deeper with why that student answered that way, because that could be a common misconception that other students have too. By pointing out and not just saying 'oh that's wrong' but seeing where they're coming from in their thinking. They might just have one little conceptual error and so If you would point that out, not that they have an error necessarily, but that their logic and thinking or something is different and you could clear that up for them and other students as well" (TCH4).

TCH5 would have liked for the teacher to be more animated and joke around more. He also wanted to know what the students had been working on prior to this lesson. At the end of segment two, he noted that he would have liked for the students to make more connections on their own, stating that he would have had "higher expectations" for his students. In segment three he thought that the teacher had missed an opportunity to facilitate more understanding with questioning, noting that informal assessment is a good time to make connections. TCH5 felt that the students could have been more clear with their responses and that teacher clarification did not show whether a student actually understood. Again he mentioned higher expectations for the students. Responding to segment five, he stated that he would have talked more about the intersection point, and would have liked to elaborate further on for whom each plan is better, rather than going back to the equations. Overall, he would have made sure that the students were engaged rather than just going through the motions. For segment four he suggested: "I think they should be more clear in their responses. because they were saying ' 10 dollars, 10 dollars' and he added on saying 'that's what you'd pay if didn't do anything at all' and that doesn't show if the students understand...some of them might understand that afterwards but some of them, like, 
you don't really know if the students made that connection themselves. So, again, I think the idea is just a little bit higher expectations. And being more clear with their explanations" (TCH5).

From the first video, TCH6 assumed a type of linear relationship. He saw the teacher as shoving information at the kids, rather than allowing students to think through a task. He said that the students should have been allowed to get the points on their own, with the teacher possibly asking some formative questions along the way. The participant thought the lesson may have been appropriate as a review, but not as an introduction. He noted that in segment two the teacher talked much less and the discussion involved the students more, but still saw their input as practice and recitation of formulas. He thought it was better than the first segment, but that the discussion was not conducive to procedural fluency. The participant liked the third video, noting that the teacher did not lead and that students were allowed to do the thinking as they were at the board. He would have liked to see more "how" and "why" questioning during the discussion afterward. A need for better teacher/student interaction and better questioning continued into segment four, and the participant stated that he would have done it differently. He stated that he saw in segment five what he would have liked to see in segment four, that is, more discussion about the interpretation of the problem outcome and making connections. Overall, he liked the graphical representation, but would not have thought to do it that way before seeing the video. He would have spent more time letting students find points and discussing where they came from, but liked the concluding interpretation. Regarding segment four he said "so much we look at all these videos and talk about how you gotta have the students try to confirm..." (TCH6).

TCH9 felt that the teacher wanted the problem set up to be solved in a certain way. He would have let them explore to find $(0,0)$, although he admitted that he may have done the same thing as the teacher to speed up the lesson. He would have had them try to graph it before 
mentioning linear equations. In segment two, he again would have let the students take some time to explore on their own, stating that: "He's very on the rails here." He would have taught differently rather than getting through the lesson quickly. He thought the teacher was pushing towards a certain way of solving, but that it was good to have everyone on the same page. For segment four, he thought the teacher was still too leading. He saw the teacher's questioning as superficial without good discussion of right or wrong answers, and thought that the students should be making their own connections. He saw segment five as mostly good, but would have let students keep discussing and arrive at a conclusion. Overall, the participant wanted to see more struggle on the part of the students. He described the lesson as being pretty typical. Of segment four he said "So, again, very on rails here. Like, the students are throwing out a couple of different answers, especially at the start there, and instead of maybe discussing why they might think each of those, having them discuss with each other would probably be even better. It's just like 'no, next' and 'what's the next thing?'” (TCH9). In response to what he would do differently in segment four, he said "Not much that I want to add, just more or less they need to be doing more of the talking instead of me just leading them on rails through the whole thing. Dragging them, really" (TCH9).

MATS. MAT3 thought that the classroom teacher should have given more reason as to why minutes was the independent variable and elaborated on why they were using linear equations to solve the problem. He also commented that the lesson moved too fast. Specifically, he did not like the emphasis on equations and would like to have seen the students think about how to arrive at an answer rather than using algorithms. MAT3 took issue with the way the intersection point was found, preferring to find it by graphing rather than having it predetermined algebraically, and he would have made the connection between slope and cost per 
minute clearer before solving. He stated that it was better to stress conceptual ideas over algorithms. Overall, he would let the students decide which direction to take in solving the problem rather than explicitly telling them to use the slope formula. The direction would be dependent upon the background of the students. He thought the lesson worked well for a general audience, because everything was explained clearly. Of segment four he said "So this part I actually really liked. Because it really made sure that students weren't just thinking about merely as lines and equations and they really made sure that the students were understanding what each actual number represents and how that number serves to solve the equation" (MAT3).

MAT4 saw the teacher as guiding, in particular in finding the $(0,0)$ point. He did not consider using linear equations on his own but thought it was the right approach after seeing the video. He thought using linear equations was appropriate if that is the current unit of study. In segment two he saw the teacher as asking students to recall prior knowledge, and stated that linear equations and point-slope form were clearly the current unit of study. He liked having students do work in class, and liked that students went to the board in segment three because it made the class seem more collaborative. In segment four, he thought the visual representation was a good way to help students understand the concept. He also liked the discussion and having students explain as opposed to the teacher lecturing, stating that it was more conducive to student understanding. Overall, he would set up and teach the lesson much as the teacher did. "Teacher started asking all the students like 'what do these lines and slopes actually mean?', 'what does the slope mean for each graph?', 'what does the intercept mean for each plan?', 'what are the real-life implications..." (MAT4).

MAT6 did not think about solving the problem in terms of $\mathrm{x}$ and $\mathrm{y}$ when solving the problem, and considered this to be a basic level lesson in preparation for upper level 
mathematics. She noted that the teacher did not explain how this problem correlates to the graphical representation. For segment two, she said the teacher used this approach because the problem is straightforward and easy to recognize $\mathrm{x}$ and $\mathrm{y}$ and use slope formula. She would prefer that the teacher said what each variable means, rather than go into the formulas in detail. For segment three, she said the teacher wanted students to use real-life examples and transfer them to equations. She thought the teacher made students understand the meaning of the problem in segment four, and noted that the teacher made students answer questions, though that would not have been her preference. In segment five, she said the teacher made students understand the problem in terms of rates and saving money, instead of just plugging numbers and getting a result. Overall, she liked the structure of the lesson: starting with simple steps, determining the needed variables, and discussion of what the equations meant. In her comments on segment four she said "Ok, I think that the teacher really tried to make the students understand what this problem actually means and how to portray it with a graph and... I think he really tried to make the students understand beyond the fact that it's just a point-slope formula that projects it onto a graph" (MAT6).

MAT8 saw the teacher as "somewhat" helping the students to get started with the problem on the right track. For segment two, he thought the teacher was giving small hints and leading but not giving answers, and liked having the equations on the board and allowing students to think. He thought having students come to the board in video three gave those students experience and helped their peers to learn from them, but began at this point to question whether the amount of guidance was appropriate or too much. For segment four, the participant felt that the teacher went into too much depth on the graph, and stated that it may have been appropriate for first learning how to solve in middle school, but college age students could have 
benefitted from a more straightforward lesson with less leading questioning. Overall, he would have given less guidance and let students express what they think. Of segment four he said that the teacher "kept asking a lot of questions" (MAT8).

PROs. The one PRO comment related to this point for segment four was in the form of a suggestion for what she would do differently: PRO1 felt that the teacher did not offer appropriate wait time when questioning students, that the questions were too leading, and that students were not fully engaged and the teachers method led to cognitive draining. Based on her teaching experience, she would have allowed students to work on their own before giving information. For segment two, she questioned what prior knowledge the students had. She would have let the students discuss whether or not the relationships were linear, and thought that the lesson as presented elicited only procedural understanding and was not conducive to the formation of conceptual understanding. She felt that the students' thinking was limited by giving too much information, and that there were other ways to go about solving the problem. For segment three, she again saw the teacher as being too leading and saw this as restricting the types of representations the students might come up with. For segment four, PRO1 liked the connections made between the two different representations, but would have preferred that the students made those connections on their own, and that questions asked by the teacher should have been more open-ended. In segment five, she liked the discussion but would have liked more connection to the graph and more discussion of the meaning of the graph. She would also have better connected the graph to the algebra and to tables. Overall, she saw the lesson as traditional, with the teacher doing too much of the thinking. Her suggestion for segment four was: "I would probably try to leave it as a more open ended question, although they're very good questions" (PRO1). 
Differences between PSTs and MATs. One of the main points that came to light during the Discussion segment of the video was that of questioning and discussion as a class. Most of the comments related to this fell under the survey questions "what is the teacher doing?" and "what would you do differently." Some of the differences between the groups can easily be seen from the different responses above. PSTs were more likely to offer suggestions for change than were the MATs. The one PRO offered a positive comment about the questioning, but still made a suggestion for improvement.

From the segment four excerpts above, several of the PSTs made statements that the questioning by the teacher elicited yes, no, or short answers from the students. These statements fell under the proposition interprets as superficial questioning. None of the MATs made statements that fell under that proposition for this video segment. These statements were often paired with a recommendation statement that fell under the proposition recommends more discussion. Half of the MATs made statements which fell under rationale: clarification or summarization. This implies that the teacher is doing what is appropriate to the situation. One of the PSTs also made a similar statement.

If more than half of the participants of a group made a statement that fell under a given proposition, that proposition was considered to be typical of that group. These percentages were calculated overall for the entire video lesson, rather than for each individual segment. In this particular segment, interprets as superficial questioning was applied to half of the participants but accounted for more that $50 \%$ over the entire lesson, so was included as being typical of PSTs. The proposition recommends more discussion applied to fewer than half of PSTs in this segment but more than half overall, so was considered typical of that group. Neither of these propositions were applied to more than 50\% of MATs, so were not considered typical for that 
group. Therefore, interprets as superficial questioning and recommends more discussion are considered to represent traits of PSTs which are different from MATs.

Relevance of Comparison to PROs. What was interesting about the comparison between the PSTs and PROs was not just what they had in common, but how they differed. PSTs and PROs had five propositions in common, whereas PSTs and MATs had only one. MATs and PROs had no propositions in common. The PSTs clearly related more closely to the PROs than the MATs.

Most PSTs had statements that fell under the propositions interprets as superficial questioning, refers to place in curriculum/textbook, and refers to purpose of lesson. None of these, however, appeared in the final list for PROs. This does not indicate necessarily that these were not valid concerns for the PROs, but that other observations took priority. It does indicate some change in focus between the PSTs and the PROs. The majority of PROs, on the other hand, interpreted the teacher as being too procedural and referred to their own experience with mathematics. This seems to indicate that pedagogical knowledge held by PSTs is approaching, or in the same vein as, that held by the professional educators. The PRO group certainly had more experience, so that difference was fairly self-explanatory.

The main takeaway, then, from the comparison between the PSTs and the PROs was the fact that the PROs saw the teacher as being too procedural, whereas the PSTs did not. Earlier in this chapter I described this as promoting procedural learning at the expense of conceptual understanding. The PSTs, then, either did not recognize the teaching as being overly procedural, or did not think it was a relevant observation within the context of the interview. 


\section{Conclusion}

I am interpreting the outcome propositions as evidence of the teaching knowledge held by participants of this study. I introduced this study by stating that I would attempt to characterize PCK as Shulman (1986) defined it — as being that knowledge held by teachers which is not held by other subject matter practitioners. As I am specifically interested in PCK held by PSTs, I have compared PSTs to their non-teaching subject matter peers, the MATs.

In order to answer the question of what types of knowledge are uniquely possessed by PSTs, I have characterized the different types of knowledge that the three participant groups; PSTs, MATs, and PROs; exhibited in responding to questions while watching an algebra lesson. I listed all of the propositions for which most PSTs (greater than 50\%) offered a response and removed propositions from that list which also characterized the responses of most MATs (see figure 11). This resulted in seven outcome propositions which were unique to PSTs in this study. Because my goal has been to characterize the knowledge unique to PSTs as PCK, at this point I will restate the seven outcome propositions. Those statements which I have been treating as outcome propositions up to this point constitute the evidence of PCK which I have collected and analyzed. The restatements, or final propositional statements, characterize the PCK evidenced by those outcome propositions.

PSTs recognize that students need to do their own thinking rather than being told by the teacher how to approach or solve a problem. (Interprets teacher as leading)

PSTs understand that teacher questioning needs to elicit thinking on the part of the students. (Interprets as superficial questioning)

PSTs recognize the importance of connecting representations, calculations and context within the solution to a problem. (Recommends making connections) 
PSTs understand the need for meaningful student involvement in class conversation.

(Recommends more discussion)

PSTs recognize the need for students to explore on their own and be allowed time to think. (Recommends more student exploration/problem solving or wait time)

PSTs recognize that the lesson is dependent on its objective. (Refers to purpose of lesson) PSTs' teaching experience contributes to their PCK. (Experience as teacher)

\section{Chapter Four Summary}

In this chapter, I presented the findings of my research in the form of outcome propositions that resulted from my analysis of the data. Using these outcome propositions, I reported the defining characteristics of each of the participant groups_-PST, MAT, PRO — and described the characteristics that differentiated the groups. Then I presented a narrative to highlight the differences between the participant groups within the context of one of the video segments critiqued by the participants. I closed the chapter with a listing of the seven outcome propositions that were unique to the PSTs and which I conclude represent the PCK of the PSTs in this study. In the next chapter, I interpret the seven propositions through the lens of Shulman's interpretation of PCK and relate them to the relevant literature. 


\section{CHAPTER V: CONCLUSIONS}

In the previous chapters I discussed the concept of pedagogical content knowledge, its conceptualizations, and the need to study it in the context of secondary mathematics. I then reviewed the relevant literature on teacher knowledge and PST preparation. In Chapter Three, I presented my method for differentiating knowledge held by different groups of participants and in Chapter Four I presented my results. In this chapter I summarize the study and my findings, discuss those findings and answer my research question within the context of the existing literature. I then discuss limitations, implications, and suggestions for future research.

\section{Summary of Study and Findings}

The goal of this research was to identify the teaching knowledge, PCK, that is possessed by those college students who have completed a mathematics education program. To do this, I sought to compare those students to college students with comparable mathematics backgrounds and coursework. According to the underlying assumptions of my study design, the differences in the teaching knowledge would provide evidence of PCK.

Twenty participants were interviewed in sessions that involved solving an algebraic task and then viewing and critiquing a lesson involving that same problem. The participants were asked to comment about what the teacher did, why he did it, and what the participant may do differently. They were also given an opportunity to make any other comments that they liked. The participants came from three groups: pre-service teachers who had just finished student teaching, mathematics students who had not had any educational coursework, and a professional group with varying degrees of teaching experience. The statements made in critiquing the lesson by each participant were categorized and the process of defining those categories led to a set of propositions regarding the thinking of the participants. These propositions, as well as summaries 
of the interviews of each participant, led to narratives describing typical characteristics of each group. The frequency of propositions related to each participant group was used to differentiate those which could be considered unique to PSTs, which was the basis of my characterization of PCK.

The seven propositions that were unique to PSTs are as follows: Interprets as leading meant that the teacher was providing too much guidance. Interprets as superficial questioning described the participants' view that the teacher's questioning as eliciting a yes, no, or short answer. The proposition recommends making connections meant that the participants recommended making connections between the problem, real-life experience, and calculations. For recommends more discussion, participants recommended more or better class discussion or recommended that the discussions be more student-led. Recommends more student exploration or wait time suggested that students have more time to explore on their own before the class goes over a problem together, or that the students have more time to think before the teacher answers a question. Refers to purpose of lesson characterized participants' comments that identified the lesson as a review, questioned its goal, or anticipated the direction it was taking. Experience as teacher referred to statements by participants related to their own experience teaching or tutoring.

\section{Discussion of Findings}

In this section, I discuss the seven propositions in terms of Shulman's conceptualization of PCK, PCK conceptualizations from the literature, and in terms of the standards for preparation of new teachers. 


\section{Propositions as Related to Shulman's Definition of PCK}

By designing my study according to Shulman's (1986) description of PCK as the knowledge that a teacher possesses but a practitioner of the subject may not, the seven outcome propositions, by definition, identify elements of PCK, or at least provide evidence of PCK. Here I give additional support for this claim by examining Shulman's (1986, 1987) conceptualization of PCK as pedagogical knowledge that is informed by the subject matter and distinct from general pedagogy, which Shulman describes as classroom management, activity organization, allocation of time and turns, assignment structure, assignment of praise, and lesson planning (1986, p. 8). Shulman described pedagogical content knowledge as going beyond subject matter to subject matter for teaching. Included in this knowledge are the most useful forms of representing ideas; the best analogies, examples, explanations, and demonstrations; ways of representing the subject that make it comprehensible to others; and alternative forms of representation based both on research and the "wisdom of practice" (p. 9). According to Shulman, PCK also includes an understanding of what makes the learning of a given topic easy or difficult, and an understanding of students' conceptions and misconceptions, as well as strategies which best facilitate the reorganization of understanding in learners. Additionally, he considered curricular knowledge as a component of PCK.

Parallels can be drawn between the outcome propositions I identified in my study and what I have just described as subject matter informed pedagogical knowledge or PCK. Various aspects of representation feature heavily in Shulman's description of PCK and are also evident in the outcome propositions. Five of the propositions-interprets as leading, interprets as superficial questioning, making connections, recommends more discussion, and recommends more student exploration - relate to the teacher's explanations and the ways he attempted to 
make the mathematics comprehensible to the students. Essentially, the PSTs perceived the teachers' approach to the lesson as lacking or not resonating with the way they thought the lesson should be conducted. For example, TCH6 thought that the teacher was too leading, stating that the teacher seemed to be "shoving" information at the students and not allowing them time to think. TCH9 also noted that the students should be allowed to think more.

The PSTs also recommended making connections and better questioning. PSTs called the questioning of the students by the teacher superficial, indicating that they did not think the teacher was effectively identifying possible student misconceptions. The teacher was "just rewarding correct answers, providing answers to students" according to TCH8, and students should be allowed to form their own "grasp" of the topic. A direct suggestion for making connections was made by TCH9, who also said at the same time that the teacher was being too leading and asking questions with yes or no answers. TCH6 wanted to see more discussion about the meaning of the intersection and some connection between the graph and phone rates. These examples also suggest the PSTs thought, given time and support of their thinking through discussion, that the students were capable of figuring out things for themselves. TCH8 said that students should think on their own, even if it takes them down unproductive paths. This seems to indicate a support for student exploration and a need for guidance through discussion.

For Shulman, another aspect of PCK pertains to the knowledge that informs teachers' decisions about what to teach. Two propositions-refers to purpose of lesson and experience as teacher - relates to curricular knowledge and decision making informed by experience teaching a particular topic. PSTs' comments about the goal of the lesson or the direction it was taking give evidence of their awareness that choices are made in deciding what is to be taught and that it is dependent on the topic and intended audience. PSTs made statements regarding the intended 
purpose and direction of the lesson, which could be seen as their having a subject-informed view of the relevant pedagogy. That is, their knowledge of the subject matter and the goal of the lesson indicate whether the lesson is appropriate for the students. For example, TCH3 asked whether the lesson was a review because it seemed that the students were already familiar with linear equations, and $\mathrm{TCH} 2$ stated that they were using this method because "that's probably the

unit they're in." Anticipating the direction of the lesson, TCH6 stated that "what we are building towards is that intersection."

PSTs also made statements referring to their teaching experience. In particular, TCH2 made a statement which seems to make a connection between experience and mathematics knowledge, stating: "I had experience with them being able to answer the question, but I truly don't believe they get the concept behind it."

One might argue that the findings of this study indicate that PCK can be taught and learned in a teacher preparation program. But this does raise the question of whether these skills develop organically as a result of teacher preparation or appeared because they were consciously included in the program. A comparison with another program would be necessary to properly answer that question. The propositions provide descriptions of the ways in which these ideas present themselves in practice, through the eyes of the PSTs in this study.

\section{Outcome Propositions as Related to Other PCK Conceptualizations}

Most researchers (DePaepe, 2013) have referred to the Shulman concept of PCK, and a large percentage to the MKT model (Hill, et al., 2008). A few have referred to PCK generically without elaboration. My research seems to be unique among PCK studies as it has attempted to characterize PCK. I have discussed my outcome propositions as related to Shulman's concept 
(1986, 1987). Because the MKT model is so widely accepted, it seems appropriate to compare my outcome propositions to its subcategories of PCK

The Mathematical Knowledge for Teaching (MKT) model included a breakdown of PCK into the three subcategories: knowledge of content and students (KCS), which focuses on how students learn particular mathematical content; knowledge of content and teaching (KCT), which concerns knowledge of teaching techniques, how to best build upon student thinking, and how best to remedy student errors; and knowledge of content and curriculum (KCC), which includes knowledge of curriculum materials (Hill et al., 2008, p. 377).

Most of the final propositions fell into the KCS category in the MKT model. The proposition interprets teacher as leading, as I have defined it, relates to the participant seeing the teacher as providing too much information. They must hold an understanding that mathematical knowledge is not best conveyed simply by telling. The students must have an opportunity to construct knowledge on their own in order to fully understand and retain the material. This reflects an understanding of how students learn a particular mathematical concept. Under similar arguments I have also classified the propositions interprets as superficial questioning, recommends more discussion, and recommends more student exploration/problem solving or wait time, and recommends making connections as possessing elements of KCS. To state that the teacher's questioning is superficial — a negative — is an acknowledgement that it is ineffective in helping students learn the content. To recommend more discussion, again, acknowledges that the teaching could be more effective. For more student exploration, the KCS comes in when recognizing that the students would learn better by thinking through the problem more on their own and to recognize the need for making connections may be regarded as KCS. 
KCT concerns knowledge of effective teaching techniques. The concepts of KCT and KCS concepts are most certainly intertwined, as the participants' recognition that this was not the most effective technique is likely based on their own understanding of how students learn this mathematical concept. The propositions interprets teacher as leading, interprets as superficial questioning, recommends more discussion, and recommends more student exploration/problem solving or wait time all possess elements of KCT. To state that the teacher's questioning is superficial acknowledges that the participant recognizes a better technique for conveying the content to the students as well as an opportunity to build on the students' thinking and correct their errors. To recommend more discussion, acknowledges that the technique to facilitate that is by encouraging discussion that is more involving of the students or even studentled. For more student exploration, the KCT is involved in fostering the problem solving and allowing the wait time.

I saw elements of KCC in the proposition recommends making connections. Making connections between representations is part of the curriculum and, in particular, $\mathrm{KCC}$ comes into play when connecting current learning to previous knowledge and anticipating how this current and previous knowledge will connect to future topics. I have also classified the proposition refers to purpose of lesson as KCC, as it relates to knowing where the current topic falls in the curriculum, what comes next, and what came before.

\section{Outcome Propositions as Related to Standards for Teacher Preparation}

In this section, I relate the outcome propositions to the standards for preparation of teachers. In Chapter 2, I discussed the AMTE (2016) Standards for Preparing Teachers of Mathematics and the NCTM (2020) Standards for the Preparation of Secondary Mathematics Teachers. 
There are three main AMTE (2016) standards that are directly applicable to the outcome propositions. Standard C.1 involves mathematics concepts, practices, and curriculum, Standard C.2 is pedagogical knowledge and practices for teaching mathematics, and C.3 involves students as learners of mathematics. Likewise, there are three NCTM (2020) standards that relate to PCK, but it is Standard 3: Knowing Students and Planning for Mathematical Learning, and Standard 4: Teaching Meaningful Mathematics that apply most directly to the outcome propositions.

Among the AMTE (2016) standards, Pedagogical Knowledge and Practices for Teaching Mathematics, has the strongest connection to the final set of propositions. This standard directly addresses pedagogical knowledge and support of students' understanding. In particular, the second standard relates to the propositions interprets teacher as leading, interprets as superficial questioning, recommends making connections, recommends more discussion, and recommends more student exploration/problem solving or wait time. The third standard, Students as Learners of Mathematics, refers to teachers holding and expanding their knowledge of students' knowledge and skills. This standard relates to the two propositions not included with the previous standard: refers to purpose of lesson and experience as teacher.

NCTM (2020) Standards 3 and 4 are each covered by four of the propositions. Both standards are related to the propositions interprets teacher as leading, interprets as superficial questioning, and recommends more discussion. Standard 3 is also covered by recommends student exploration, and Standard 4 by recommends making connections. Neither standard is connected to refers to purpose of lesson or experience as teacher. Next, I discuss the relevant standards by proposition. 
I have connected interprets teacher as leading to C.2.3 which is implement effective instruction. The PSTs have clearly used their knowledge of effective instruction in recognizing that the teacher's method is ineffective. AMTE standard 3d: resist the urge to tell students how to solve a problem and 4f: develop conceptual understanding also apply to this proposition.

Interprets as superficial questioning is also related to AMTE C.2.3, implement effective instruction, as PSTs saw the questioning as being ineffective. I would also connect this proposition to C.3.2, which concerns understanding and recognizing student engagement. Here, the PSTs recognized that the students were not properly engaged. Among the NCTM standards, $3 \mathrm{~b}$ asks students to restate problems and 3e asks the teacher to ask students questions that will prompt their thinking are both relevant, as is $4 \mathrm{e}$ : elicit and use student responses.

The proposition recommends making connections is related to the AMTE standard C.2.3, implement effective instruction, and C.3.1, anticipate and attend to students' thinking about mathematical content. In recommending making connections, the PSTs are using their knowledge to recognize what students need to get from a topic and how best to instill it. The proposition is also related to NCTM $4 \mathrm{~b}$, use mathematical representations, and 4f, develop conceptual understanding, as the use of representations contributes to making connections which in turn is conducive to the development of conceptual understanding.

Recommends more discussion relates to C.2.3, implement effective instruction, and C.3.1, anticipate and attend to students' thinking. The PSTs have recognized that more discussion will be beneficial for the students' understanding of the topic. This proposition hits several of the NCTM standards. Student assumptions are covered in 3b, 3g states that a teacher should encourage students to ask questions of themselves and others, $3 \mathrm{~h}$ involves an expectation on the part of the students to communicate their reasoning, $4 \mathrm{e}$ calls for a teacher to elicit and use student 
responses, and $4 \mathrm{~g}$ for the teacher to facilitate discourse. Clearly discussion is a main theme in the 2020 NCTM standards.

The next proposition is recommends more student exploration, problem solving, or wait time. This proposition fits with C.2.3 implement effective instruction and C.3.1 anticipate and attend to student thinking. The PSTs see allowing student exploration and wait time as elements of effective instruction which allows for student thinking. As related to the NCTM standards, 3a involves providing tasks that require students to figure things out for themselves, $3 \mathrm{c}$ calls for the teacher to give students time to analyze and explore a problem, and $3 \mathrm{f}$ calls for adequate wait time for students to formulate their own reasoning.

The proposition refers to purpose of lesson can be related to C.1.4, which refers to the teacher' analysis of the mathematical content of the lesson and C.2.2 which is to plan for effective instruction. It is necessary to understand the content and its importance to the student and the curriculum, and that leads to planning for effectiveness. I did not connect this directly with any of the NCTM 2020 standards, though I will note that it fits with Principals to Actions (NCTM, 2014) call to establish mathematics goals to focus learning.

How the PSTs fared compared to the standards. In all, the PSTs had connections to several of the preparation standards for teachers. The AMTE (2016) standards that were represented were: C.1.4, analyze the mathematical content of curriculum: C.2.2, plan for effective instruction; C.2.3, implement effective instruction; C.2.4, analyze teaching practice; and C.3.1, anticipate and attend to student thinking.

Several of the NCTM (2020) standards were represented as well: 3a, provide tasks requiring students to figure things out; $3 b$, ask students to restate problems; $3 c$, allow time for students to analyze the problem; $3 \mathrm{~d}$, resist the urge to tell the students how to solve the problem; 
3e, ask questions to prompt thinking; $3 \mathrm{f}$, allow adequate wait time; $3 \mathrm{~g}$, encourage questioning; $3 \mathrm{~h}$, expect students to communicate their reasoning; $4 \mathrm{a}$, use mathematical representations; $4 \mathrm{~b}$, elicit and use student responses; $4 \mathrm{c}$, develop conceptual understanding and procedural fluency; and $4 \mathrm{~d}$, facilitate discourse.

\section{Limitations}

There were several limitations that I can identify in the study in regards to its scope and generalizability. The results were based on a single algebraic task which was chosen because it was considered to be equally accessible to all participant groups. While this task was effective in helping to distinguish PCK differences among the groups, having multiple tasks could have helped clarify whether the results were specifically related to this particular task or whether the participants would exhibit the same characteristics on multiple tasks.

The sample, having a total of twenty participants among the three groups, was relatively small. With such a small group, as well as the fact that all of the PSTs came from the same program at the same university, it is not possible to make statements about pre-service teachers' PCK in general. It was not my intent, however, to make sweeping statements about PSTs' PCK, but only to begin to characterize their PCK. Still, my findings will certainly reflect what is taught to mathematics pre-service teachers at this particular school.

Another limitation of the study was that knowledge of student thinking and misconceptions is part of PCK, yet the interview questions were focused on the teacher rather than the students. Thus, participants' references to student thinking and misconceptions might have been limited because of the design of the prompts.

To improve the study, in addition to having a larger sample from each of the three participant groups, I would add participants from other schools to compare similarities and 
differences. This would allow me to make broader generalizations about PST knowledge, and these in turn could be compared to still more programs. I would also expand the interview process to include the composition of an informal lesson plan - that is a format that would not be biased against the non-education majors - before doing the lesson critique portion. I believe this would have two useful effects. First, it would provide useful data to add depth to the findings and, second, it would allow the participants to put more thought into the lesson before critiquing it.

\section{Significance of the Study}

Research has shown that PSTs should possess PCK in order to be effective in teaching mathematics (Kinach, 1996). According to Sowder (2007) novice secondary teachers tended to have had fewer pedagogy and education classes than elementary teachers and therefore were more likely to fall back upon traditional practices. Turnuklu and Yesildere (2007) determined that it was necessary but not sufficient to hold a deep understanding in mathematics in order to teach it, and that teachers should have CK and PCK education during their university years.

This study demonstrated a research technique which provided a narrow set of findings from a small sample. An obvious question then is whether the same propositions would emerge if students from another, or several, teacher education programs were studied. Another important question was to ask how the identification of these propositions can benefit secondary mathematics education?

This study is significant because it provides a basis for a sort of reverse engineering of knowledge characteristics which contribute to positive outcomes for students. Studies involving practicing teachers could be used to generate outcome propositions, and studies involving students and their teachers could be used to determine the knowledge traits possessed by teachers 
of the students with the best academic outcomes. Comparing this database of desirable characteristics of teachers with a similar database of typical characteristics of PSTs knowledge would allow for a finer alignment of teacher education program outcomes with the needs of beginning teachers. This would allow beginning teachers to be effective as early in their careers as possible.

This study arose from the general need to better understand the traits of effective teachers of mathematics. In pursuit of this goal, I examined traits of pre-service teachers which revealed some characteristics of the pedagogical content knowledge that they held. It is my intention that the identification of these characteristics will serve as building blocks for connecting knowledge held by teachers to positive student outcomes in the service of better preparing aspiring mathematics teachers. 


\section{REFERENCES}

Adler, J., Ball, D., Krainer, K., Lin, F. L., \& Novotna, J. (2005). Reflections on an emerging field: Researching mathematics teacher education. Educational Studies in Mathematics, 60(3), 359-381.

Aguirre, J M, del Rosario Zavala, M. \& Katanyoutanant, T. 2012. Developing robust forms of preservice teachers' pedagogical content knowledge through culturally responsive mathematics teaching analysis. Mathematics Teacher Education and Development, vol. 14, no. 2, pp. 113-136.

Al Riyami, T. (2015). Main approaches to educational research. International Journal of Innovation and Research in Educational Sciences, 2(5), 412-416.

Appleton, K. (2003). How do beginning primary school teachers cope with science? Toward an understanding of science teaching practice. Research in Science Education, 33, 1-25.

Appleton, K., and I. Kindt. 2002. Beginning elementary teachers' development as teachers of science. Journal of Science Teacher Education 13(1): 43-61.

Association of Mathematics Teacher Educators. (2017). Standards for Preparing Teachers of Mathematics. Available online at amte.net/standards.

Australian Curriculum Assessment and Reporting Authority (ACARA) (2012).

Australian Curriculum: English. Version 3.0. Sydney: Australian Curriculum Assessment and Reporting Authority. Retrieved from http://www.australiancurriculum. edu.au/English/Curriculum/F-10.

Aziz, T. A., Pramudiani, P., \& Purnomo, Y. W. (2018, January). Differences between quadratic equations and functions: Indonesian pre-service secondary mathematics teachers' views. In Journal of Physics: Conference Series(Vol. 948, No. 1, p. 012043). IOP Publishing. 
Ball, D. L. (1988). Unlearning to teach mathematics. For the Learning of Mathematics, 8(1), $40-48$.

Ball, D. L. (1990). Breaking with experience in learning to teach mathematics: The role of a preservice methods course. For the learning of mathematics, 10(2), 10-16.

Ball, D. L. (1990). The mathematical understandings that prospective teachers bring to teacher education. The elementary school journal, 90(4), 449-466.

Ball, D. L. (2000). Bridging practices: Intertwining content and pedagogy in teaching and learning. Journal of Teacher Education, 51(3), 241-247.

Ball, D. L., \& Bass, H. (2000). Interweaving content and pedagogy in teaching and learning to teach: Knowing and using mathematics. Multiple perspectives on the teaching and learning of mathematics, 83-104.

Ball, D. L., \& Forzani, F. M. (2010). Teaching skillful teaching. Educational Leadership, 68(4), $40-45$.

Ball, D. L., Hill, H. C., \& Bass, H. (2003). Developing measures of mathematics knowledge for teaching. Retrieved December, 2.

Ball, D., \& Lampert, M. (1999). Multiples of evidence, time, and perspective: Revising the study of teaching and learning. In: E. Lagemann \& L. Shulman (Eds.), Issues in education research: Problems and possibilities (pp. 371-398). New York: Jossey-Bass.

Ball, D.L., Thames, M.H., \& Phelps, G. (2008). Content knowledge for teaching: What makes it special? Journal of Teacher Education, 59(5), 389-407.

Barker, W., Bressoud, D., Epp, S., Ganter, S., Haver, B., \& Pollatsek, H. (2004). Undergraduate programs and courses in the mathematical sciences: CUPM curriculum guide 2004. Washington, DC: The Mathematical Association of America. 
Baumert, J., Kunter, M., Blum, W., Brunner, M., Voss, T., Jordan, A., Klusmann, U., Krauss, S., Neubrand, M., \& Tsai, Y. M. (2010). Teachers' mathematical knowledge, cognitive activation in the classroom, and student progress. American educational research journal, 47(1), 133-180.

Beswick, K., \& Goos, M. (2012). Measuring Pre-Service Primary Teachers' Knowledge for Teaching Mathematics. Mathematics Teacher Education and Development, 14(2), 70-90.

Bieda, K., Cavanna, J., \& Ji, X. (2013). Developing Mathematical Knowledge for Teaching through Mentor-Guided Lesson Study. North American Chapter of the International Group for the Psychology of Mathematics Education.

Boaler, J. (Ed.). (2000). Multiple perspectives on mathematics teaching and learning. Stanford, CA: Elsevier Science.

Brownell, W. A. (1947). The place of meaning in the teaching of arithmetic. Elementary School Journal, 47, 256-265.

Brundrett, M., \& Rhodes, C. (2013). Theories of educational research. Researching Educational Leadership and Management, Sage Publications Ltd, London, 12-23.

Buss, R. R. (2010). Efficacy for teaching elementary science and mathematics compared to other content. School Science and Mathematics, 110(6), 290-297.

Callingham, R., Chick, H. L., \& Thornton, S. (2013). Evidence-based approaches to developing content knowledge and pedagogical content knowledge in pre-service mathematics teacher education. Mathematics Teacher Education and Development, 14(2), 1-3.

Cardetti, F., \& Truxaw, M. P. (2014). Toward improving the mathematics preparation of elementary preservice teachers. School Science and Mathematics, 114(1), 1-9. 
Carlsen, W. (1999). Domains of teacher knowledge. In Examining pedagogical content knowledge (pp. 133-144). Springer, Dordrecht.

Carpenter, T. P., \& Lehrer, R. (1999). Teaching and learning mathematics with understanding. In Fennema, E. \& Romberg, T. (Eds.), Mathematics classrooms that promote understanding (pp. 19-32). Mahwah, NJ: Erlbaum.

Chapman, O. (2005). Constructing Pedagogical Knowledge of Problem Solving: Preservice Mathematics Teachers. International Group for the Psychology of Mathematics Education, 2, 225-232.

Chapman, O. (2015). Understanding and supporting mathematics teachers' knowledge for teaching. Journal of Mathematics Teacher Education, 18(2), 101-103.

Charalambous, C. Y., \& Philippou, G. N. (2010). Teachers' concerns and efficacy beliefs about implementing a mathematics curriculum reform: integrating two lines of inquiry. Educational studies in Mathematics, 75(1), 1-21.

Charalambous, C. Y., Philippou, G. N., \& Kyriakides, L. (2008). Tracing the development of preservice teachers' efficacy beliefs in teaching mathematics during fieldwork. Educational Studies in Mathematics, 67(2), 125-142.

Common Core State Standards Initiative. (2010). Common Core State Standards for Mathematics (CCSSM). Washington, DC: National Governors Association Center for Best Practices and the Council of Chief State School Officers.

Conference Board of the Mathematical Sciences. (2001). The mathematical education of teachers. Providence, Rhode Island: Mathematical Association of America, in cooperation with the American Mathematical Society. 
Conference Board of the Mathematical Sciences. (2012). The mathematical education of teachers II. Providence RI and Washington DC: American Mathematical Society and Mathematical Association of America.

Cooney, T. J. (1999). Conceptualizing teachers' ways of knowing. Educational Studies in Mathematics, 38, 163-187.

Da Ponte, J. P., \& Chapman, O. (2006). Mathematics teachers' knowledge and practices. In A. Gutierrez \& P. Boero (Eds.), Handbook of research on the psychology of mathematics education: Past, present and future (pp. 461-494). Rotterdam: Sense.

Da Ponte, J. P., \& Chapman, O. (2008). 11 Preservice mathematics teachers' knowledge and development. Handbook of international research in mathematics education, 223.

Depaepe, F., Torbeyns, J., Vermeersch, N., Janssens, D., Janssen, R., Kelchtermans, G., \& Van Dooren, W. (2015). Teachers' content and pedagogical content knowledge on rational numbers: A comparison of prospective elementary and lower secondary school teachers. Teaching and Teacher Education, 47, 82-92.

Depaepe, F., Verschaffel, L., \& Kelchtermans, G. (2013). Pedagogical content knowledge: A systematic review of the way in which the concept has pervaded mathematics educational research. Teaching and teacher education, 34, 12-25.

Dewey, J. (1910). How we think. Boston, MA: Heath.

Dewey, J. (1933). How we think: A restatement of the relation of reflective thinking to the educative process. Boston, MA: Heath.

Emerick, S., Hirsch, E., \& Berry, B. (2003). Unfulfilled promise: Ensuring high quality teachers for our nation's students. Retrieved January, 5, 2014. 
Ernest, P. (1989). The impact of beliefs on the teaching of mathematics. Retrieved from http://people.exeter.ac.uk/PErnest/impact.htm.

Even, R., \& Tirosh, D. (2002). Teacher knowledge and understanding of students' mathematical learning. Handbook of international research in mathematics education, 219-240. Fennema, E., \& Franke, M. L. (1992). Teachers' knowledge and its impact.

Fennema, E., \& Romberg, T. A. (Eds.). (1999). Mathematics classrooms that promote understanding. Mahwah, NJ: Erlbaum.Gardner, D. P., Larsen, Y. W., Baker, W., Campbell, A., \& Crosby, E. A. (1983). A nation at risk: The imperative for educational reform. United States Department of Education.

Fernandez, C. (2014). Knowledge base for teaching and pedagogical content knowledge (PCK): Some useful models and implications for teachers' training. Problems of Education in the 21st Century, 60, 79.

Furinghetti, F. (2007). Teacher education through the history of mathematics. Educational Studies in Mathematics, 66(2), 131-143.

Gess-Newsome, J. (1999). Pedagogical Content knowledge: an introduction and orientation. In: Gess-Newsome, J.; Lederman, N.G. (Eds.) Examining Pedagogical Content Knowledge, Dordrecht, The Netherlands: Kluwer Academic Publishers, 3-17.

Gess-Newsome, J., \& Carlson J. (2013). The PCK summit consensus model and definition of pedagogical content knowledge. In: The Symposium "Reports from the Pedagogical Content Knowledge (PCK) Summit, ESERA Conference 2013, September, 2013.

Glaser, B. G., \& Strauss, A. L. (1967). The discovery of grounded theory: Strategies for qualitative research. Chicago, IL: Aldine. 
Glennon, V. J. (1949). A study in needed redirection in the preparation of teachers of arithmetic. The Mathematics Teacher, 42(8), 389-396.

Goldhaber, D. D., \& Brewer, D. J. (2000). Does teacher certification matter? High school teacher certification status and student achievement. Educational evaluation and policy analysis, 22(2), 129-145.

Goldin, G. A. (2000). A scientific perspective on structured, task-based interviews in mathematics education research. In A. E. Kelly, \& R. A. Lesh (Eds.), Handbook of research design in mathematics and science education (pp. 517-545). Mahwah, NJ: Erlbaum.

Goos, M. (2013). Knowledge for teaching secondary school mathematics: what counts?. International Journal of Mathematical Education in Science and Technology, 44(7), 972983.

Grissom, J. A., \& Youngs, P. (Eds.). (2016) Improving teacher evaluation systems: Making the most of multiple measures. Teachers College Press.

Grossman, P. L. (1990). The making of a teacher: Teacher knowledge and teacher education. New York, NY: Teachers College Press.

Grossman, P.L., Valencia, S., Evans, K., Thompson, C., Martin, S. and Place, N. (2000), Transitions into teaching: Learning to teach writing in teacher education and beyond, Journal of Literary Research, 32, 631-662.

Hammerness, K., Darling-Hammond, L., Bransford, J., Berliner, D., Cochran-Smith, M., McDonald, M., et al. (2005). How teachers learn and develop. In L. Darling-Hammond \& J. Bransford (Eds.), Preparing teachers for a changing world: What teachers should learn and be able to do. San Francisco, CA: Wiley. 
Hiebert, J. (1997). Making sense: Teaching and learning mathematics with understanding. Portsmouth, NH: Heinemann.

Hiebert, J. (2013). The constantly underestimated challenge of improving mathematics instruction. In Vital directions for mathematics education research (pp. 45-56). New York, NY: Springer.

Hiebert, J., Morris, A. K., Berk, D., \& Jansen, A. (2007). Preparing teachers to learn from teaching. Journal of teacher education, 58(1), 47-61.

Hiebert, J., \& Wearne, D. (1993). Instructional tasks, classroom discourse, and students' learning in second-grade arithmetic. American Educational Research Journal, 30, 393-425.

Hill, H., Ball, D. L., \& Schilling, S. G. (2008). Unpacking pedagogical content knowledge: Conceptualizing and measuring teachers' topic-specific knowledge of students. Journal For Research in Mathematics Education, 39(4), 372-400.

Hill, H. C., Rowan, B., \& Ball, D. L. (2005). Effects of teachers' mathematical knowledge for teaching on student achievement. American Educational Research Journal, 42(2), 371406.

Hill, H. C., Schilling, S. G., \& Ball, D. L. (2004). Developing measures of teachers' mathematics knowledge for teaching. The elementary school journal, 105(1), 11-30.

Hine, G. (2015). Improving the mathematical content knowledge of pre-service middle school teachers.

Hine, G. (2015). Preparing secondary mathematics teachers: a review of research.

Hine, G. S. (2015). Strengthening Pre-Service Teachers' Mathematical Content Knowledge. Journal of University teaching and learning practice, 12(4), 5. 
Hubeňáková, V., Semanišinová, I., \& Šveda, D. (2017). Pre-service mathematics teachers: How to make them ready to be ready.

Hungerford, T. W. (1994). Future elementary teachers: The neglected constituency. The American Mathematical Monthly, 101(1), 15-21.

Hutchison, L. (1997). Learning for Teaching: A Case of Constructing the Bridge between Subject Matter Knowledge and Pedagogical Content Knowledge.

İmre, S. Y., \& Akkoç, H. (2012). Investigating the development of prospective mathematics teachers' pedagogical content knowledge of generalising number patterns through school practicum. Journal of Mathematics Teacher Education, 15(3), 207-226.

Kennedy, M. M., Ball, D. L., \& McDiarmid, G. W.(1993). A study package for examining and tracking changes in teachers' knowledge.

Jarvis, T., \& Pell, A. (2004). Primary teachers' changing attitudes and cognition during a two-year science in-service programme and their effect on pupils. International journal of science education, 26(14), 1787-1811.

Kersting, N. B., Givvin, K. B., Sotelo, F. L., \& Stigler, J. W. (2010). Teachers' analyses of classroom video predict student learning of mathematics: Further explorations of a novel measure of teacher knowledge. Journal of Teacher Education, 61(1-2), 172-181.

Kersting, N. B., Givvin, K. B., Thompson, B. J., Santagata, R., \& Stigler, J. W. (2012).

Measuring usable knowledge teachers' analyses of mathematics classroom videos predict teaching quality and student learning. American Educational Research Journal, 49(3), $568-589$. 
Kinach, B. M. (1996). Logical trick or mathematical explanation? Re-negotiating the epistemological stumbling blocks of prospective teachers in the secondary mathematics methods course. Proceedings of the International Group for the Study of the Psychology of Mathematics Education. Columbus, OH: Ohio University.

Kind, V. (2009). Pedagogical content knowledge in science education: perspectives and potential for progress. Studies in science education, 45(2), 169-204.

Kleickmann, T., Richter, D., Kunter, M., Elsner, J., Besser, M., Krauss, S., \& Baumert, J. (2013). Teachers' Content Knowledge and Pedagogical Content Knowledge The Role of Structural Differences in Teacher Education. Journal of Teacher Education, 64(1), 90106.

Krauss, S., Baumert, J., \& Blum, W. (2008). Secondary mathematics teachers' pedagogical content knowledge and content knowledge: validation of the COACTIV constructs. Zdm, 40(5), 873-892.

Krauss, S., Brunner, M., Kunter, M., Baumert, J., Blum, W., Neubrand, M., \& Jordan, A. (2008). Pedagogical content knowledge and content knowledge of secondary mathematics teachers. Journal of Educational Psychology, 100(3), 716-725.

Lanahan, L., Scotchmer, M., \& McLaughlin, M. (2004). Methodological critique of current NCES survey measures of instructional processes. Retrieved May, 14, 2006.

Kunter, M., Klusmann, U., Dubberke, T., Baumert, J., Blum, W., Brunner, M., ... \& Tsai, Y. M. (2007). Linking aspects of teacher competence to their instruction: Results from the COACTIV project. In Studies on the educational quality of schools: The final report on the DFG Priority Programme (pp. 39-59). Waxmann. 
Lannin, J. K., Webb, M., Chval, K., Arbaugh, F., Hicks, S., Taylor, C., \& Bruton, R. (2013). The development of beginning mathematics teacher pedagogical content knowledge. Journal of Mathematics Teacher Education, 16(6), 403-426.

Leikin, R., \& Levav-Waynberg, A. (2007). Exploring mathematics teacher knowledge to explain the gap between theory-based recommendations and school practice in the use of connecting tasks. Educational Studies in mathematics, 66(3), 349-371.

Leinhardt, G., \& Smith, D. A. (1985). Expertise in mathematics instruction: Subject matter knowledge. Journal of educational psychology, 77(3), 247.

Lesh, R. (1979). Some trends in research and the acquisition and use of space and geometry concepts. In 2nd international conference for the psychology of mathematics education. Bielefeld, Germany: Institute for Didactics in Mathematics.

Lincoln, Y., \& Guba, E. (1985). Naturalistic inquiry, Beverly Hills, CA: Sage.

Lloyd, G. M. (2014). Research into teachers' knowledge and the development of mathematics classroom practices. Journal of Mathematics Teacher Education, 17(5), 393-395.

Loe, M., \& Rezak, H. (2006). Creating and implementing a capstone course for future secondary mathematics teachers. The Work of Mathematics Teacher Educators: Continuing the Conversation, 3 , 45-62.

Lortie, D. C. (1975). Schoolteacher: A sociological study. Chicago, IL: University of Chicago Press.

Lumpe, A., Czerniak, C., Haney, J., \& Beltyukova, S. (2012). Beliefs about teaching science: The relationship between elementary teachers' participation in professional development and student achievement. International Journal of Science Education, 34(2), 153-166. 
Ma, X. (1999). A meta-analysis of the relationship between anxiety toward mathematics and achievement in mathematics. Journal for research in mathematics education, 520-540.

Magnusson, S., Krajcik, J., \& Borko, H. (1999). Nature, sources and development of pedagogical content knowledge for science teaching. In J. Gess-Newsome \& N. G. Lederman (Eds.), Examining pedagogical content knowledge (pp. 95-132). Dordrecht, The Netherlands: Kluwer.

Marshall, J. (1981). Making sense as a personal process. In Reason, P. \& Rowan, J. (Eds.) Human inquiry: A sourcebook of new paradigm research (pp. 395-399). New York, NY: Wiley.

Mayer, R. E. (2004). Teaching of subject matter. Annu. Rev. Psychol., 55, 715-744.

Maykut, P., \& Morehouse, R. (1994). Beginning qualitative research: A philosophic and practical approach. Bristol, PA: Falmer.

Meany, T \& Lange, T 2012. Knowing mathematics to be a teacher. Mathematics Teacher Education and Development, vol. 14, no. 2, pp. 50-69.

Merriam, S. (1998). Qualitative research and case study applications in education. San Francisco: Jossey-Bass.

Mitton Kukner, J., \& Murray Orr, A. (2015). Inquiring into pre-service content area teachers' development of literacy practices and pedagogical content knowledge. Australian Journal of Teacher Education, 40(5), 3.

National Council of Teachers of Mathematics. (1980). An agenda for action. Reston, VA: Author.

National Council of Teachers of Mathematics. (1989). Curriculum and evaluation standards for school mathematics. Reston, VA: Author. 
National Council of Teachers of Mathematics. (1991). Professional standards for teaching mathematics. Reston, VA: Author.

National Council of Teachers of Mathematics. (1995). Assessment standards for teaching mathematics. Reston, VA: Author.

National Council of Teachers of Mathematics. (2000). Principles and standards for school mathematics. Reston, VA: Author.

National Council of Teachers of Mathematics. (2014). Principles to actions: Ensuring mathematical success for all. Reston, VA: Author.

National Council of Teachers of Mathematics. (2020). Standards for the Preparation of Secondary Mathematics Teachers. Reston, VA: Author.

National Governors Association Center for Best Practices \& Council of Chief State School Officers. (2010). Common Core State Standards for Mathematics. Washington, DC: Authors.

National Research Council, \& Mathematics Learning Study Committee. (2001). Adding it up: Helping children learn mathematics. Washington, DC: National Academies Press.

Nilsson, P. (2008). Teaching for understanding: The complex nature of pedagogical content knowledge in pre-service education. International Journal of Science Education, 30(10), 1281-1299.

Nolan, B., Dempsey, M., Lovatt, J., \& O'Shea, A. (2015). Developing Mathematical Knowledge for Teaching (MKT) for pre-service teachers: a study of students' developing thinking in relation to the teaching of mathematics. Proceedings of the British Society for Research into Learning Mathematics, 35(1). 
Norton, A., McCloskey, A., \& Hudson, R. A. (2011). Prediction assessments: Using video-based predictions to assess prospective teachers' knowledge of students' mathematical thinking. Journal of Mathematics Teacher Education, 14(4), 305-325.

Pajares, M. F. (1992). Teachers' beliefs and educational research: Cleaning up a messy construct. Review of educational research, 62(3), 307-332.

Palmer, D. (2006). Durability of changes in self-efficacy of preservice primary teachers. International Journal of science education, 28(6), 655-671.

Park, S., \& Oliver, S. (2008). Revisiting the conceptualization of pedagogical content knowledge (PCK): PCK as a conceptual tool to understand teachers as professionals. Research in Science Education, 38, 261-284.

Patton, M. Q. (1990). Qualitative evaluation and research methods. Newbury Park, CA: Sage.

Peressini, D., Borko, H., Romagnano, L., Knuth, E., \& Willis, C. (2004). A conceptual framework for learning to teach secondary mathematics: A situative perspective. Educational Studies in Mathematics, 56(1), 67-96.

Philipp, R., Ambrose, R., Lamb, L., Sowder, J., Schappelle, B., Sowder, L., et al. (2007). Effects of early field experiences on the mathematical content knowledge and beliefs of prospective elementary school teachers: An experimental study. Journal for Research in Mathematics Education, 38(5), 438-476.

Piaget, J. (1960). The child's conception of number. London: Routledge.

Pizam, A., \& Mansfeld, Y. 2009. Consumer behaviour in travel and tourism. New York: Howarth Hospitality Press.

Richardson, A. (2008). An examination of teacher qualifications and student achievement in mathematics (Doctoral dissertation). 
Romberg, T. A., \& Carpenter, T. P. (1986). Research on teaching and learning mathematics: Two disciplines of scientific inquiry. In M. C. Wittrock (Ed.), Handbook of research on teaching (3rd ed., pp. 850-873.) New York, NY: Macmillan.

Stanford Center for Assessment, Learning, and Equity. (2016). edTPA Secondary Mathematics Assessment Handbook. Stanford, CA: Author.

Schmidt, K. (2002). Classroom action research: A case study assessing students' perceptions and learning outcomes of classroom teaching versus online teaching. Journal of Industrial Teacher Education, 40(1), 45-59.

Schmidt, H. G., \& Boshuizen, H. P. (1992). Encapsulation of biomedical knowledge. In Advanced models of cognition for medical training and practice (pp. 265-282). Springer, Berlin, Heidelberg.

Schoenfeld, A. H. (1982). On the Analysis of Two-Person Problem Solving Protocols. Paper presented at the Annual Meeting of the American Educational Research Association (66th, New York, NY, March 19 - 23, 1982).

Schoenfeld, A. H. (2011). Noticing matters. A lot. Now what?. In Mathematics teacher noticing (pp. 253-268). Routledge.

Scholz, J. M. (1995). Professional development for mid-level mathematics. Paper presented at the Annual Meeting of the American Educational Research Association, San Francisco, CA, April 1995.

Schwab, J. J. (1978). Science, curriculum and liberal education. Chicago, IL: University of Chicago Press. 
Senk, S. L., Tatto, M. T., Reckase, M., Rowley, G., Peck, R., \& Bankov, K. (2012). Knowledge of future primary teachers for teaching mathematics: an international comparative study. Zdm, 44(3), 307-324.

Shulman, L. S. (1986). Those who understand: Knowledge growth in teaching. Educational Researcher, 15(2), 4-14.

Shulman, L. (1987). Knowledge and teaching: Foundations of the new reform. Harvard educational review, 57(1), 1-23.

Smith, L. K., \& Southerland, S. A. (2007). Reforming practice or modifying reforms?:

Elementary teachers' response to the tools of reform. Journal of Research in Science Teaching: The Official Journal of the National Association for Research in Science Teaching, 44(3), 396-423.

Sowder, J. T. (2007). The mathematics education and development of teachers. In F. K. Lester Jr (Ed.), Second handbook of research on mathematics teaching and learning (pp. 157223). Charlotte, NC: Informational Age.

Speer, N. M., King, K. D., \& Howell, H. (2015). Definitions of mathematical knowledge for teaching: using these constructs in research on secondary and college mathematics teachers. Journal of mathematics teacher education, 18(2), 105-122.

Steele, M. D., \& Hillen, A. F. (2012). The content-focused methods course: A model for integrating pedagogy and mathematics content. Mathematics Teacher Educator, 1(1), 53-70.

Stigler, J. W., \& Perry, M. (1988). Mathematics learning in Japanese, Chinese, and American classrooms. New Directions for Child and Adolescent Development (41), 27-54. 
Stohlmann, M. S., Moore, T. J., \& Cramer, K. (2013). Preservice elementary teachers' mathematical content knowledge from an integrated STEM modelling activity. Journal of Mathematical Modelling and Application, 1(8), 18-31.

Stohlmann, M., Moore, T., Cramer, K., \& Maiorca, C. (2015). Changing Pre-Service Elementary Teachers' Beliefs about Mathematical Knowledge. Mathematics Teacher Education and Development, 16(2), 4-24.

Strauss, A., \& Corbin, J. (1998). Basics of Qualitative Research : Techniques and Procedures for Developing Grounded Theory. Thousand Oaks, CA: Sage publications.

Swars, S., Hart, L. C., Smith, S. Z., Smith, M. E., \& Tolar, T. (2007). A longitudinal study of elementary pre-service teachers' mathematics beliefs and content knowledge. School Science and Mathematics, 107(8), 325-335.

Tchoshanov, M. A. (2011). Relationship between teacher knowledge of concepts and connections, teaching practice, and student achievement in middle grades mathematics. Educational Studies in Mathematics, 76(2), 141-164.

Tilgner, P. J. (1990). Avoiding science in the elementary school. Science Education, 74(4), 421-431.

Tirosh, D. (2000). Enhancing prospective teachers' knowledge of children's conceptions: The case of division of fractions. Journal for research in Mathematics Education, 5-25.

Turnuklu, E. B., \& Yesildere, S. (2007). The Pedagogical Content Knowledge in Mathematics: Pre-Service Primary Mathematics Teachers' Perspectives in Turkey. Issues in the Undergraduate Mathematics Preparation of School Teachers, 1. 
Tutak, F. A., \& Adams, T. L. (2017). A study of geometry content knowledge of elementary preservice teachers. International Electronic Journal of Elementary Education, 7(3), 301318.

Thompson, P. W. (1992). Notations, conventions and constraints: Contributions to Effective uses of concrete materials in elementary mathematics. Journal for Research in Mathematics Education, 23(2), 123-147.

Thompson, P. W. (2013). In the absence of meaning.... In Vital directions for mathematics education research (pp. 57-93). New York, NY: Springer.

Thomson, M. M., DiFrancesca, D., Carrier, S., \& Lee, C. (2017). Teaching efficacy: exploring relationships between mathematics and science self-efficacy beliefs, PCK and domain knowledge among preservice teachers from the United States. Teacher Development, 21(1), 1-20.

Turnuklu, E. B., \& Yesildere, S. (2007). The Pedagogical Content Knowledge in Mathematics: Pre-Service Primary Mathematics Teachers' Perspectives in Turkey. Issues in the Undergraduate Mathematics Preparation of School Teachers, 1.

Vamvakoussi, X., Van Dooren, W., \& Verschaffel, L. (2012). Naturally biased? In search for reaction time evidence for a natural number bias in adults. The Journal of Mathematical Behavior, 31(3), 344-355.

Van Dooren, W., Verschaffel, L., \& Onghena, P. (2002). The impact of preservice teachers' content knowledge on their evaluation of students' strategies for solving arithmetic and algebra word problems. Journal for Research in mathematics education, 319-351.

Velthuis, C., Fisser, P., \& Pieters, J. (2014). Teacher training and pre-service primary teachers' self-efficacy for science teaching. Journal of science teacher education, 25(4), 445-464. 
Wigfield, A., \& Eccles, J. S. (2002). The development of competence beliefs, expectancies for success, and achievement values from childhood through adolescence. In Development of achievement motivation (pp. 91-120). Academic Press.

Wilburne, J. M., \& Long, M. (2010). Secondary Pre-Service Teachers' Content Knowledge for State Assessments: Implications for Mathematics Education Programs. Issues in the Undergraduate Mathematics Preparation of School Teachers, 1.

Winsor, M. S., Barker, D. D., \& Kirwan, J. V. (2020). Promoting Knowledge Integration in Teacher Education Programs: An Example from Secondary Mathematics Teacher Education. In International Perspectives on Knowledge Integration (pp. 349-369). Brill Sense.

Yin, R. K. (1994). Case study research: Design and methods (2nd ed.). Thousand Oaks, CA: Sage.

Zaslavsky, O., \& Leikin, R. (2004). Professional development of mathematics teacher educators: Growth through practice. Journal of mathematics teacher education, 7(1), 5-32.

Zumwalt, K., \& Craig, E. (2005). Teachers' characteristics: Research on the demographic profile. Studying teacher education: The report of the AERA panel on research and teacher education, 111-156. 


\title{
APPENDIX A: CONSENT FORM
}

\author{
Consent Form
}

Dear Particip ants:

As mathematics educators, we are interested in how undergraduate students think about the teaching and learning of mathematics. We have designed a study to examine this and would like you to be a participant in this study. You have been chosen to participate because you are at the end of your program and were recommended for the study by a professor in the Mathematics department.

Your participation in the study will involve solving an algebra problem and the analysis and discussion of a pre-recorded lesson video. You will be asked to attend one interv iew session of about 45 minutes in duration, which will be audio recorded. The interview will be scheduled at your convenience during the last two weeks of the Spring 2017 semester.

The risks of participating in this research project are no greater than the risks associated with everyday life or what you experience in school. The most likely risk you would be exposed to is the challenge of trying to find the solution to an unfamiliar algebra problem. The audio recordings will be transcribed and you will be referred to only by a pseudonym within the transcription as well as any written reports associated with the study. Participants in the study will be described as undergraduate students from a public university in the Midwest.

Your participation is voluntary and if you choose not to participate in this study there will be no negative consequences and it will not affect your grades. You may discontinue participation at any time and, again, there will be no negative consequences and it will not affect your grades.

If you have any questions concerning the research study or your participation in this study, please contact Dr. Cynthia Langrall at 309-438-2225. If you have any questions about your rights as a participant in this research, or if you feel you have been placed at risk, you can contact the Research Ethics \& Compliance Office at Illinois State University at 309-438-2529. To give consent for participation in this study, please complete the attached form (keeping one copy for your own records) and return it to the mathematics department.

Sincerely,

Cynthia Langrall

Professor, Mathematics Education

Department of Mathematics

Illinois State University

Normal, IL 61761

(309) 438-2225

langrall@ilstu.edu
Steven Turner

Doctoral Student, Mathematics Education

Department of Mathematics

Illinois State Univ ersity

Normal, IL 61761

(309) 438-8781

sturner@ilstu.edu 
Please complete this form, keeping one copy for yourself, and return it in the enclosed envelope to Jean Conley, the secretary in the mathematics office.

\section{Particip ant Consent Form}

I have read the information presented above and have had an opportunity to ask questions and receive answ ers pertaining to this research project. I am aw are that my permission is voluntary and that I am free to withdraw my permission at any time without any penalties to myself.

I give consent for my participation in the mathematics education research study. Participation includes being audio recorded during the program.

Please state preferred method of contact so that we may schedule your interview at a convenient time.

Email:

Phone:

I do not give consent for my participation in the mathematics education research study.

Print First and Last Name

Signature of Participant

Date 


\section{APPENDIX B: VIDEO TRANSCRIPT}

\section{[Segment 1: INTRODUCTION]}

Student 6: "Two competing wireless companies advertise sample rates for their phone services. The first company advertises two sample rates for its plan: 400 minutes for $\$ 30$ a month or 700 minutes for $\$ 45$ a month. The second company advertises that you only pay for the minutes you use, there is no fixed monthly charge, and gives as an example rate 600 minutes for $\$ 42 . "$

Student 1: "JulissaPhone advertises two example prices for their phone plan: 400 minutes for $\$ 30$ a month or 700 minutes for $\$ 45$ a month.”

Teacher: "Do you see a linear equation?"

Student 5: "Yeah, it will be 400 and 30, sevenhundred and 45 dollars."

Teacher: "What's going to be on the x-axis?"

Student 5: "Um, minutes. No, price."

Teacher: "What depends on what?"

Student 5: "Minutes."

Teacher: "You say minutes. Do you agree with her? So, if minutes are on the xaxis, our two points for JulissaPhone are?"

Student 6: “( $\quad(400,30)$ and $(700,45) . ”$

Teacher: "Are you ready for the next service? Carl?"

Student 3: "TeleCarl advertises that you will pay only for the minutes you use. If you don't talk, you don't pay. An example rate is 600 minutes for $\$ 42 . "$

Teacher: "So, we need to figure out points for TeleCarl."

Student 2: "I have one point. $(600,42) . "$

Teacher: "Is that the only point we have? What does it cost if you talk zero minutes per month, according to the ad?" 
Student 3: "Nothing."

Teacher: "So?"

Student 4: “Zero, zero.”

Teacher: "Zero, zero. There you go. Good.”

[Segment 2: FORMULAS]

Teacher: "Now step one, find linear equations for both of these. What's our formula? What's our first formula we're going to use?"

Student 2: "Slope."

Teacher: “Slope. Which is?”

Student 6: "Y two minus y one over $\mathrm{x}$ two minus $\mathrm{x}$ one."

Teacher: "And once we use that, we're going to use what?"

Student 5: "Slope intercept."

Teacher: "Which is?"

Student 1: "Y one..."

Teacher: "Are we going to use slope intercept?"

Teacher 4: "Point slope."

Multiple students: "Y..."

Teacher: "Ok, somebody. Nancy, tell me what it is."

Student 4: "Y "Y two minus y one equals $\mathrm{m} x$ minus $\mathrm{x}$ one."

Teacher: "OK, and then what are we going to do?"

Student 4: "Slope. Yeah."

Teacher: "Alright, so now I want you to work on these two equations."

\section{[Segment 3: EXPLANATION]}

Student 1: "Well, I found out what the slope was by plugging it into that equation over there. It's one over twenty, or .05. And then I made it into slope-intercept form by plugging into this, and changing to that." 
Teacher: "So, will you read your final answer to the class?"

Student 1: "Y equals .05 x plus 10."

Teacher: "What's the slope?"

Student 1: "One over twenty."

Teacher: "Or?"

Student 1: "Or .05."

Teacher: "And what's the y intercept?"

Student 1: "Ten."

Student 4: $\quad$ "I used the slope-intercept, I mean slope formula."

Teacher: "What slope did you get?"

Student 4: “.07.”

Teacher: "Then what did you do with that?"

Student 4: "Then I used point-slope, and then..."

Teacher: "Now on your graph paper you are going to draw one big graph. Now, $\mathrm{x}$ represents what?"

Student 6: "Minutes."

Teacher: "Minutes. How far up are we going to need to go to get all our information on here?"

Student 5: "700 at least."

Teacher: “At least 700. Right?”

\section{[Segment 4: DISCUSSION]}

Teacher: "This line describes what?"

Student 2: "The more minutes you use, the more money."

Teacher: “Good. For who’s plan?”

Student 6: "JulissaPhone."

Teacher: "What is the y-intercept?" 
Multiple students: "Ten."

Teacher: "What does the y-intercept mean?"

Student 5: " "The amount of money that you spend."

Student 3: "The amount you spend on the phone."

Teacher: “Alright, it's a flat ten dollars before you even talk and then what?"

Student 2: "It goes up per minutes you use."

Teacher: "How much?”

Student 3: "Five cents."

Teacher: "What do you know about the 5 cents in the equation? It's the what?"

Student 4: "'Slope."

Student 2: "It's the fixed monthly rate."

Student 6: "No, it's the slope."

Teacher: "Good. What in the equation represents the fixed monthly rate?"

Student 3: "Five."

Student 5: "No, the ten."

Teacher: "The ten. The?"

Student 1: "The y-intercept."

Teacher: "Yep. And what does the slope represent?"

Student 6: "The amount you pay for each minute."

Teacher: "Correct. Good. So, JulissaPhone is going to cost you 10 bucks and five cents per minute. Right?”

Teacher: "Now, TeleCarl. Tell me about TeleCarl."

Student 5: "He doesn't charge you for the first minutes." 
Teacher: $\quad$ "OK, somebody tell me about Carl's good deal.”

Student 2: "Basically, Carl's saying that it's based on what you use."

Teacher: "OK, so if I talk zero minutes in a month what is going to cost me?"

Student 6: "Nothing."

Teacher: "So the rate is based entirely on?"

Student 5: "How much you talk."

Teacher: "Good. What does a minute cost?"

Student 2: "Seven cents."

Teacher: "Seven cents. Right?"

Student 5: "So, that's how they get you?"

Teacher: "Yes, that's how they get you." Now, when I graph the line, what are our two points?"

Student 6: “( $(0,0) . "$

Teacher: “(0,0). Right there."

Student 1: “( $\quad$ " 600,42$). ”$

Teacher: “There?"

Student 4: “A little lower."

Student 2: “That's good.”

Teacher: "Alright. The two lines cross approximately there. Right?"

Student 3: "At 500.”

Teacher: "500. And this way?"

Student 6: “35, 37?"

Teacher: "Alright. This one was Carl's."

[Segment 5: INTERPRETATION] 
Teacher: "My question is which one is the best deal?"

Student 5: "JulissaPhone

Student 1: "If you talk for more than 500 minutes, then..."

Student 2: "Depends on your needs."

Student 5: "I think TeleCarl, because she started with a fixed monthly rate of ten

dollars. But I still think it would be cheaper, because it was seven cents as opposed to ten dollars."

Student 3: "Opposed to what?"

Student 5: "Ten dollars, and five cents."

Teacher: “Anybody else? Good. Now somebody said, I believe it was Julissa. What did you say, Jules?"

Student 1: "If you talk more than 500 minutes, JulissaPhone is better. If you talk for less, TeleCarl is better."

Teacher: "Is she right?"

Student 6: "Yeah."

Student 3: "Julissa's plan is better for elderlies."

Student 5: "No, your plan is better for elderlies. Old people don't talk that much."

Student 1: "I would say mine is better for teenagers."

Teacher: "So, if you talk for more than 500 minutes, JulissaPhone is cheaper.

Right? But if you talk fewer than 500 minutes, TeleCarl is cheaper. So. The turning point is at 500 minutes." 


\section{APPENDIX C: INITIAL CATEGORIES AND RULES FOR INCLUSION}

\section{Interprets}

Interprets teacher as leading. The participant sees the teacher as providing the students with more guidance than appropriate.

Interprets teacher as guiding. The participant sees the teacher as providing an appropriate amount of lesson guidance.

Interprets as direct instruction. The participant recognizes the teaching technique as appropriate direct instruction.

Interprets as questioning to elicit. The participant sees the teacher as questioning the students in such a way as to elicit thinking.

Interprets as questioning to elicit prior knowledge. The participant sees the teacher is questioning students to have them recall prior knowledge.

Interprets as superficial questioning. The participant states that the teacher's questioning is mostly affirmation. Yes/no or short answers without elaboration.

Interprets as teacher doing the work. The participant states that the teacher is effectively solving the problem, removing the cognitive challenge for the students.

Interprets as too procedural, lacks conceptual. The participant sees the teacher's action as promoting procedural learning at the expense of conceptual understanding.

\section{Rationale}

Rationale: Getting students started. The participant sees the teacher's introductory procedure as a starting point for solving the problem. 
Rationale: Motivating students to think. The participant sees the teacher's questioning of students as a means to have them form ideas about solving the problem or interpret the meaning of the solution.

Rationale: Clarification or summarization: procedural. The participant sees the teacher's reiteration of the preceding discussion as a means to to reinforce the procedure for solving the problem.

Rationale: Clarification or summarization: conceptual. The participant sees the teacher's reiteration of the preceding discussion as a means to reinforce meaning.

Rationale: Student explanation experience. The participant sees the teacher as allowing students to explain procedure or meaning to gain experience.

Rationale: Class learn from fellow students/correct mistakes. The participant sees the teacher as allowing students to explain procedure or meaning as an opportunity for everyone to 'get on the same page'.

\section{Refers To}

Refers to problem context. The participant makes a reference to the connection between calculations and the context of the problem.

Refers to place in curriculum/textbook. The participant questions whether the lesson is appropriate based on students' grade level or prior knowledge.

Refers to visual representation. The participant makes reference to the graph or formulas presented on board.

\section{Educationese}

Educationese. Education related terms that appear in the participants' responses. 


\section{Recommendations}

Recommendations: make connections. The participant recommends making connections between problem, real-life experience and calculations, or makes reference to multiple representations.

Recommendations: more discussion. The participant recommends more and/or higher quality class discussion.

Recommendations: more questioning. The participant recommends more and/or higher quality questioning of students by the teacher.

Recommendation: more wait time or time for students to explore/problem solve. Includes recommendations for wait time as well as recommendations for students to try/explore on their own.

Recommendations related to graphical display. Includes recommendations regarding what is given on the board including graphs, points and equations.

Recommendation: Would be more direct, give more information. The participant states that more direct instruction would be appropriate.

Other recommendations. Includes any statement in which participant disagrees with the teacher, but recommendation does not fit into any of the preceding categories.

Disagrees with teacher's approach but no recommendations. Includes any statement in which the participant disagrees with the teacher, but no specific recommendation is given.

Agreed with teacher's approach; may suggest changes. Includes statements in which the participant fundamentally agrees with the teacher, but may or may not suggest changes.

\section{Refers to one's Own Experience}


Experience as learner. The participant refers to, or appears to be relying upon, their own experience as a student.

Experience as teacher. The participant refers to, or appears to be relying upon, own experience teaching or tutoring.

Experience solving problem. The participant refers to, or appears to be relying upon, their experience solving the research problem.

Experience w/ math. The participant refers to, or appears to be relying upon, their experience learning or practicing mathematics.

\section{Other}

Teacher not answering/responding. The participant sees the teacher as being unresponsive to student's questions.

Anticipation of lesson direction. Statements by the participant which predict the direction that lesson is likely to take.

Informal assessment. The participant sees questioning by the teacher as a means to gauge student understanding.

Refers to student thinking. Statements which directly refer to student thought.

\section{Changes to the Initial Categories}

I combined the categories "interprets teacher as leading", "interprets as direct instruction", and "interprets as teacher doing the work" into one category labeled "interprets the teacher as leading." The categories "rationale: clarification or summarization: procedural", and "rationale: clarification or summarization: conceptual" were combined under the category "rationale: clarification or summarization". The categories "rationale: student explanation 
experience" and "rationale: class learn from fellow students/correct mistakes" were combined into the category "rationale: student led discussion".

I expanded or slightly modified some category definitions. The category "interprets teacher as guiding" was expanded to include getting students on the same page. "Refers to place in curriculum/textbook" was changed to include the phrase addressing basic content that students will need in the future. To "recommendations: make connections" I added to students' toolbox to pull from when solving problems. The phrase more student-led discussion was added to "recommendations: more discussion." To "recommendation: would be more direct, give more information" was added suggests lowering the problem complexity (easier numbers).

I rephrased the category "recommendation: more wait time or time for students to explore/problem solve" to "recommendation: more student exploration/problem solving or wait time" and the phrase students present their solutions was added to the description. The title of the category "anticipation of lesson direction" was amended to "refers to purpose of lesson" and the description was expanded to include statements which identify the lesson as review. 


\section{APPENDIX D: PARTICIPANTS' LESSON ANALYSIS SUMMARIES}

\section{TCH1}

TCH1 recognized that the teacher was attempting to relate rates to the steepness of lines. He stated that he would probably not use graphing as the large numbers involved would be problematic to fit on a graph. He would have preferred to demonstrate slope by dividing with a calculator, and would have focused more on how to solve the problem than on the discussion of slope.

TCH1 did eventually admit to being curious about how the class would find the better deal using slope. He thought that showing that the plans were the same where the lines crossed, otherwise one was better or worse than the other, was an interesting way to demonstrate how what you pay is based on your phone habits. He suggested using smaller "unrealistic" numbers that would fit better on a graph, interpreting better, and beginning with motivating questions to get students thinking about cell phones.

\section{TCH2}

$\mathrm{TCH} 2$ was not sure if the first plan was linear and so would have discussed "staying consistent" in discussing it. She then stated that the teacher in the video had asked the students to pull the appropriate data from the problem and start doing calculations, having students recall the process for the point-slope form. She would have graphed the equations at this point and have the visual representation up on the board and use multiple representations rather than the equations alone. By the end of the third segment, she began to see where the teacher was headed and agreed with his direction.

$\mathrm{TCH} 2$ agreed that this is similar to the way that she herself had presented such material, 
relating contextual word problems to linear equations. She would have gone farther after the teacher had concluded the lesson, however. She would have continued to explore the conclusion and model it in words and symbols. TCH2 thought that the appropriateness of the lesson depended upon where the lesson falls in the sequence of teaching linear equations. She would have liked to see the lesson be more student rather than teacher led. And would have left the choice of tools for solving the problem more open, allowing the students to choose the best path for solving the problem.

\section{TCH3}

TCH3 initially saw the first plan as a piecewise function and thought graphing it would be confusing to students and that the problem was too abstract. He asked what the target age of the lesson would be. At the end of the second video segment, he did not see where the lesson was going. He stated that the teacher had asked the students to graph two lines, although he thought there was only one.

He called into question the teacher's response to a student when the student suggested slope-intercept form. The teacher corrected her and said it should be in point-slope form, even though the former could actually have been used. Segment three was mostly algebraic manipulation and he stated that he would have done the same. He also noted that the pacing seemed very quick, and that the choice of methods for solving the problem may have come from the unit they were studying at the time. Overall, TCH3 felt that the students should have been allowed to attempt the problem on their own first and decide for themselves how to go about solving it rather than being pushed to solve it as a system of linear equations.

\section{TCH4}

TCH4 noted that the teacher asked guiding questions, and pointed out a moment when a 
student did not get a response to her question as a good place for discussion. For the first three segments, she would not have done anything differently, and especially liked having the students go to the board. In the fourth segment, she felt that the discussions could have gone deeper than just having students supply answers to questions, as a way to deal with possible errors or conceptual misunderstandings.

TCH4 liked the class discussion of which plan is the better deal, but dismissed the part about for whom the plan was better as "mathematically irrelevant." Overall she would have taught much the same. She would ask more guiding questions that required more than one word answers. She would spend more time discussing student answers, rather than just saying right or wrong.

\section{TCH5}

TCH5 would have liked for the teacher to be more animated and joke around more. He wanted to know what the students had been working on prior to this lesson. At the end of segment two, he noted that he would like for the students to make more connections on their own, stating that he would like to have "higher expectations" for his students. In segment three thought that the teacher had missed an opportunity to facilitate more understanding with questioning, noting that informal assessment is a good time to make connections.

TCH5 felt that the students could be more clear with their responses and that teacher clarification does not show whether a student actually understands. Again he mentioned higher expectations for the students. Responding to segment 5, he would have talked more about the intersection point, and would have liked to elaborate further on for whom each plan is better, rather than going back to the equations. Overall, he would make sure the students were engaged rather than just going through the motions. 


\section{TCH6}

From the first video, the participant assumes a type of linear relationship. He sees the teacher as shoving information at the kids, rather than allow students to think through a task. Students should have been allowed to get the points on their own, with the teacher possibly asking some formative questions along the way. The participant thought it may have been appropriate as a review, but not as introduction. Noted that in video two that teacher talked much less and the discussion involved the students more, but still saw their input as practice and recitation of formulas. Application of formulas to concepts discussed in the first video. Better than the first video, but discussion not conducive to procedural fluency.

The participant liked the third video, noting that the teacher did not lead and that students were allowed to do the thinking as students were at the board. Would have liked to see more 'how' and 'why' questioning during discussion afterward. Need for better teacher/student interaction and better questioning continued into video four, and the participant stated that he would have done it differently. Saw in video five what he would have liked to see in video four. More discussion about the interpretation of the problem outcome and making connections. The teacher summarized the problem, as well as the students. Overall, he liked the graphical representation, but would not have thought to do it that way before seeing the video. Would have spent more time letting students find points and discussing where they came from, but liked the concluding interpretation.

\section{TCH7}

Participant thought approach would offer a good way to visualize change in price with respect to minutes between the two companies, and she would do something similar. Saw it as a good starting point. In video two, she sees the teacher as giving them the formulas rather than 
allowing them to work from that starting point. She would have done differently. Once having the points would have suggested using linear equations and go from there on their own, providing support as necessary and bringing the class together for discussion after appropriate work time. She saw video three, having the students going to the board and discussion, as good and would not have done it differently.

Liked the level of detail in the discussion of video four. She thought discussion of what slope and y-intercept represent was good, would have talked more about the meaning of the intersection point. Liked the 'debate' in video five and would not have done it differently. She suggested that there may be benefit in changing the numbers so that students could observe and think about how the graph would change. Overall, she saw a lot of 'call and response' but saw some reasoning and conceptual understanding toward the end. Would have scaffolded formulas more if appropriate, but overall would have taught very similarly.

\section{TCH8}

The participant saw the teacher as just rewarding correct answers. Would prefer to allow students to explore more, even if it took them down non-productive paths. It appears that the students should know the procedure and are possibly reviewing. Teacher wants to 'structure' the way the problem will be solved. The procedure may not be immediately apparent to all students though they might understand the concept. The participant saw this as 'very direct instruction'. Would have them explore more with less spoon feeding. In video three, the participant sees that the students going to the board know the procedure, but questions whether they really understand what they are doing. She sees it as probably being a problem of interest to the students, but the teacher is 'taking the fun out' of finding the solution by forcing the formulas.

She uses the words 'rigid', 'forced', and 'forcibly' to describe the way the lesson is led, 
and feels that the students could probably not do the problem again with the formulas and procedure provided for them. In video four the conversation is occurring, and the teacher is getting right and wrong answers to his questions, but not addressing why some answers are wrong. There is no good discussion of the meaning of the intersection. In video five, the participant kies the conversation, but would have liked to see the summarization provided by a student rather than the teacher. He tends to cut them off right when they are getting to a point. Overall, too teacher-led and not enough problem solving by the students. Would have discussed good wrong answers more, and done a better job overall of eliciting conversation among students.

\section{TCH9}

The participant felt that the teacher wanted the problem set up to be solved in a certain way. He would have let them explore to find $(0,0)$, although he admitted that he may have done the same thing as the teacher to speed up the lesson. Would have had them try to graph it before mentioning linear. In video two, he again would have let the students take some time to explore on their own. 'He's very on the rails here.' Would have done differently rather than getting through the lesson quickly. Saw students showing work as their taking responsibility for the material. Still saw the teacher as pushing towards a certain way of solving, but good to have everyone on the same page.

For video four, the teacher is still too leading. He saw questioning as superficial without good discussion of right or wrong answers. Students should be making their own connections. Would find another way of finding intersection point, such as solving equations. Video five is mostly good until the teacher cuts off discussion in the end. Would have let students keep discussion and arrive at conclusion. Overall, the participant wanted to see more struggle on the 
part of the students. Describes the lesson as pretty typical.

\section{MAT1}

MAT1 would not have done anything differently in the first two segments rather than clarify that "m" stands for slope. She liked that he asked about points, because students may not have thought about $(0,0)$. And, she also liked the way the teacher handled segments 3 through 5 .

Her overall comments were that she may have drawn the graph at the beginning, but reconsidered, thinking that it may be confusing. She liked the questioning and discussion of answers. "I like when they recognize when you understood something." Noted that the choice of linear equations to solve this problem was probably dictated by their current unit of study.

\section{MAT2}

MAT2 generally agreed with what the teacher did in the video segments. He did comment that the computerized voices without pauses in the animation were disconcerting. He would have had the students write down the slope formula on their own or possibly derive it if necessary, depending upon their prior knowledge. He thought having students go to the board helped them engage in the class.

Overall, MAT2 noted that what occurred during the lesson was dependent upon what they did and knew beforehand. He would have had them try to work more out on their own, but said there are also things that you can just tell or write on the board. He particularly liked the idea of the students coming to the board, as it gives an opportunity to evaluate their understanding and work through misconceptions or decide if teaching adjustments need to be made.

\section{MAT3}


MAT3 thought that the classroom teacher should have given more reason as to why minutes was the independent variable and elaborated on why they were using linear equations to solve the problem. He also commented that the lesson moved too fast. Specifically, he did not like the emphasis on equations and would like to have seen the students think about how to arrive at an answer rather than using algorithms.

MAT3 took issue with the way the intersection point was found, preferring to find it by graphing rather than having it pre-determined algebraically, and he would have made the connection between slope and cost per minute clearer before solving. Better to stress conceptual ideas over algorithms. Teacher made sure students at different levels were understanding. Overall, he would let the students decide which direction to take in solving the problem rather than explicitly telling them to use the slope formula. This would be dependent upon the background of the students. He thought the lesson worked well for a general audience, because everything was explained clearly.

\section{MAT4}

The participant saw the teacher as guiding, in particular in finding the $(0,0)$ point. He did not consider using linear equations on his own but thinks it's the right approach after seeing the video. Sees using linear equations as appropriate if that is the current unit of study. In video two sees the teacher as asking students to recall prior knowledge and states that linear equations and point-slope form are clearly the current unit of study. Liked having students do work in class. Liked that students went to the board in video three because it made the class seem more collaborative.

In video four, he thought the visual representation was a good way to help students understand the concept. Also liked discussion and having students explain as opposed to 
lecturing, feeling that is more conducive to student understanding. In video five, he sees the class getting off topic and pulling the student discussion back to finding the better deal. Overall, he would set up and teach the lesson much as the teacher did.

\section{MAT5}

MAT5 found it interesting that the teacher went with the graphing approach, as she had done it differently. Liked that the students were involved to make them think. Would have graphed in video one to make visualization clearer. For video two, saw the teacher as having students construct equations rather than having them given, hoping that students would remember them. Would have kept points listed on the board for reference. Saw students presenting problems in video three as a way for them to get experience and to help classmates correct mistakes. Would have kept all information, points and formulas, on the board for students who did follow or take notes as quickly.

She talked more about the visual representation for video four. Would have color-coded equations with appropriate graphs. Teacher involved students in creating the graphs at the board so that all students would have the correct graph. For video five, she thought it was good that students came to the conclusion through discussion rather than telling them the answer. By doing their own work, students learn to analyze a graph and make their own decisions.

\section{MAT6}

MAT6 did not think about solving the problem in terms of $\mathrm{x}$ and $\mathrm{y}$ when solving the problem. Considers this a basic level lesson in preparation for upper level mathematics. Teacher did not explain how this problem correlates to a graphical representation. For video two, the teacher used this approach because the problem is straightforward and easy to recognize $\mathrm{x}$ and $\mathrm{y}$ and use slope formula. She would prefer the teacher said what each variable means, rather than 
go into formulas in detail. For video three, the teacher wants students to use real-life examples and transfer them to equations. Would like the teacher to explain more what goes into each variable and why.

Teacher made students understand the meaning of the problem in video four. Notes that the teacher makes students answer questions, though that wouldn't be her preference. In video five, the teacher made students understand the problem in terms of rates and saving money, instead of just plugging numbers and getting a result. Overall, she liked the structure of the lesson. Starting with simple steps, determining the needed variables, and discussion of what the equations meant.

\section{$\operatorname{MAT7}(\mathbf{S})$}

MAT7 stated that the teacher's use of an x-y approach was a different way to solve than the way she did it. She thought the teacher's approach was a good way for visual learners or students just learning how to do the problem. After video two, she anticipated that the lesson was going to involve finding the intersection of the line to find the better deal based on the number of minutes used, and that the equations would be used to find the intersection. For video three, she stated that she misinterpreted the problem and was learning from watching the video. Noted that she would have graphed beyond 700 to get the 'big picture'.

For video four, she stated that the teacher used the graphical approach because it made clear the idea that the best deal depends on which side of the point of intersection your phone usage falls. In video five, she would like to have seen the equations and graphs on the board together. Liked the class discussion overall, except for the teenager/elderly comments. Overall, she would have liked to see more discussion of students' wrong approaches. 


\section{MAT8 (T)}

The participant saw the teacher as 'somewhat' helping the students to get started with the problem on the right track. For video two, he saw the teacher as giving small hints and leading but not giving answers. Liked equations on board and allowing students to think. Having students come to the board in video three gives those students experience and helps their peers to learn from them. Begins at this point to question whether the amount of guidance is appropriate or too much. Depends on the students.

For video four, the participant felt that the teacher went into too much depth on the graph. May have been appropriate for first learning how to solve in middle school, but college age students could have benefitted from a more straightforward lesson with less leading questioning. Overall, would have given less guidance and let students express what they think.

\section{PRO1}

The participant felt that the teacher did not offer appropriate wait time when questioning students, and that questions were too leading. Students were not fully engaged and the teachers method led to cognitive draining. Based on her teaching experience, she would have allowed students to work on their own before giving information. For video two, she questioned what prior knowledge the students had. She would have let the students discuss if the relationships were linear. Felt that the lesson as presented elicited only procedural understanding and was not conducive to the formation of conceptual understanding. She felt that the students' thinking was limited by giving too much information, and that there were other ways to go about solving the problem. For video three, she again saw the teacher as too leading and saw this as restricting the types of representations the students might come up with.

For video four, PRO1 liked the connections made between the two different 
representations, but would have preferred that the students made those connections on their own. Questions asked by the teacher should have been more open-ended. In video five, she liked the discussion but would have liked more connection to the graph and more discussion of the meaning of the graph. She would also better connect the graph to the algebra and to tables. Overall, she saw the lesson as traditional, with the teacher doing too much of the thinking.

\section{PRO2}

Participant sees the teacher as a facilitator or director providing too much guidance. Students did not have time to think or engage in productive struggle. She would have let them explore the problem, rather than regurgitate. She would not have introduced the equations as in video two, but would have allowed them to explore by handing out graph paper and letting them explore solutions. Students are using a slope formula, rather than thinking minutes per amount of money. Video three the lesson seems backwards, because the equations were found and then the class graphed the lines. She sees this as fitting into a traditional lesson, however.

She would have graphed both equations and explain before talking about the individual graphs, and let students put the work on the board. She thought about cents per minute and the importance of connecting that with the concept of slope. PRO2 thought the wrap up in video five was 'pretty good'. She would have had the discussion be more student led. Overall, she would have talked more about how specific parts of the equations connect to the graph.

\section{PRO3}

The participant liked the way the teacher directly related the problem to linear functions. Thought it was necessary to draw out $(0,0)$ from the students and described the teacher's help as 'scaffolding'. He may have drawn out the $\mathrm{x}-\mathrm{y}$ axis. In video two, PRO3 begins to recognize that the teacher is leading too much. Teacher's questions elicit short responses. Would have let 
students in groups work through the problem first and discover ideas for themselves before telling the formulas and equations, as there are multiple routes of solving the problem. Liked having the students come to the board as in video three. Noticed that the teacher was doing a lot of questioning and discussing multiple representations of slope.

In video four, he noticed that a student would say an incorrect answer and another would correct them, but the teacher did not respond to or explain why the answer was incorrect. He would have liked to see the incorrect answers addressed for the sake of the other students who may also have misconceptions. Anticipates finding the exact point of intersection and finds student discussion interesting. Liked finding the point of intersection in video five and that one student noticed which plan was better depending on which side of point. He liked the use of graphing, but thought it might be difficult to do by hand for students. Suggested use of Desmos or other tools for graphing. Would have given students more time on their own. He felt that some students may have found different ways to do it using only tables, graphs, or equations. Overall, he described the lesson as 'pretty good', and thought the subject would interest students. 